\title{
Essays on open market operations, the maturity composition of the public debt, and the term structure
}

Seth J. Kopchak

West Virginia University

Follow this and additional works at: https://researchrepository.wvu.edu/etd

\section{Recommended Citation}

Kopchak, Seth J., "Essays on open market operations, the maturity composition of the public debt, and the term structure" (2010). Graduate Theses, Dissertations, and Problem Reports. 4619.

https://researchrepository.wvu.edu/etd/4619

This Dissertation is protected by copyright and/or related rights. It has been brought to you by the The Research Repository @ WVU with permission from the rights-holder(s). You are free to use this Dissertation in any way that is permitted by the copyright and related rights legislation that applies to your use. For other uses you must obtain permission from the rights-holder(s) directly, unless additional rights are indicated by a Creative Commons license in the record and/ or on the work itself. This Dissertation has been accepted for inclusion in WVU Graduate Theses, Dissertations, and Problem Reports collection by an authorized administrator of The Research Repository @ WVU.

For more information, please contact researchrepository@mail.wvu.edu. 


\title{
Essays on Open Market Operations, the Maturity Composition of the Public Debt, and the Term Structure
}

\author{
Seth J. Kopchak \\ Dissertation submitted to the \\ College of Business and Economics \\ at West Virginia University in partial \\ fulfillment of the requirements for the degree of
}

Doctor of Philosophy

in

Economics

Ronald Balvers, Ph.D., Chair

Arabinda Basistha, Ph.D.

Stratford Douglas, Ph.D.

Alexei Egorov, Ph.D.

Alex Kurov, Ph.D.

Department of Economics

Morgantown, West Virginia

2010 


\section{Abstract \\ Essays on Open Market Operations, the Maturity Composition of the Public Debt, and the Term Structure}

\section{Seth J. Kopchak}

This dissertation addresses issues related to liquidity and market determination of interest rates. Chapters two and three address the market for overnight loans of federal funds. Deviations of the federal funds rate from its target can be interpreted as demand innovations for federal funds. These demand shocks can be modeled as an unobserved component and estimated using the Kalman filter to identify liquidity effects. The effect of a $\$ 1$ billion increase in the average sum of open market operations over a one-week period results in a decrease of the federal funds rate by about 12 basis points. In addition, unexpected shocks identify pressure on the funds rate target and isolate policy-motivated changes of the Fed's funds rate target from those resulting from interest rate smoothing. A metric of accumulated demand pressure derived from the state space model is positively related to the size of open market operations as well as the direction and likelihood of federal funds rate target changes at Federal Open Market Committee meetings. The final chapter relates the effect of U.S. Treasury auctions of notes and bonds to changes in relative discount yields. An event study methodology is employed to test the hypothesis that off-the-run relative yields are insulated from the effects related to the auction calendar. A statistically significant positive increase in relative yields is associated with introduction of additional cashflows at the corresponding and neighboring horizons. An analogous methodology is employed for on-the-run bonds, finding a significant and longer lived negative effect at the benchmark five, ten, and 30-year horizons. 


\section{Contents}

1 Purpose and Agenda $\quad 1$

2 The Liquidity Effect of Open Market Operations 3

2.1 Introduction . . . . . . . . . . . . . . . . . . . . 3

2.2 The Liquidity Effect . . . . . . . . . . . . . . . . . . . 5

2.3 A Model of the Desk's Decision . . . . . . . . . . . . . . . . . . . . . . . . . . .

2.3.1 Identification . . . . . . . . . . . . . . . . . . . 14

2.4 Hypothesis . . . . . . . . . . . . . . . . . . . . . . . . . 15

2.5 Data and Estimation . . . . . . . . . . . . . . . . 16

2.5.1 Maximum Likelihood Estimates of State Space Model . . . . . . . . . 17

2.5.2 Relationship with Previous Results . . . . . . . . . . . . . . 18

2.6 Robustness of Results to Alternative Specifications . . . . . . . . . . . . . 20

2.6.1 Ordinary Least Squares Estimation . . . . . . . . . . . . . . . 20

2.6.2 Estimation of Identification Equation . . . . . . . . . . . . . . . 21

2.6.3 Out-of-Sample Open Market Operation Prediction . . . . . . . . . . . 23

2.7 Conclusion . . . . . . . . . . . . . . . . . . . . . . 24

3 Interest Rate Smoothing 33

3.1 Introduction . . . . . . . . . . . . . . . . . . . . 33

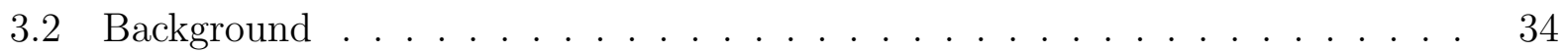

3.3 Properties of Demand Pressure . . . . . . . . . . . . . . . . . . 37

3.4 Hypothesis . . . . . . . . . . . . . . . . . . . . . . . . . . . . . . . . . . . . . .

3.5 Results from Tests of Pressure on the Target Rate . . . . . . . . . . . . . . . 42

3.5.1 FOMC Meetings and Demand Pressure . . . . . . . . . . . . . . 44

3.5.2 General Specification . . . . . . . . . . . . . . . . . . . 45

3.5.3 Specification and Results . . . . . . . . . . . . . . . . 47

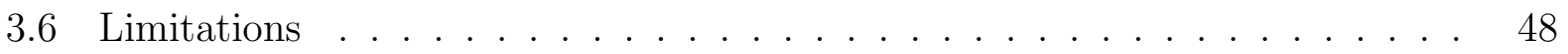

3.7 Conclusion . . . . . . . . . . . . . . . . . . . . . 49

4 The Impact of U.S. Treasury Auctions on Discount Yields 58

4.1 Introduction . . . . . . . . . . . . . . . . . . . 58

4.2 Background and Hypothesis . . . . . . . . . . . . . . . . . . . . 60

4.2.1 Event Definition and Data . . . . . . . . . . . . . . . 63

4.3 Empirical Method . . . . . . . . . . . . . . . . 66

4.4 Specification . . . . . . . . . . . . . . . . . . 69 
4.5 Results . . . . . . . . . . . . . . . . . . . . . . 71

4.5.1 Auction Size and Yield Effects . . . . . . . . . . . . . . . . . 74

4.5.2 Expanded Window Surrounding Auction Events . . . . . . . . . . . 74

4.5.3 Cross-Maturity Auction Effects . . . . . . . . . . . . . . . . 76

4.5.4 Summary of Results . . . . . . . . . . . . . . . . . . . . . 78

4.5.5 Non-parametric Test Statistics . . . . . . . . . . . . . . . . . . 81

4.6 Extensions . . . . . . . . . . . . . . . . . . . . . . . . 82

4.6.1 Auction Impact on Yields Adjusted for Expected Inflation . . . . . . 82

4.6.2 On-the-run Zero-Coupon Yields . . . . . . . . . . . . . . . . . 85

4.6.3 Departures from Off-the-run Results . . . . . . . . . . . 87

4.7 Conclusion . . . . . . . . . . . . . . . . . . . . . . . . . . . . . . . . . 89

A Appendix: The Kalman Filter 133

A.1 Application of the Kalman Filter to the model of $\S 2.3 \ldots \ldots$. . . . . . . 136 


\section{List of Figures}

2.1 Timeline of Information Arrival in Funds Market. . . . . . . . . . . . . . 25

2.2 Diagram for Identification of $\beta \ldots \ldots \ldots$

3.1 Diagram Showing Net Negative OMO to Maintain Target. . . . . . . . . . 50

3.2 Weekly Open Market Operations and Demand Pressure. . . . . . . . . . . 50

3.3 Scatter Plot of Pressure Metric $\Omega$ and Target Changes. . . . . . . . . . . . . 54

3.4 Ordered Probit Model. Dependent Variable Equals $\{-1,0,1\} \ldots \ldots$

3.5 Marginal Effects of Ordered Probit Model. . . . . . . . . . . . . . . 57

4.1 Yield Curve Data Sample . . . . . . . . . . . . . . . . . . . . . 90

4.2 Auction Event Timing Across Maturity Horizons. . . . . . . . . . . . . . . . 91

4.3 Monthly Auction Distribution by Maturity Horizon. . . . . . . . . . . . . . 92

4.4 Face Value of Auction Events by Month. . . . . . . . . . . . . . . . . . 93

4.5 Auction Event Timing Across Maturity Horizons. . . . . . . . . . . . . . . . 94

4.6 Auction and Announcement Timing . . . . . . . . . . . . . . . . . 95

4.7 Relative Yield Data . . . . . . . . . . . . . . . . . . . . . . . 96

4.8 Cumulative Changes in Relative Yield _ . . . . . . . . . . . . . . . . 97

4.9 Test Statistics for Auction Event Studies on Relative Yields. . . . . . . . . 98

4.10 Auction Event Studies on Two-day Changes in Relative Yields. . . . . . . . 100

4.11 Auction Event Studies on Three-day Changes in Relative Yields. . . . . . . 101

4.12 Changes in Relative Yields Between Previous and Following Day. . . . . . . 102

4.13 Changes in Relative Yields Between Previous and Two-Business Days Following Auction. . . . . . . . . . . . . . . . . . . 103

4.14 Changes in Relative Yields Between Two Days Previous and Day Following Auction. . . . . . . . . . . . . . . . . . . . . . . . . . . 104

4.15 Cumulative Changes in Relative Yield . . . . . . . . . . . . . . . . . . 105

4.16 Cumulative Changes in Relative Yield - Three Year Horizon . . . . . . . . . 106

4.17 Non-Parametric Statistics for Auction Event Studies on Relative Yields. . . 107

4.18 Yield Curve and Inflation . . . . . . . . . . . . . . . . . . . . . 108

4.19 Cumulative Changes in Expected Inflation Corrected Yields . . . . . . . . . 109

4.20 Test Statistics for Auction Event Studies on Inflation Corrected Yields. . 110

4.21 Auction Event Studies on Two-day Changes in Inflation Corrected Yields. . 111

4.22 Auction Event Studies on Three-day Changes in Inflation Corrected Yields. 112

4.23 Changes in Relative Yields Between Previous and Following Day. . . . . . . 113

4.24 Changes in Inflation Corrected Yields Between Previous and Two-Business

Days Following Auction. . . . . . . . . . . . . . . . . . . . . . . . 114 
4.25 Changes in Inflation Corrected Yields Between Two Days Previous and Day Following Auction. . . . . . . . . . . . . . . . . . . . . 115

4.26 Auction Event Timing During On/Off-the-run Sample. . . . . . . . . . . 116

4.27 Off-the-run Discount Yield Premium . . . . . . . . . . . . . . . . . 117

4.28 Ten-Year Yields from On and Off-the-run Prices . . . . . . . . . . . . 118

4.29 Cumulative Changes in Relative on-the-run Yields . . . . . . . . . . . . . . 119

4.30 Cumulative Changes in On/Off-the-run Relative Yield . . . . . . . . . . . 120

4.31 Test Statistics for Auction Event Studies On/Off-the-run Relative Yields. . 121

4.32 Event Studies of Two-day Changes in On/Off-the-run Relative Yields. . . . 122

4.33 Studies of Three-day Changes in On/Off-the-run Relative Yields. . . . . . . 123

4.34 Changes in On/Off-the-run Relative Yields Between Previous and Following Day. . . . . . . . . . . . . . . . . . . . . . . . . . . . . . . . 124

4.35 Changes in On/Off-the-run Relative Yields Between Previous and Two-Business Days Following Auction. . . . . . . . . . . . . . . . . . . . . . . . . 125

4.36 Changes in On/Off-the-run Relative Yields Between Previous and ThreeBusiness Days Following Auction. . . . . . . . . . . . . . . . 126

4.37 Changes in On/Off-the-run Relative Yields Between Previous and Four-Business Days Following Auction. . . . . . . . . . . . . . . . . . . . 127 


\section{List of Tables}

2.1 Summary Statistics Weekly OMO. . . . . . . . . . . . . . . . 25

2.2 Detailed OMO Statistics at Target Changes. . . . . . . . . . . . . . 26

2.3 Maximum Likelihood Estimates of the Unobserved Components Model. . . 27

2.4 Ordinary Least Squares Estimates of Reduced Form. . . . . . . . . . . . . . 28

2.5 OLS estimates of Open Market Operation Out-of-sample Forecasts . . . . . . 28

2.6 FIML of system $(2.15)$ and $(2.16) \ldots \ldots \ldots \ldots \ldots$

2.7 Ordinary Least Squares Estimates for Forecast Error Model. . . . . . . . . . 30

2.8 DFBETAS Influence Statistics from Forecast Error Funds Rate Model. . . . 31

2.9 Robust Least Squares Estimates for Forecast Error Model. . . . . . . . . . . 32

3.1 FOMC Meetings Sorted by Accumulated Pressure on the Target Rate . . . 51

3.2 Ordinary Least Squares Estimates Binary Pressure Specification Model. . . . 52

3.3 Least Squares Estimates for Nonlinear Pressure Specification Model. . . . . . 53

3.4 Ordered Probit Model. Dependent Variable Equals $\{-1,0,1\} \ldots \ldots 5$

4.1 Auction Size and Relative Yield OLS Results. . . . . . . . . . . . . . . . . 99 


\section{Chapter 1}

\section{Purpose and Agenda}

The price of lending, determined in markets governed by the supply and demand of assets, informs almost all financial decision making. This dissertation investigates two critical markets where interest rates are determined, emphasizing the important role of supply effects in these markets. Three central questions are addressed: (1) What are the liquidity effects on the federal funds rate of open market operations? (2) Can the Fed's policy for choosing funds rate targets be characterized as accommodating or activist? (3) What are the effects of debt management policy on the prices of outstanding treasury securities?

Chapter 2 presents identification and estimation of the liquidity effect of open market operations. The Trading Desk at the Federal Reserve Bank of New York buys and sells bonds from banks, changing the overall supply of base money. A model of their objective to minimize the deviation of the realized rate from the target obtains a structural model where deviations of the target rate are a function of the demand forecast miss. Estimates of the unobservable demand forecast are found using the Kalman filter and used to identify the liquidity effect.

The result, that an increase in weekly open market operations of $\$ 1$ billion will lower the average federal funds rate in that period by 12 basis points, suggests that the funds market 
is less liquid than previously estimated.

Chapter 3 develops a measure of market pressure exerted on the funds rate target. The cumulative sum of demand-forecast errors describes the persistence of innovations in demand which exceed the Fed's expectation. The change of funds rate target in the direction of the accumulated pressure supports the hypothesis that an accommodating policy of interest rate smoothing is in place. As hypothesized, the size of open market operations is negatively related to the measure of inter-FOMC meeting pressure on the target federal funds rate, and the accumulated pressure metric has a positive and significant effect on the probability of an increase in the target rate.

Chapter 4 investigates the relationship between U.S. Treasury auctions and the off-therun yield curve. By examining discount yields constructed from off-the-run treasury prices during auction events, an event study approach finds an increase in relative yields at the auction horizon. The absorption effect of the additional supplies of future cashflows on the debt influences relative yields at the auction horizons and neighboring maturities. Since off-the-run bonds are used to calculate the discount rate, the effect is measured apart from the premium paid for highly liquid newly issued bonds. 


\section{Chapter 2}

\section{The Liquidity Effect of Open Market Operations}

\section{$2.1 \quad$ Introduction}

The Federal Reserve Bank of New York's Open Market Trading Desk (the Desk) conducts sales and purchases debt securities to achieve its mandate from the Federal Open Market Committee (FOMC.) Kos (2004) reports the directive of the Desk, “... to foster conditions in the reserves market consistent with maintaining the federal funds rate at an average around a specified target rate." The federal funds rate, the price negotiated between depository institutions (banks hereafter) for overnight loans between accounts at the Fed, serves as the primary instrument for the implementation of monetary policy and, thus, is an integral link in the transmission process of policy to the economy.

Banks manage reserve balances to meet statutory requirements and also to facilitate check clearing and transfers. During the two-week maintenance period, which ends on a Wednesday, banks must hold, by daily average, an FOMC-determined fraction of their total demand-deposit account holdings as reserves. These reserves include deposits in accounts at the Fed, (federal funds), and currency in the bank's vaults. Since 1998, the reserve requirement must be met against demand-deposit balances held over a computation period 
two maintenance periods earlier. Under this accounting convention, banks possess knowledge of the required average-reserve balance during the maintenance period. However, uncertainty remains regarding realized current-period transfers, deposits, and withdrawals. Additionally, banks may autonomously choose to hold excess reserves against the possibility of overdrafts or for other private purpose. Thus, a bank's maintenance-period demand for additional federal funds is not strictly determined by the regulatory requirement.

Since reserves at the Fed do not pay interest, ${ }^{1}$ balances in excess of operating and regulatory requirements are undesirable. Banks holding excess reserves may choose to lend to banks with shortfalls, with the price of borrowing determined by the supply and demand of those funds. Borrowing and spending behavior of the institutions' customers, borrowing from the Fed's discount window, transfers into U.S. Treasury accounts and, thus, out of the pool of traded federal funds, as well as the Fed's choices regarding the exhaustion or injection of funds through open market purchases or sales of securities, all affect the overall quantity of reserves available and thus the demand for additional funds supplied by the Fed.

In this study, the identification of the relationship between the market rate for overnight loans and the quantity of funds supplied through open market operations is achieved using a structural model of the market for federal funds, with demand shocks modeled as an unobservable component. The approach provides a context for the funds rate target in terms of interest rate smoothing hypothesis and an estimate of the liquidity effect of open market operations. In this framework, deviations from the target rate are a function of the Fed's demand forecast miss. In particular, data describing the Desk's open market transactions

\begin{tabular}{l}
\hline The announcement by the Board of Governors on October 6, 2008 de- \\
scribes a change in this policy enacted after the period under study here. \\
http://www.federalreserve.gov/newsevents/press/monetary/20081006a.htm
\end{tabular}


permits estimation of the market demand forecast miss, by way of maximum likelihood estimation and the Kalman filter algorithm. The model solution takes advantage of the theories of rational expectations and adaptive learning to estimate the ratio of permanent to temporary innovations in the demand for funds supplied through open market operations.

Section 2.2 provides context on the liquidity effect in the funds market. Section 2.3 develops the model of the market for non-borrowed reserves, finding the solution to the Desk's decision problem for choosing the size of each week's net open market operations. Section 2.5 reports on the data and results from model estimation, and the relationship with the hypothesis stated in section 2.4 .

\subsection{The Liquidity Effect}

Thornton (2001) discusses attribution of the phrase "liquidity effect" to Milton Friedman, relating to the hypothesized negative association between the supply of money and nominal interest rates. In the context of the federal funds market, the liquidity effect refers to the specific relationship between the supply of federal funds and the overnight lending rate; an increase in the supply of reserve balances brings about a lower federal funds rate. The elusiveness of an accurate and non-controversial estimate for the magnitude and properties of the liquidity effect is commonly, and perhaps correctly, attributed to the difficulty isolating exogenous policy activity of the Federal Reserve from the effect of the Fed's anticipation of the expected funds rate, the market's anticipation of the Fed's future actions, or other endogenous factors.

Each day, the Trading Desk determines the type and size of open market operations to be initiated, based on forecasts regarding the market for reserves. The transactions are executed 
and the funds rate and market conditions are monitored. ${ }^{2}$ Estimates for the path of reserve balances are altered based on the behavior of the funds rate and any new information. A liquidity effect implies the funds rate will firm when the Fed reduces the supply of reserves available to banks, and will soften when reserve levels are augmented, but this simple relation need not always hold. For example, expectations of lower future rates might depress current demand moving the funds rate lower, in absence of a contemporaneous increase in supply. Seasonally driven reserve demand, discount window borrowing, or other influences of the banking sector may cause the Desk to conduct open market operations which affect the funds market differently from those prescribed by a strict liquidity-effect analysis. Furthermore, a large portion of open market operations are made to offset fluctuations in reserve levels due to changes in U.S. Treasury balances, the impact of check float, expected demand fluctuations, or other autonomous variability which affect the supply of nonborrowed reserves.

Closely related antecedent studies examine the liquidity effect at a high frequency. Hamilton (1997) delivers an important innovation to the approach for estimating the liquidity effect. He proposes that the Desk's forecast miss of U.S. Treasury account adjustments serves as an instrument of exogenous changes in the supply of reserves, and estimates the daily liquidity effect. Following the treatment of Gilchrist (2001), discussing Thornton (2001), the high frequency liquidity effect models focusing on the supply and demand of total reserves can be summarized by the system:

$$
\begin{aligned}
& T R_{t}^{d}=\beta f f r_{t}+v_{t}^{d} \\
& T R_{t}^{s}=B_{t}+v_{t}^{s} .
\end{aligned}
$$

Where the supply of total reserves is adjusted by the Desk, with the objective to supply $B_{t}^{*}$,

\footnotetext{
${ }^{2}$ Feinman (1993) provides a detailed examination of the operational procedure of the Trading Desk.
} 
the level of reserves which achieves the target rate,

$$
\begin{aligned}
& B_{t}=B_{t}^{*}+\omega_{t} \\
& B_{t}^{*}=\beta f f r_{t}^{*} .
\end{aligned}
$$

Here, $v_{t}^{s}, v_{t}^{d}$, and $\omega_{t}$ are i.i.d. and $\omega_{t}$ equals the control error for the desired level of reserves. The model reduces to:

$$
f f r_{t}=f f r_{t}^{*}+\frac{1}{\beta}\left(v_{t}^{s}-v_{t}^{d}-\omega_{t}\right)
$$

obtaining a result analogous to the solution of this paper's model developed below. Hamilton estimates supply forecast misses which serve as an instrument for $v_{t}^{s}$ and estimates the liquidity effect of total reserves, $1 / \beta$. Carpenter and Demiralp (2006) use a more comprehensive and accurate measure of the same forecast miss, and find an estimable liquidity effect, but one that according to Carpenter and Demiralp (2008), imply, "the change in balances necessary for even a 25-basis point change in funds rate would lead to implausibly large open market operations."

Thornton (2001) disputes the effectiveness of Hamilton's approach, citing sensitivity of results to a small subset of days with large spikes in the funds rate. Thornton (2006) reassesses the contribution of Carpenter and Demiralp (2006), and finds a very small, but statistically significant liquidity effect, with little practical economic significance. Thornton (2007), noting that the Fed can not judge perfectly the magnitude of autonomous factors affecting reserve supply such as currency, float, and the Treasury balance, investigates an operating policy rule for open market operations for a liquidity effect, with particular attention paid to the conduct of operations at the time of target changes. Not finding convincing evidence, he proposes an explanation; market forces may drive interest rates higher or lower, 
relieving the Fed of the requirement to conduct sizable open market operations to affect changes in the market rate. This paper seeks to bridge the gap between the previous work on the liquidity effect and that suggesting market forces may influence the Fed's conduct and choice of interest rate target.

Here, the procedure concentrates on the fact that as the desk conducts an open market purchase for example, the counterparties' accounts are credited by the Trading Desk, and thus, nonborrowed reserves are increased. This instantaneous change in nonborrowed reserves occurs without measurement error. The fact that some, if not most, of any open market operation is made to offset or sanitize idiosyncratic fluctuations in reserves resulting from factors such as float, currency demand, or Treasury balance adjustments, is not under dispute. These factors are completely independent of the Fed's influence, and manifest as innovations of demand for additional funds supplied by open market operations.

Hamilton (1997) addresses the possibility that the liquidity effect estimated using an instrument for the supply of reserves may be in part incorporating the influence in the demand-for-reserves function. However, both Carpenter and Demiralp (2006) and Hamilton present models which rely on dummy variables corresponding to features of the calendar to control for these variations in demand. The approach developed here utilizes data directly observable to market participants in real time, and models the unobserved innovations in demand as an unobserved component estimated using the Kalman filter. Since the Desk supplies additional reserves inelastically to achieve the target rate, there is no distinction between a (positive) demand forecast error and a supply forecast error resulting in insufficient funds to achieve the target rate.

Instead of attempting to isolate exogenous from endogenous changes in the level of re- 
serves, the present study uses a model of adaptive expectations to model the persistence in the idiosyncratic innovations of demand for reserves which manifest as deviations from the target rate. By utilizing a state space formulation, the model isolates the temporary, idiosyncratic shocks absorbed by defensive open market operations from persistent innovations in the demand for federal funds. The estimate of the Fed's expectation of each period's demand permits identification of the slope of the demand curve.

\subsection{A Model of the Desk's Decision}

Weekly demand for funds $R_{t}^{d}$ depends linearly on the federal funds rate, $f f r$, a stochastic demand component, $\delta$, and a vector of known, seasonal or calendar factors influencing the level of demand, $\mathbf{X}$,

$$
R_{t}^{d}=\Psi^{\prime} \mathbf{X}_{t}+\beta f f r_{t}+\delta_{t} .
$$

The demand shock $\delta$ segments the disturbance to demand into two components. One portion, $\varepsilon$, manifests as idiosyncratic noise; the other, $\eta$, evolves following a random walk with constant drift.

$$
\begin{array}{rlrl}
\delta_{t}=\eta_{t}+\varepsilon_{t}, & \varepsilon_{t} & \sim N\left(0, \sigma_{\varepsilon}^{2}\right) \\
\eta_{t}=\mu+\eta_{t-1}+\xi_{t}, & \xi_{t} \sim N\left(0, \sigma_{\xi}^{2}\right) .
\end{array}
$$

The supply of reserves equals the level of reserves at the beginning of period $t$, plus the net open market operations $(O M O s)$ initiated by the Desk,

$$
R_{t}^{s}=R_{t-1}^{s}+O M O_{t} .
$$


The following optimization program captures the mandate of the Trading Desk.

$$
\begin{aligned}
& \min _{\left\{O M O_{t}\right\}} E_{t-1}\left(f f r_{t}-f f r_{t}^{*}\right)^{2} \\
& \text { s.t. } \quad f f r_{t}=\frac{1}{\beta}\left(R_{t}^{s}-\boldsymbol{\Psi}^{\prime} \mathbf{X}_{t}-\delta_{t}\right) .
\end{aligned}
$$

The choice of open market operation minimizes the difference between the target and expected market funds rate, subject to the equilibrium condition that the supply of funds equals the demand.

The Desk determines the size of the net open market operation at time $t$, based on its knowledge of the parameters $\beta$ and $\boldsymbol{\Psi}$. Figure 2.1 shows a timeline for the choice and information discovery. The total demand shock is realized and the market funds rate is observed at the end of the period. While the components of the shock are not observed, they may be inferred in part, given the set of parameter estimates.

As $R_{t}^{s}=R_{t-1}+O M O_{t}$, and with the Fed's expectation that the day's realized rate equal the target, $E_{t-1} f f r_{t}=f f r_{t}^{*}$, the solution to (2.4) determines the supply of reserves selected by the Desk to achieve the target rate,

$$
R_{t}^{s^{*}}=\Psi^{\prime} \mathbf{X}_{t}+\beta f f r_{t}^{*}+E_{t-1} \delta_{t}
$$

In equilibrium, (2.1) and (2.5) find the deviation of the realized funds rate from target is a function of the difference between realized and expected demand shock,

$$
\beta\left(f f r_{t}^{*}-f f r_{t}\right)=\delta_{t}-E_{t-1} \delta_{t}
$$

Consideration of equation (2.6) in the context of the demand equation (2.1) and the discussion from section 2.2 demonstrates why naive estimation of the relationship between reserves supplied by open market operations and the federal funds rate will provide biased estimates. Since $\delta$, is correlated with the realized deviation from the funds rate target, the assumption 
of orthogonal error terms necessary for unbiased ordinary least squares estimates is violated in the direct estimation of equation (2.1).

An alternative approach to the intuition of the result of (2.6) follows from the adaptive expectations formulation of Nerlove (1958), Cagan (1956), and specifically, the updating Equation (2.7) derived explicitly from the Kalman filter algorithm in appendix A. In any period $t-1$, the previous period forecast of $\delta, E_{t-2} \delta_{t-1}$, can be evaluated in light of the new information about the true value of the state vector obtained through the measurement equation.

$$
E_{t} \delta_{t+1}=\mu+E_{t-1} \delta_{t}+\lambda\left(\delta_{t}-E_{t-1} \delta_{t}\right)
$$

Equation (2.7) describes the evolution of information discovery that the Fed uses to determine the size of future open market operations. Assuming that the Fed knows the true values $\beta$ and the hyperparameter $\boldsymbol{\Psi}$, or at least that the Fed is not systematically incorrect in its expectations, the decomposition of the disturbances is achievable. After observing the market realization of the funds rate each period - in the context of the intended targetthe question of interest is the proportion of the deviation from target which is attributed to transitory versus permanent influences. If, for instance, an unexpectedly large quantity of funds are withdrawn from the banking sector during a particular week, the Fed will learn through account reporting and the behavior of the rate. If the disturbance implies a permanent increase in demand for base money the shock will require larger open market operations. On the other hand, if the deviation from target is a temporary shock it will have no effect on the future path of reserves.

Setting the structural model in state space form, decomposition of the forecast miss into the temporary and permanent components is achieved by the Kalman filter. Appendix A 
provides details and derivation of the Kalman algorithm. Translation of the model above into state space form is straightforward. Writing the measurement equation, the observed series $R$, in terms of the unobserved component $\delta$ :

$$
R_{t}=\Psi^{\prime} \mathbf{X}_{t}+\beta f f r_{t}+\delta_{t}
$$

and transition equations describing the state process:

$$
\begin{aligned}
& \delta_{t}=\eta_{t}+\varepsilon_{t} \\
& \eta_{t}=\mu+\eta_{t-1}+\xi_{t} .
\end{aligned}
$$

Within this framework, the Kalman gain $\lambda$ equals $\sigma_{\xi}^{2} /\left(\sigma_{\xi}^{2}+\sigma_{\varepsilon}^{2}\right)$, and represents the new information contained in period $t-1$ 's forecast error, to be included in the forecast for $\delta_{t}$. The errors $\varepsilon$ are transitory, idiosyncratic noise, and those of $\xi$ are persistent. Regardless of the variance of $\varepsilon$, the optimal next-period forecast equals zero. If the variance of $\xi$ is high relative to the variance of $\varepsilon$, then the information content of $(\delta-E(\delta))$ is high. The fraction of forecast error attributed to the persistent component of $\delta$ is relatively greater, and so, a larger percentage of that error is expected to transmit to the following period. Section 2.5.1 reports maximum likelihood results of the Kalman filter algorithm for the system of equations (2.8).

Taking the first difference of (2.5) shows that the net open market operation at time $t$ equals

$$
\Delta R_{t}^{s^{*}}=\mathbf{\Psi}^{\prime} \Delta \mathbf{X}_{t}+\beta \Delta f f r_{t}^{*}+E_{t-1} \delta_{t}-E_{t-2} \delta_{t-1}
$$

Substituting (2.9), in to (2.7) gives,

$$
\Delta R_{t}^{s^{*}}=O M O_{t}^{*}=\mu+\Psi^{\prime} \Delta \mathbf{X}_{t}+\beta \Delta f f r_{t}^{*}+\lambda \beta\left(f f r_{t-1}^{*}-f f r_{t-1}\right)
$$


This form of the model expresses the Desk's mandate in terms of a policy directive to provide additional funds which will account for the trend in demand $(\mu)$, to offset effects related to the calendar $(\mathbf{X})$, for any change in the target $\left(f f r^{*}\right)$, and to account for the portion of the previous period's target miss attributable to a permanent shock, $\left(f f r^{*}-f f r\right)$. The parameter $\lambda \beta$ captures how much the Fed must compensate for the permanent component of the previous day's forecast miss, given the elasticity of the rate to open market operations.

Section 2.6.1 reports ordinary least squares estimates of the model

$$
\Delta R_{t}^{s^{*}}=O M O_{t}^{*}=\mu+\Psi^{\prime} \Delta \mathbf{X}_{t}+\beta \Delta f f r_{t}^{*}+\lambda \beta\left(f f r_{t-1}^{*}-f f r_{t-1}\right)+e_{t} .
$$

The error term $e_{t}$ in (2.11) results from the unobserved effects influencing the Desk's choice of open market operation not included in the updating rule of (2.7). These effects are not systematically correlated to the realization of the federal funds rate, since the Desk's objective is to minimize the difference between the target and rate. Errors which occur in reaching this objective should, under the paradigm of rational expectations, result in neither consistently high or low levels of the federal funds rate. Suppose for example, that because of an event such as the distribution of an economic stimulus check or tax rebate, the Desk determines that a maintenance period will require a larger net open market operation than that specified by (2.7). An augmentation of that period's operation serves to sanitize the effect of the additional demand for federal funds, with the intention of equating the rate to the target. Therefore, any deviation from target as a result of forecast error will not be systematically high or low.

There is likewise no systematic relationship between the contemporaneous error and the lagged value of the target miss. Lagged deviations from target capture the relevant state of the market during the previous period, reflecting the failure, or unwillingness of the Fed to 
provision reserves precisely to equate demand and supply at the target. These deviations are typically quite small, display little persistence, and previous period target misses would not inform economic decisions affecting market conditions in period $t$. Along with the results of the ordinary least squares estimates of (2.11) in section 2.6.1 a full information maximum likelihood specification provides a robustness check for bias resulting from a correlation between the lagged federal funds rate and the error term.

\subsubsection{Identification}

As discussed in section 2.2, studies of the high-frequency liquidity effect have concentrated on the supply shocks which originate from Treasury balance forecasts and other disturbances in the supply of reserves. The intuition behind the model described in section 2.3 is that there is a relationship between the federal funds rate and demand for additional nonborrowed reserves. The unexpected impact of factors like check float, unexpected currency demand, or even increased discount window borrowing are relevant in this context only insofar as that they increase the value of $\delta$, the unobservable component of demand for additional funds in excess of $E(\delta)$, the forecast of the demand component made by the Fed. Factors which permanently influence the end-of-day period of supply of funds affect the next period's demand for additional nonborrowed reserves, and manifest in the model above through the forecast of the next period's demand for open market operations, $E_{t} \delta_{t+1}$. The temporary component of $\delta$, attributable to shortages or surpluses which will be reversed in the very short term, do not contribute to the forecast.

Since the mandate of the Desk is to provide additional or fewer funds to facilitate trading on average around the target rate, the Desk's failure to achieve that objective manifests in 
a market rate different from the target. Figure 2.2 depicts the strategy for identifying the slope of the demand curve. All else equal, the size of the open market operation for each period equals the forecast of the unobserved demand component. If the target is unchanged, and the Desk acts to sanitize any demand shock, an open market operation equal to $E_{t-1} \delta_{t}$ will leave the rate unchanged. If the realized rate differs from the target, the difference is a function of the error in the Desk's forecast. It is the additional structure of the Trading Desk's "learning function" that allows estimation of the slope parameter. Some part of the forecast miss was noise, and another signal. If innovations in demand show persistence, then information from the target miss is incorporated into the next period's forecast, and the slope of the demand curve is identified.

\subsection{Hypothesis}

\section{Hypothesis 1: The Supply of Additional Reserves Provided by Open Market Operations Decreases the Realized Federal Funds Rate.}

Previous literature has addressed the relationship between the supply of reserves and the federal funds rate, yielding mixed results. The market reaction to high frequency monetary policy in the interbank overnight market has not been conclusively resolved. All else equal, an increase in the supply of funds via open market operations increases the supply of reserves and decreases the market price of those reserves, the federal funds rate. In terms of the equation of interest from the model developed in Section 2.3, Hypothesis 1 can be expressed 
as:

$$
\begin{aligned}
R_{t} & =\boldsymbol{\Psi}^{\prime} \mathbf{X}_{t}+\beta f f r_{t}+\delta_{t}, \\
\frac{\partial f f r}{\partial R_{t}}<0 & \Longrightarrow \frac{1}{\beta}<0 .
\end{aligned}
$$

\subsection{Data and Estimation}

For each week $t$, ending January 5, 2000 through December 19, 2007, the level of open market operation supplied reserves, $R_{t}$ equals the Thursday-through-Wednesday average of accumulated new, less expiring, temporary and permanent daily open market operations, as reported by the Federal Reserve Bank of New York. The Federal Reserve also provides the transactions-weighted average of the federal fund and target rates $f f r_{t}, f f r_{t}^{*}$. The remaining regressors, collectively labeled $\mathbf{X}_{t}$, are a matrix of $0 / 1$ dummies accounting for the effects related to the calendar. Positive elements correspond to weeks which include the first days of months and quarters, weeks which include the first business day after the 15th of each month, and for all weeks in the month of December. These periods are associated with atypically high payroll, spending, and government transfer activity. Additionally, dummies are included for FOMC meetings and target changes, the second week of the maintenance period, and the entire maintenance period during and the week following the terrorist attacks of September 2001.

In the sample under study, the average net open market operation equals $\$ 0.77$ billion. In the six weeks with 25 basis point reductions in the funds rate target, the average net open market operation equals $\$ 0.67$ billion. For the 19 weeks with 25 basis point increases in the target rate, the average net open market operation equals $\$ 0.89$ billion. These values are $\$ 0.11$ billion less and more than the average open market operation of $\$ 0.77$ billion 
respectively. The only 50 basis point increase in the target corresponds to a change equal to $-\$ 2.31$ billion, and the ten 50 basis point reductions in the target occur with an average operation of $\$ 5.5$ billion. Table 2.1 reports summary statistics for net open market operations during weeks with target rate changes.

\subsubsection{Maximum Likelihood Estimates of State Space Model}

Table 2.3 displays the maximum likelihood estimates for the state-space model of (2.8). As predicted by hypothesis 1 , the parameter estimate of primary interest, the relationship between the funds rate and reserves supplied through open market operations $\partial f f r / \partial R=$ $1 / \hat{\beta}<0$. The value of $\hat{\beta}=-8.10$ implies that an increase in the average sum of open market operations of $\$ 1$ billion results in a decrease of the federal funds rate by $1 / \hat{\beta}=12.34$ basis points. Since, in general, maximum likelihood estimates are asymptotically normal, a 95\% confidence interval for $\hat{\beta}$ equals $\hat{\beta} \pm 1.96 \cdot \hat{\sigma}_{\hat{\beta}}=(-11.68,-4.51)$.

The components of the hyperparameter $\hat{\Psi}$, show that operations are larger in the second week of the maintenance period, December, the week of the $15^{\text {th }}$, and last of the month. Of the 69 FOMC meetings during the sample period, 16 coincided with announcement of a change to a lower funds rate, 20 to a higher funds rate, and the remaining 33 announcing no change. A relatively high parameter estimate of 6.567 is associated with the six unannounced meetings. Four of the six unscheduled FOMC meetings resulted in lower funds rate targets. The other two, occurring in the weeks of August 10 and 18, 2007 follow a scheduled meeting the week ending August 3, 2007. August and September mark a turbulent period in the 2007 financial crisis. None of the August meetings resulted in a change to the target rate.

During the week the markets reopened following the 2001 attacks on the World Trade 
Center the Fed announced a lower target and open market operations combined for a net effect of $\$ 46.5$ billion. In the weeks following the attacks, the target rate would be lowered by 100 basis points. The high parameter estimates of 18.18 and 7.2 on dummies spanning this period reflect that increased activity. On average, larger open market operations are conducted during weeks including the first days of the first and third quarters. Statistically insignificant parameter estimates are reported for the first weeks of quarters two and four.

The standard error estimates for the transitory and permanent components of demand are $\hat{\sigma}_{\varepsilon}=2.572$ and $\hat{\sigma}_{\xi}=2.411$ respectively, with constant drift in $\eta, \hat{\mu}=0.733$. The Kalman gain in the univariate framework $\hat{\lambda}=\hat{\sigma}_{\xi}^{2} /\left(\hat{\sigma}_{\varepsilon}^{2}+\hat{\sigma}_{\xi}^{2}\right)=0.467$. The standard error of this function of parameters $\hat{\lambda}\left(\hat{\sigma}_{\xi}^{2}, \hat{\sigma}_{\varepsilon}^{2}\right)=0.0395$. The Kalman gain as estimated within the state space procedure quickly (after $t=7$ ) converges to the steady-state value of 0.596 . The estimate reports that the permanent component accounts for $59.6 \%$ of each period's forecast miss. The remaining $40.4 \%$ comes from idiosyncratic noise, and does not influence the next period's forecast of demand.

\subsubsection{Relationship with Previous Results}

Carpenter and Demiralp (2006) find estimates for the daily liquidity effect for each of the 10 business days of the maintenance period. Their results suggest that, on average, an increase of $\$ 1$ billion to reserve balances will lower the daily funds rate by one basis point. However, a $\$ 1$ billion addition to reserves on the last day of a maintenance period will result in a 3.41 basis point reduction in the funds rate. Based on their results, for the second week of a maintenance period, a $\$ 1$ billion increase in reserves on Settlement Wednesday will lower the average weekly funds rate by 0.487 basis points, and average weekly reserves by 
$\$ 0.1429$ billion. These estimates suggest that significant quantities of funds are necessary to bring about changes the size of typical target adjustments. The average daily liquidity effect suggests an increase of $\$ 25$ billion to reserves would be needed to effect a 25 basis point reduction in the average weekly funds rate. Hamilton (1997) finds an open market sale of $\$ 420$ million occurring on the last day of the maintenance period will increase the funds rate by 10 basis points.

The liquidity effect estimated by Carpenter and Demiralp (2006), following a similar technique of Hamilton (1997), addresses the supply of reserves directly. Their use of the instrument for changes in reserve balances produces values for the effect of changes directly to the supply of reserves. The change in reserves affected by open market operations is instantaneously equivalent to a change in reserves, although the quantity a bank chooses to retain as reserve balances is then outside of the Fed's direct influence. The liquidity effect identified in this study finds the elasticity of the funds rate to open market operations, or additional supplies of base money. While certainly these two measures are very closely related, a strict 1:1 comparison of these liquidity effects is inappropriate. However, regardless of this difference in specification, the liquidity effect of open market operation estimated here finds the reserves market to be far less liquid than in previous studies, and can be interpreted in terms of the observed operations conducted by the Fed. 


\subsection{Robustness of Results to Alternative Specifications}

\subsubsection{Ordinary Least Squares Estimation}

As derived in section 2.3, the adaptive updating of the Desk's operating procedure can be written as:

$$
\Delta R_{t}^{s^{*}}=O M O_{t}^{*}=\mu+\mathbf{\Psi}^{\prime} \Delta \mathbf{X}_{t}+\beta \Delta f f r_{t}^{*}+\lambda \beta\left(f f r_{t-1}^{*}-f f r_{t-1}\right)+e_{t} .
$$

Table 2.4 shows ordinary least squares the estimates for the specification (2.14). The param-

eter estimate of $\hat{\beta}=-9.41$ suggests a slightly smaller but not significantly different liquidity effect from that found using maximum likelihood estimation of the Kalman filter, of $1 / \hat{\beta}=$ 10.6 basis points. Parameter estimates for $\mu$, and the hyperparameter $\boldsymbol{\Psi}$ are consistent with those derived from the maximum likelihood approach.

The indirect least squares estimate of $\lambda$ found by estimating equation (2.14) equals $\hat{\lambda \beta} / \hat{\beta}=0.95$ with a $95 \%$ confidence interval of $(0.557,1.34)$. This result is not inconsistent with the MLE estimate of $\lambda=0.59$ found using maximum likelihood techniques.

As a robustness check against the possibility of correlation between the lagged federal funds rate on the right hand side of (2.14) and the error term, the system

$$
\begin{aligned}
\Delta R_{t}^{s^{*}}=O M O_{t}^{*} & =\mu+\mathbf{\Psi}^{\prime} \Delta \mathbf{X}_{t}+\beta \Delta f f r_{t}^{*}+\lambda \beta f f r_{t-1}^{*}-\lambda \beta f f r_{t-1}+\epsilon_{1 t} \\
f f r_{t-1} & =\alpha_{1} f f r_{t-2}+\epsilon_{2 t}
\end{aligned}
$$

is estimated using full information maximum likelihood allowing for contemporaneous correlation of errors $\epsilon_{1 t}$ and $\epsilon_{2 t}$. Table 2.6 displays the results of estimation. The $A R(1)$ specification of $f f r_{t-1}$ in (2.16) finds an $R^{2}=0.99$, and coefficient estimates of (2.15) not statistically different from ordinary least square estimates of (2.14). This result supports the 
proposition that any simultaneity bias has neither a statistically or economically significant influence upon the ordinary least squares estimates from (2.14). Estimation of the system expanded in terms of the lagged funds rate and target opposed to the deviation from the target rate circumvents the weak instruments problem that arises since weekly deviations from target exhibit nearly no persistence, any $A R$ specification for $\left(f f r_{t-1}^{*}-f f r_{t-1}\right)$ displays an $\bar{R}^{2}$ less than 0.02 .

\subsubsection{Estimation of Identification Equation}

As discussed in section 2.2 and 2.3, the demand forecast miss is used to identify the liquidity effect. Equation (2.6) provides an additional channel for examining the relationship between the forecast miss and target deviation, and thus the suitability of the model assumptions. Table 2.7 displays the parameter estimates from ordinary least squares of the relationship between deviation from target and the period $t$ forecast error derived from the Kalman filter procedure,

$$
\delta_{t}-E_{t-1} \delta_{t}=\beta\left(f f r_{t}^{*}-f f r_{t}\right),+e_{t} .
$$

The sample period is abridged by three weeks from the original sample. The first week is used as a conditioning value for the state space estimation, and the next two observations are deleted to allow for the high initial variance before practical convergence of the updating Kalman ratio. This specification provides a robustness check of the model specification of the maximum likelihood estimates of the Kalman filter.

The parameter estimate for $\hat{\beta}$ is not significantly different from zero at the $10 \%$ level. However, closer examination of the data provides a plausible explanation for this failure to reject the hypothesis that $\hat{\beta}=0$. Table 2.8 displays the dates of the 10 observations 
which exert the largest (in magnitude) inordinate influence on the parameter estimate. The observation which corresponds to the week that financial markets reopened after the terrorist attacks of September 2001 exerts an exceptionally large influence on the parameter estimate. This influence, measured by $D F B E T A,{ }^{3}$ where

$$
\operatorname{DFBETA}_{j i}=\frac{b_{j}-b_{j,-i}}{s_{-i} \sqrt{c_{j j}}} .
$$

For the $i^{\text {th }}$ observation and $j^{\text {th }}$ parameter, DFBETA $A_{j i}$ equals the difference between the parameter estimate if all observations were included, and the parameter estimate if the $i^{\text {th }}$ observation were excluded from the estimation. This difference is scaled by $s_{-i} \sqrt{c_{j j}}$, the product of the root residual mean square error calculated from the estimation which does not include the $i^{\text {th }}$ observation, $s_{-i}$, and the $j j^{\text {th }}$, element of $\left(\mathbf{X}^{\prime} \mathbf{X}\right)^{-1}, c_{j j}$. This influence statistic measures the number of standard errors that the coefficient changes between the estimation from the whole sample, and the sample which does not include the $i^{t h}$ observation.

For the week including September 19, 2001, the ordinary least square estimate of $\hat{\beta}$ in (2.17), DFBETAS $S_{\beta,-9 / 11}=3.86$, which is 5.3 times larger in magnitude than the second most influential observation. Estimates from the model without that observation changes the point estimate for $\beta$ by 3.86 times the standard error of 2.654 . The sign of DFBETAS is also meaningful, since a positive value of implies the parameter estimate without the influence of the period following the 2001 World Trade Center attack $\left(b_{j,-i}\right.$ from $\left.(2.18)\right)$ is relatively low.

Table 2.9 shows the regression parameters with estimation robust to outliers. There, the parameter estimate for $\beta$ equals -7.207 and is significant at the $5 \%$ level. With confidence interval $(-12.8242,-1.589), \hat{\beta}$ is consistent with parameter estimates derived from

\footnotetext{
${ }^{3}$ For a complete discussion of this statistic see Myers (1990)
} 
the maximum likelihood approach.

\subsubsection{Out-of-Sample Open Market Operation Prediction}

The Kalman filter approach for estimating components of the structural model for the federal funds market produces out-of-sample forecasts for the unobserved demand component $\delta$. These estimates imply a size of open market operation to achieve $R_{t}^{s *}$, the predicted level of reserves in a period equals:

$$
R_{t}^{s *}=\hat{\mathbf{\Psi}}^{\prime} \mathbf{X}_{t}+\hat{\beta} f f r_{t}^{*}+E_{t-1} \delta_{t}
$$

The predicted size of the open market operation in period $t$ equals

$$
O M O_{t}^{s *}=\Delta R_{t}^{s *}
$$

and a measure of the forecast can be made by fitting an ordinary least squares estimate between $O M O_{t}^{*}$ and the observed change in the measure of funds supplied by open market operation, $O M O_{t}$ using the relation

$$
O M O_{t}=a_{0}+a_{1} O M O_{t}^{s *}+e_{t}
$$

Table 2.5 shows the parameter estimates for the specification of (2.21). The parameter estimate of $\hat{a}_{1}=0.60$ implies that a $\$ 1$ billion increase in permanent demand will increase the size of the open market operation by $\$ 600$ million. A $95 \%$ confidence interval for $\hat{a}_{1}=$ $(0.5,0.7)$. Hamilton (1997) finds a relationship between the estimate of the Treasure balance forecast miss and change in reserves equal to 0.42 . The result $\hat{a}_{1}=0.60$ provides support for the model specification and the suitability of out-of-sample forecasts as an instrument

for identification of the liquidity effect. A naive forecast of the open market operation based 
only on the previous period's $O M O$, has a $R^{2}$ of $23 \%$, and a parameter estimate of -0.47 significant at the $1 \%$ level.

\subsection{Conclusion}

The unique structure of the federal funds market allows the behavior of the Fed to be modeled in an adaptive expectations framework. The Trading Desk enters the market by buying and selling bonds to equalize the funds rate with a FOMC determined target. This structure allows for the identification of the liquidity effect of open market operations. In a departure from the previous studies of Hamilton (1997) and Carpenter and Demiralp (2006), this paper measures the elasticity of demand for additional reserves in terms of the observed open market operation, not through use of supply forecast errors unavailable to market participants. The unobserved demand component accounts for a misspecification of the demand for funds found in previous studies which yield conspicuously small liquidity effects.

Estimates of the liquidity effect derived from maximum likelihood estimates of a Kalman filtering algorithm agree with the ordinary least squares estimates of the reduced form model: an increase in open market operations of $\$ 1$ billion above the average results in a decline in the federal funds rate by about 12 basis points. 


\section{Figure 2.1: Timeline of Information Arrival in Funds Market.}

This diagram shows the timing of observation for the variables of interest.

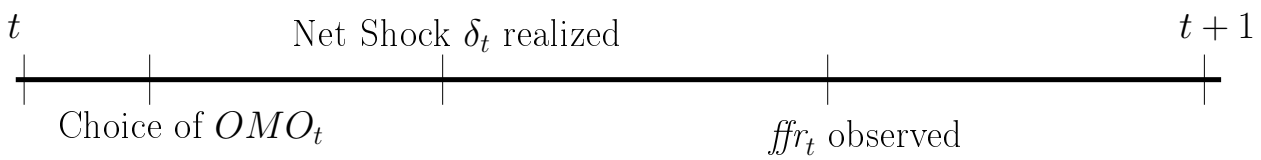

Figure 2.2: Diagram for Identification of $\beta$.

Setting $\mathbf{X}_{t}=\mathbf{X}_{t+1}, \delta_{t-1}=E_{t-2} \delta_{t-1}=0$, and $f f r_{t}^{*}=f f r_{t+1}^{*}$, the figure below shows the identification scheme for the constant slope of the demand curve for federal funds $D$. The period's open market operation equals the expected demand shock. The deviation of the funds rate from the target is linearly related to the demand shock forecast miss. The target rate $f f r^{*}$, the funds rate $f f r$, and information derived from the forecast miss $E_{t} \delta_{t+1}$ identify the slope of the demand curve $\beta$.

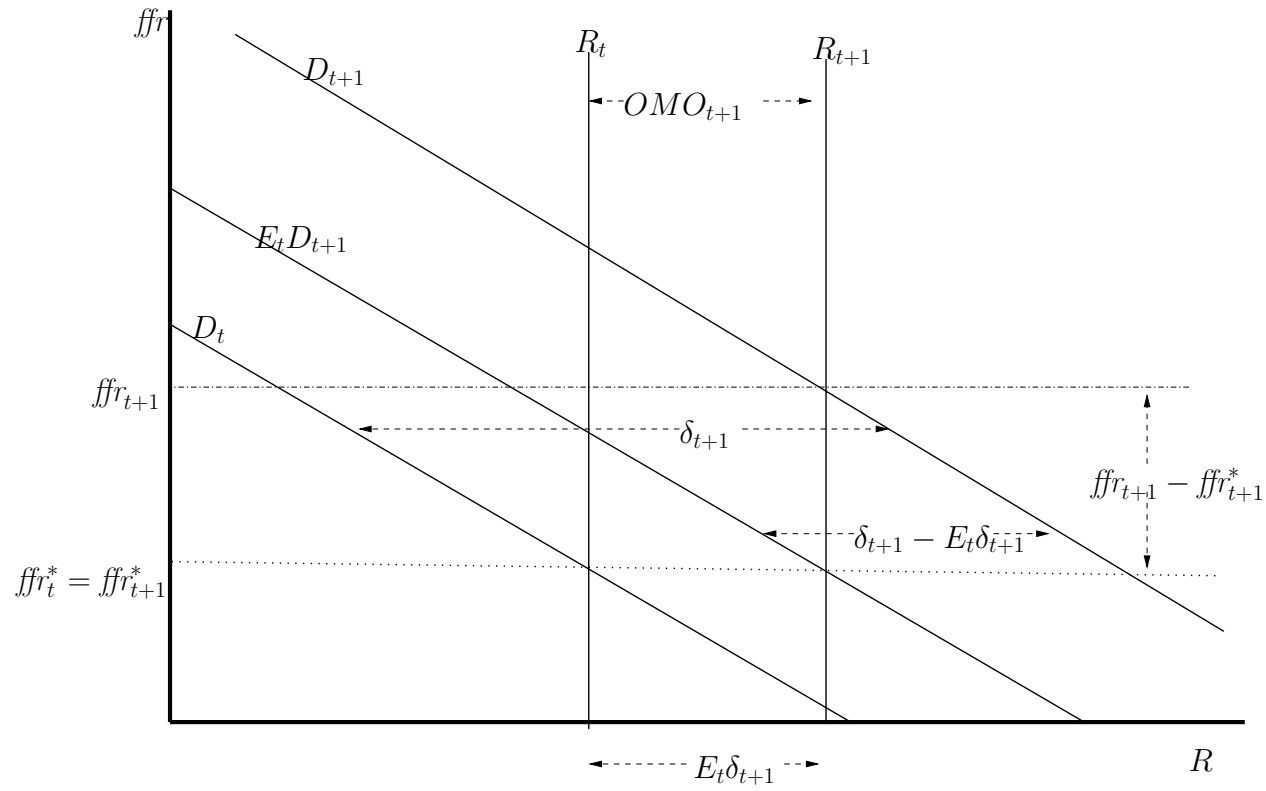

Table 2.1: Summary Statistics Weekly OMO.

This table shows the net OMO for weeks when a change in the target rate was announced.

\begin{tabular}{lcrcrr}
\hline TARGET & $N$ & MEAN & ST.DEV. & MIN & \multicolumn{1}{c}{ MAX } \\
\hline \hline$\Delta f f r^{*}=25 \mathrm{bs}$ & 19 & 0.895 & 5.012 & -7.786 & 11.036 \\
$\Delta f f r^{*}=-25 \mathrm{bps}$ & 6 & 0.671 & 3.629 & -4.836 & 5.268 \\
$\Delta f f r^{*}=50 \mathrm{bps}$ & 1 & -2.318 &. & -2.318 & -2.318 \\
$\Delta f f r^{*}=-50 \mathrm{bps}$ & 10 & 5.509 & 15.594 & -11.139 & 46.554
\end{tabular}




\section{Table 2.2: Detailed OMO Statistics at Target Changes.}

This table shows the size of net open market operations for weeks when the target was changed along with the size and direction of the target adjustment.

\begin{tabular}{|c|c|c|c|c|}
\hline DATE & UP25 & UP50 & DOWN25 & $\overline{\text { DOWN50 }}$ \\
\hline $2 / 2 / 2000$ & 10.521 & & . & \\
\hline $3 / 21 / 2000$ & 1.729 & & • & \\
\hline $5 / 16 / 2000$ & & -2.318 & & . \\
\hline $1 / 3 / 2001$ & & $\cdot$ & & 9.18 \\
\hline $1 / 31 / 2001$ & & . & & -2.559 \\
\hline $3 / 20 / 2001$ & & . & & 6.567 \\
\hline $4 / 18 / 2001$ & & . & & 4.250 \\
\hline $5 / 15 / 2001$ & & . & & 5.539 \\
\hline $6 / 27 / 2001$ & & & -0.511 & $\cdot$ \\
\hline $8 / 21 / 2001$ & & & 5.268 & . \\
\hline $9 / 17 / 2001$ & & . & & 46.554 \\
\hline $10 / 2 / 2001$ & & . & & 1.917 \\
\hline $11 / 6 / 2001$ & & . & & -11.139 \\
\hline $12 / 11 / 2001$ & & & -4.835 & . \\
\hline $11 / 6 / 2002$ & & . & & -2.035 \\
\hline $6 / 25 / 2003$ & & & 1.786 & . \\
\hline $6 / 30 / 2004$ & 2.39 & & . & \\
\hline $8 / 10 / 2004$ & -2.893 & & . & \\
\hline $9 / 21 / 2004$ & -0.872 & & . & \\
\hline $11 / 10 / 2004$ & 0.809 & & . & \\
\hline $12 / 14 / 2004$ & -1.383 & & . & \\
\hline $2 / 2 / 2005$ & 4.429 & & - & \\
\hline $3 / 22 / 2005$ & -2.143 & & . & \\
\hline $5 / 3 / 2005$ & 0.207 & & - & \\
\hline $6 / 30 / 2005$ & 6.964 & & . & \\
\hline $8 / 9 / 2005$ & -7.786 & & . & \\
\hline $9 / 20 / 2005$ & 0.429 & & $\cdot$ & \\
\hline $11 / 1 / 2005$ & 3.223 & & - & \\
\hline $12 / 13 / 2005$ & -3.714 & & . & \\
\hline $1 / 31 / 2006$ & 2.536 & & . & \\
\hline $3 / 28 / 2006$ & -6.915 & & . & \\
\hline $5 / 10 / 2006$ & -1.571 & & . & \\
\hline $6 / 29 / 2006$ & 11.036 & & . & \\
\hline $9 / 18 / 2007$ & & . & & -3.179 \\
\hline $10 / 31 / 2007$ & & & 3.536 & . \\
\hline $12 / 11 / 2007$ & & & -1.214 & . \\
\hline averages & 0.895 & -2.318 & 0.671 & 5.509 \\
\hline
\end{tabular}


Table 2.3: Maximum Likelihood Estimates of the Unobserved Components Model.

This table contains maximum likelihood estimates for parameters of the model with measurement equation,

$$
R_{t}=\Psi^{\prime} \mathbf{X}_{t}+\beta f f r_{t}+\eta_{t}+\varepsilon_{t},
$$

and transition equation

$$
\eta_{t}=\mu+\eta_{t-1}+\xi_{t} .
$$

The disturbance terms, $\varepsilon$ and $\xi$, are assumed to be iid. Components of $\mathbf{X}$ are dummy variables for calendar effects. $R$ equals the weekly average of cumulative open market operations, $f f r$, the weekly transactions-weighted average federal funds rate.

The start-up value for the algorithm, $\delta_{0}$ the initial state equals the first observation of the series $R_{t}$, not included in the estimation sample. The value of $\boldsymbol{\Sigma}$ equals $10^{9}$. Initial values for hyperparameter $\boldsymbol{\Psi}$ and $\beta$ equal $\mathbf{0}$. The results are robust to perturbations of these initial conditions.

The sample period includes weeks ending January 5, 2000 to the last FOMC meeting in 2007, December 19, 2007.

\begin{tabular}{lrlr}
\hline VARIABLE & ESTIMATE & ST.ERR. & $z$-VALUE \\
\hline \hline$f f r_{t}$ & -8.105 & 1.825 & 0.000 \\
Week two & 1.955 & 0.281 & 0.000 \\
December & 2.311 & 1.123 & 0.040 \\
15th of Month & 2.070 & 0.365 & 0.000 \\
Last of Month & 4.138 & 0.418 & 0.000 \\
Unscheduled Meeting & 6.567 & 1.639 & 0.000 \\
Meeting & -0.990 & 0.443 & 0.025 \\
Terror & 18.194 & 3.267 & 0.000 \\
Lag Terror & 7.226 & 3.823 & 0.059 \\
First day Q4 & 0.710 & 1.257 & 0.572 \\
First day Q3 & 3.248 & 1.248 & 0.009 \\
First day Q2 & -0.810 & 1.320 & 0.540 \\
First day Q1 & 6.046 & 1.575 & 0.000 \\
$\sigma_{\varepsilon}$ & 2.572 & 0.226 & 0.000 \\
$\sigma_{\xi}$ & 2.412 & 0.277 & 0.001 \\
$\mu$ & 0.773 & 0.119 & 0.000 \\
\hline
\end{tabular}




\section{Table 2.4: Ordinary Least Squares Estimates of Reduced Form.}

The table below displays OLS estimates for the specification

$$
O M O_{t}^{*}=\mu+\Psi^{\prime} \Delta \mathbf{X}_{t}+\beta\left(f f r_{t}^{*}-f f r_{t-1}^{*}\right)+\lambda \beta\left(f f r_{t-1}^{*}-f f r_{t-1}\right)+e_{t}
$$

Components of the dummy variables capturing calendar effects $\Delta \mathbf{X}$ are listed by name. $f f r$ and $f f r^{*}$ are weekly transactions-weighted averages of the federal funds rate and funds rate target. The sample includes the 415 weeks ending between January 12, 2000 and the last FOMC meeting of 2007, December 19, 2007.

\begin{tabular}{|c|c|c|c|c|}
\hline \multicolumn{5}{|c|}{$\bar{R}^{2}=0.5019, N=415$} \\
\hline VARIABLE & EstimATE & ST.ERR. & $t$-stat & $p$-VALUE \\
\hline Intercept & 0.78399 & 0.21376 & 3.67 & 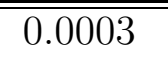 \\
\hline$f f r_{t-1}^{*}-f f r_{t-1}$ & -8.94652 & 3.34973 & -2.67 & 0.0079 \\
\hline$f f r_{t}^{*}-f f r_{t-1}^{*}$ & -9.41594 & 2.78338 & -3.38 & 0.0008 \\
\hline 2nd Week & 1.97328 & 0.21492 & 9.18 & $<.0001$ \\
\hline December & 0.05272 & 1.24839 & 0.04 & 0.9663 \\
\hline 15 th & 2.15419 & 0.31919 & 6.75 & $<.0001$ \\
\hline Last of Month & 4.06459 & 0.36309 & 11.19 & $<.0001$ \\
\hline Unscheduled Meeting & 8.47105 & 1.53409 & 5.52 & $<.0001$ \\
\hline Meeting & -0.66986 & 0.39292 & -1.70 & 0.0890 \\
\hline Terror & 11.25008 & 3.74799 & 3.00 & 0.0029 \\
\hline Lag Terror & -1.61312 & 3.76999 & -0.43 & 0.6690 \\
\hline First Day Q4 & 0.21825 & 1.16854 & 0.19 & 0.8519 \\
\hline First Day Q3 & 2.28155 & 1.12900 & 2.02 & 0.0440 \\
\hline First Day Q2 & -0.29044 & 1.12958 & -0.26 & 0.7972 \\
\hline First Day Q1 & 3.31435 & 1.32355 & 2.50 & 0.0127 \\
\hline
\end{tabular}

Table 2.5: OLS estimates of Open Market Operation Out-of-sample Forecasts The table below shows the ordinary least squares estimates of the relationship between out-of-sample open market operation forecasts $O M O_{t}^{s *}$ and the observed net open market operation in period $t$. The parameter estimate of $\hat{a}_{1}=0.603$ implies that for a $\$ 1$ billion increase in expected demand, the open market operation will be $\$ 600$ million greater.

$$
O M O_{t}=a_{0}+a_{1} O M O_{t}^{s *}+e_{t}
$$

\begin{tabular}{llccr}
\hline \multicolumn{5}{c}{$\bar{R}^{2}=0.253036, N=414$} \\
VARIABLE & Estimate & St.ERR. & $t$-stat & $p$-VALUE \\
\hline \hline Constant & 0.326866 & 0.265119 & 1.232904 & 0.2183 \\
OMO* $^{*}$ & 0.602955 & 0.050856 & 11.85605 & $<0.0001$
\end{tabular}


Table 2.6: FIML of system (2.15) and (2.16)

Full Information Maximum Likelihood estimates for the system of equations,

$$
\begin{aligned}
O M O_{t} & =\mu+\boldsymbol{\Phi}^{\prime} \mathbf{X}_{\mathbf{t}}+\beta \Delta f f r_{t}^{*}+\lambda \beta f f r_{t-1}^{*}-\lambda \beta f f r_{t-1}+e_{1 t} \\
f f r_{t-1} & =\alpha_{1} f f r_{t-2}+e_{2 t},
\end{aligned}
$$

under the assumption that the contemporaneous errors have a joint normal distribution.

\begin{tabular}{lrrrr}
\hline \multicolumn{4}{c}{$R^{2}=0.5172, N=414$, DET. RES. COVARIANCE $=0.282731$} \\
VARIABLE & Estimate & ST.ERR. & \multicolumn{1}{c}{$z$-stat } & $p$-VALUE \\
\hline \hline Intercept & 0.429145 & 0.494399 & 0.868014 & 0.3854 \\
$f f r_{t}^{*}-f f r_{t-1}^{*}$ & -9.481881 & 3.008684 & -3.151504 & 0.0016 \\
$f f r_{t-1}^{*}$ & -6.999666 & 3.714997 & -1.884165 & 0.0595 \\
$f r_{t-1}$ & 7.103709 & 3.721526 & 1.908816 & 0.0563 \\
2nd Week & 1.980645 & 0.242255 & 8.175859 & $<0.0001$ \\
December & 0.001462 & 1.024955 & 0.001426 & 0.9989 \\
15th & 2.177284 & 0.363977 & 5.981933 & $<0.0001$ \\
Last of Month & 4.075480 & 0.389276 & 10.46937 & $<0.0001$ \\
Unscheduled Meeting & 8.644554 & 0.911646 & 9.482355 & $<0.0001$ \\
Meeting & -0.665149 & 0.456605 & -1.456728 & 0.1452 \\
Terror & 11.47917 & 2.355908 & 4.872503 & $<0.0001$ \\
Lag Terror & -1.003466 & 2.814909 & -0.356482 & 0.7215 \\
First Day Q4 & 0.185309 & 1.382168 & 0.134071 & 0.8933 \\
First Day Q3 & 2.269931 & 1.886192 & 1.203447 & 0.2288 \\
First Day Q2 & -0.285796 & 1.888041 & -0.151372 & 0.8797 \\
First Day Q1 & 3.180813 & 0.908262 & 3.502089 & 0.0005 \\
\hline \hline \multicolumn{5}{c}{$R^{2}=0.9957, N=414$} \\
\hline$f f r_{t-2}$
\end{tabular}




\section{Table 2.7: Ordinary Least Squares Estimates for Forecast Error Model.} The table below displays OLS estimates for the specification

$$
\delta_{t}-E_{t-1} \delta_{t}=\alpha+\beta\left(f f r_{t}^{*}-f f r_{t}\right) .
$$

The right hand side, $f f r_{t}$ and $f f r^{*}$ are the transactions-weighted averages of the federal funds rate and funds rate target. The dependent variable equals the week $t$ unobserved demand component forecast miss. The sample includes the 413 weeks ending between January 26, 2000, the first FOMC meeting in the study sample period, and the last FOMC meeting of 2007, December 19, 2007.

\begin{tabular}{lclrl}
\hline \multicolumn{5}{c}{$\bar{R}^{2}=0.0027, N=413$} \\
VARIABLE & Estimate & ST.ERR. & $t$-stat & $p$-VALUE \\
\hline \hline Intercept & -0.00352 & 0.199 & -0.02 & 0.9859 \\
$\left(f f r^{*}-f f r\right)$ & 3.85415 & 2.654 & 1.45 & 0.1471 \\
\hline
\end{tabular}


Table 2.8: DFBETAS Influence Statistics from Forecast Error Funds Rate Model.

This table reports

$$
\operatorname{DFBETA}_{j i}=\frac{b_{j}-b_{j,-i}}{s_{-i} \sqrt{c_{j j}}},
$$

for the ten most influential observations on the parameter estimates for the model

$$
\delta_{t}-E_{t-1} \delta_{t}=\alpha+\beta\left(f f r_{t}^{*}-f f r_{t}\right)+e_{t}
$$

Table 2.17 shows the results from the ordinary least square estimates. DFBETA equals the difference between the parameter estimate if all observations were included, and the parameter estimate if the $i^{\text {th }}$ observation were excluded from the estimation, scaled by $s_{-i} \sqrt{c_{j j}}$, the product of the root residual mean square error without including the $i^{\text {th }}$ observation, $s_{-i}$, and the $j j^{t h}$, element of $\left(\mathbf{X}^{\prime} \mathbf{X}\right)^{-1}, c_{j j}$. This influence statistic measures the number of standard errors that the coefficient changes between the estimation from the whole sample, and the sample which does not include the $i^{\text {th }}$ observation. The column $\beta_{-i}$ reports the value of $\beta$ for the model excluding that week's observation.

\begin{tabular}{lcl}
\hline DATE & DFBETAS & \multicolumn{1}{c}{ EvENT } \\
\hline \hline $9 / 19 / 2001$ & 3.7986 & Week Following World Trade Center Attacks \\
$1 / 3 / 2001$ & -0.718 & 50 basis point Target Change \\
$8 / 22 / 2007$ & -0.5722 & Unannounced FOMC meeting during 2007 Crisis \\
$7 / 5 / 2000$ & -0.3721 & Settlement Wed. Following Holiday \\
$8 / 20 / 2003$ & -0.3675 & Large Net OMO \\
$9 / 5 / 2007$ & 0.331 & 2007 Financial Crisis \\
$2 / 2 / 2000$ & -0.2351 & FOMC meeting
\end{tabular}




\section{Table 2.9: Robust Least Squares Estimates for Forecast Error Model.}

The table below displays robust least squares estimates for the specification

$$
\delta_{t}-E_{t-1} \delta_{t}=\alpha+\beta\left(f f r_{t}^{*}-f f r_{t}\right)+e_{t}
$$

The right hand side, $f f r_{t}$ and $f f r^{*}$ are the transactions-weighted averages of the federal funds rate and funds rate target. The dependent variable equals the week $t$ unobserved demand component forecast miss. The sample includes the 413 weeks ending between January 26, 2000 and the last FOMC meeting of 2007, December 19, 2007.

\begin{tabular}{lccrrrr}
\multicolumn{8}{c}{$\bar{R}^{2}=0.003, N=413$} \\
\hline PARAMETER & STD. & $95 \%$ \\
\hline & ESTIMATE & ERROR & CONFIDENCE LIMITS & $\chi^{2}$ & PR $>\chi^{2}$ \\
\hline Intercept & -0.1137 & 0.1799 & -0.4662 & 0.2388 & 0.40 & 0.5273 \\
$\left(f f r^{*}-f f r\right)$ & -7.2065 & 2.8662 & -12.8242 & -1.5889 & 6.32 & 0.0119
\end{tabular}




\section{Chapter 3}

\section{Interest Rate Smoothing}

\subsection{Introduction}

Federal funds rate target changes are considered significant indicators of the stance of monetary policy. A substantial literature examines the impact of monetary policy on financial markets and the real economy, and how monetary policy might react to external economic forces. This chapter presents a measure of demand pressure exerted on the federal funds rate target. Estimates from a structural model derived from the Federal Reserve's mandate to maintain the overnight borrowing rate between depository institutions around a target provide the metric, based on the relationship between realized deviations of the federal funds rate from target and reserves supplied through open market operations.

The Trading Desk (the Desk) at the Federal Reserve Bank in New York conducts open market operations to in an effort to equalize the supply and demand for reserves at a target rate. If demand for funds increases, an open market purchase may only satisfy the increased

demand, and will not necessarily lower the funds rate. Furthermore, failure of the Desk to sanitize the effect of the additional demand will result in a higher equilibrium rate without directly reducing the supply of reserves through open market operations. This chapter develops a metric of the extent the market for federal funds is influenced by demand pressure 
from market participants. Movement to a higher target rate, occurring in the direction of market pressure, may not necessarily be a clear demonstration of activist monetary tightening as that made in the presence of increased demand for federal funds. Utilization of the unobserved state variables from maximum likelihood estimates from the Kalman filter model developed in Section 2.3 allows for a characterization of this demand pressure.

Section 3.3 describes the measure of demand pressure metric building on the model developed in Section 2.3. Sections 3.5 and 3.5.1 describe results testing the hypothesis of Section 3.4. Section 3.7 concludes.

\subsection{Background}

Thornton (2004) formalizes the distinctions between three alternative views regarding the Fed's management of the funds rate target. Of those, the "open market" and "open mouth" hypothesis require the Fed to inject funds to achieve a lower rate, and remove them to increase the realized rate. While the open market view requires movements in the short-term rate to be synchronous with adjustments in reserve balances, the open mouth hypothesis asserts that the Fed can achieve the new target simply by announcing the target change. Although, as discussed by Taylor (2001), even with open mouth effects, open market operations must eventually be conducted to realize a target change.

The third possibility exists, dubbed "interest rate smoothing," whereby the Fed acts to smooth transitions between target levels determined by movements in the market-equilibrium short-term rate. For example, under the open market hypothesis, an increase in the federal funds rate target is achieved through a tightening of the supply of credit. Alternatively, if an increase in the target rate is a response to demand pressure at the current rate, forcing the 
Fed to supply an inordinate quantity of reserves to maintain the target, the target change is a response to other real factors, and not necessarily a new policy stance. Distinguishing between the open mouth and interest rate smoothing hypothesis is more complicated than simply determining the correlation between open market operations and the funds rate. For example, the announcement of, and the market trading at a lower federal funds rate target, not accompanied contemporaneously by open market purchases, might be interpreted as a policy change implemented by way of the open mouth hypothesis. However, as discussed by Thornton (2004), if the underlying market rate had already adjusted, and was only being restrained artificially by decreasing the rate of open market purchases, the change to the new lower rate may even be accompanied by further reductions in the rate of open market purchases, to keep the rate from falling even lower. The interest rate smoothing hypothesis provides a channel by which the Fed could engage in activist policy without changing the nominal interest rate target. For example, an increase in demand for federal funds would require relatively larger open market operations to maintain the target rate, action typically associated with loosening monetary policy.

In broad terms, the extant literature addressing interest rate smoothing can be separated into two categories. One considers the phenomenon at longer-term, quarterly frequency, the other at monthly or higher frequency. At the lower frequency, adjustments to the interest rate target can be viewed in terms of the response to factors such as unemployment, prices, and the output gap. ${ }^{1}$

Guthrie and Wright $(2004,2002)$ provide a theoretical framework for the decision to

\footnotetext{
${ }^{1}$ Theoretical and empirical studies of the low-frequency smoothing and inertial qualities of the target rate include: McCallum (1981), Mankiw (1987), Woodford (1999) Sack and Wieland (2000), Hamilton and Jordá (2002), Rudebusch (2002), and Florio (2006) among others.
} 
address the questions of how and when a central bank will change its short-run interest rate target at the higher frequency. They propose a model where the monetary authority targets a particular rate, and the preferred value of the interest rate follows a Brownian motion process. The market rate managed by the policymaker deviates with a zero mean error about the target, due to liquidity shocks which are outside of the central bank's control. The target rate deviates from the preferred rate following a Wiener process, and these deviations are modeled to be costly according to a quadratic loss of the deviation. Incorporating costs for the two types for target changes; fixed and proportional to the size of the change, the authors show their model's consistency with many observed behavior of target rate changes.

The approach discussed in Section 3.3 addresses the Fed's interest rate target using a similar argument, but with a question of interest framed somewhat differently. Here, the object is to quantify the amount of pressure being exerted on the target rate, and in that way to characterize policy in the presence or absence of target changes. In the framework provided by Guthrie and Wright, a market rate, (here, the funds rate) is effectively controlled at the target and the market rate. The interest rate smoothing hypothesis, as framed here, suggests that the market rate may, at times, be driven by forces outside of the Fed's control, and therefore is not managed to be equal to the target without cost, even when the objective is achieved.

Thornton (2004) proposes that because of what he calls policy endogeneity, the liquidity effect can only be identified if, in response to a shock in the real interest rate, policymakers adjust the nominal interest rate by an amount greater than is needed to keep the rate unchanged. This would only be the case if they did so precisely, as the deviation from the nominal target rate does provide information about the market demand for reserves and 
the amount by which the Fed's open market operations are failing to placate demand at the target rate. It is this observation which is utilized to identify the liquidity effect and, additionally, to measure the amount of market pressure exerted on the rate.

\subsection{Properties of Demand Pressure}

The issues discussed by Thornton (2004) and those summarized by Figure 3.1 demonstrate that funds rate movements may not be accompanied by open market operations in the opposite direction. If, for example, the demand for funds falls, the Fed would be inclined to drain (or provide fewer) reserves simply to maintain the target. A similar argument holds at the time of target changes. The Fed may choose inaction or to slow the rate of open market purchases in order to move the equilibrium rate higher.

Since 1994 the procedure of the FOMC has typically been to announce target changes at the time of scheduled FOMC meetings. Of the 36 federal funds rate target changes occurring in the period under study ${ }^{2}$ only four were announced after unscheduled FOMC meetings. The announcement of a new or unchanged policy rate has been accompanied by a description of the policy stance, and decisions which will be made at the next meeting depend on the events that occur in the intervening period.

Rudebusch (2002) notes a New York Times article (July, 26, 2000) where FOMC Chairman Greenspan reports the FOMC's “... decision about whether to raise interest rates again at its meeting next month would hinge in large part on economic data released in coming weeks." Rudebusch concludes, that after the FOMC announcement, "there was little if any pent-up pressure from the past for further adjustment." The suggestion that market expec-

\footnotetext{
${ }^{2}$ Data for the study is derived from Federal Reserve Bank of New York data on open market operations between July 2000 and December 2007. Operations data is unavailable before this period.
} 
tations and behavior are adjusted by the announcements made at FOMC meetings, and that the Desk evaluates the funds rate market at a fairly high frequency, inform the specification of the model below. ${ }^{3}$

Let the demand for federal funds equal $R_{t}^{d}$, The weekly demand for funds $R_{t}^{d}$ depend linearly on the federal funds rate, $f f r$, a stochastic demand component, $\delta$, and a vector of known, seasonal or calendar factors influencing the level of demand, $\mathbf{X}$.

$$
R_{t}^{d}=\Psi^{\prime} \mathbf{X}_{t}+\beta f f r_{t}+\delta_{t}
$$

The demand shock $\delta$ segments the disturbance to demand into two components. One portion, $\varepsilon$, manifests as idiosyncratic noise; the other, $\eta$, evolves following a random walk with constant drift.

$$
\begin{aligned}
\delta_{t}=\eta_{t}+\varepsilon_{t}, & \varepsilon_{t} \sim N\left(0, \sigma_{\varepsilon}^{2}\right) \\
\eta_{t}=\mu+\eta_{t-1}+\xi_{t}, & \xi_{t} \sim N\left(0, \sigma_{\xi}^{2}\right) .
\end{aligned}
$$

Let $\overline{R_{t}^{s^{*}}}$ equal the level of funds that the Fed would supply in each period $t$ if the demand component $\delta_{t}$ were known. The required supply of reserves equals demand at the target rate,

$$
\overline{R_{t}^{s^{*}}}=\Psi^{\prime} \mathbf{X}_{t}+\beta f f r_{t}^{*}+\delta_{t}
$$

As addressed in section 2.3, the Fed actually supplies

$$
R_{t}^{s^{*}}=\boldsymbol{\Psi}^{\prime} \mathbf{X}_{t}+\beta f f r_{t}^{*}+E_{t-1} \delta_{t}
$$

Let the $L$ FOMC meetings during the period under study occur in periods $t_{l}$, where $l \in$ $\{1 . . L\}$. Let the number of weeks between meeting $l$ and $l+1$ equal $k_{l}$. For example, if the

\footnotetext{
${ }^{3}$ Further examples of the high-frequency determination of open market operations can be found in Feinman (1993) and Thornton (2007) among others.
} 
first FOMC meeting occurs in period $t_{1}$, their next meeting occurs in period $t_{2}=t_{1}+k_{l}+1$. The cumulative sum of the forecast errors for reserves required to maintain the target between FOMC meetings equals the unexpected change in demand between periods $t_{l}$ and $t_{l}+k_{l}$. Figure 3.2 summarizes the notation and the demand metric. A positive accumulation of estimation errors implies that the additional funds supplied through open market operations are less than those required to maintain the target rate. Given, that for all $n$, the stochastic demand component in period $t+n$ equals,

$$
\begin{aligned}
\delta_{t+n}= & \eta_{t+n}+\varepsilon_{t+n} \\
= & \mu+\eta_{t+n-1}+\xi_{t+n}+\varepsilon_{t+n} \\
= & 2 \mu+\eta_{t+n-2}+\xi_{t+n}+\xi_{t+n-1}+\varepsilon_{t+n} \\
& \vdots \\
= & n \mu+\eta_{t}+\sum_{j=1}^{n} \xi_{t+n-j}+\xi_{t+n}+\varepsilon_{t+n} .
\end{aligned}
$$

Expectations of $\delta_{t+n}$ formed in period $t+n-1$ equal:

$$
\begin{aligned}
E_{t+n-1} \delta_{t+n} & =n \mu+\eta_{t}+\sum_{j=1}^{n} \xi_{t+n-j}+E_{t+n-1} \xi_{t+n}+E_{t+n-1} \varepsilon_{t+n} \\
& =n \mu+\eta_{t}+\sum_{j=1}^{n} \xi_{t+n-j} .
\end{aligned}
$$

The amount of pressure exerted on the funds rate target between FOMC meetings, the accumulated difference between $R_{t}^{s^{*}}$ and $\overline{R_{t}^{s^{*}}}$, can be written as:

$$
\sum_{i=0}^{k_{l}}\left(\overline{R_{t_{l}+i}^{s^{*}}}-R_{t_{l}+i}^{s^{*}}\right)=\sum_{i=0}^{k_{l}}\left(\delta_{t_{l}+i}-E_{t_{l}+i-1} \delta_{t_{l}+i}\right) .
$$

The difference between Equations (3.8) and (3.10) give

$$
\begin{aligned}
\delta_{t+n}-E_{t+n-1} \delta_{t+n} & =n \mu+\eta_{t}+\sum_{j=0}^{n-1} \xi_{t+n-j}+\xi_{t+n}+\varepsilon_{t+n}-n \mu-\eta_{t}-\sum_{j=0}^{n-1} \xi_{t+n-j} \\
& =\xi_{t+n}+\varepsilon_{t+n}, \quad \forall n \in \mathbb{N}^{+}
\end{aligned}
$$


Thus, the right hand side of (3.11) can be written as:

$$
\sum_{i=0}^{k_{l}}\left(\delta_{t_{l}+i}-E_{t_{l}+i-1} \delta_{t_{l}+i}\right)=\sum_{i=0}^{k_{l}}\left(\xi_{t_{l}+i}+\varepsilon_{t_{l}+i}\right) .
$$

Since $t_{l+1}=t_{l}+k_{l}+1$, define $\Omega_{l+k}$, the demand pressure variable for each week in the sample, as the sum of accumulated pressure $k$ weeks following the last FOMC meeting

$$
\Omega_{l+k}=\sum_{i=0}^{k}\left(\xi_{t_{l}+i}+\varepsilon_{t_{l}+i}\right),
$$

where $k=\left\{1 . . k_{l}\right\}$ for each value of $l$. The lower frame of Figure 3.2 shows a timeline of the values of $\Omega_{l+k}$ between meetings $l$ and $l+1$, where

$$
\Omega_{l+k_{l}}=\sum_{i=0}^{k_{l}}\left(\xi_{t_{l}+i}+\varepsilon_{t_{l}+i}\right),
$$

gives the value for the pressure metric in the week before an FOMC meeting.

\subsection{Hypothesis}

The interest rate smoothing hypothesis, as stated by Thornton (2004) asserts that, "the Fed does not move rates per se, but rather changes its target for the nominal interest rate in response to economic shocks." Measuring the pressure on the funds rate to trade away from its target provides a quantitative estimate for the policy endogeneity of new target rates. Since, in general, activist policy need not manifest through changing the market rate, changes in line with market pressure on the target would provide support that the target change is endogenous, and moving against or without market pressure supports that the

change is exogenous. Within this framework, the implementation and effects of policy may be examined in the light of activist or policy-driven target changes versus those which are the result of the Fed relenting to other market pressures. 
Hypothesis 1: Accumulated upward pressure on the target rate between FOMC meetings is associated with larger open market operations

With the metric of demand pressure at each week throughout the inter-FOMC meeting period equal

$$
\Omega_{l+k}=\sum_{i=0}^{k}\left(\xi_{t_{l}+i}+\varepsilon_{t_{l}+i}\right),
$$

the inequality:

$$
\frac{\partial \Delta R_{t_{l}+k}}{\partial \Omega_{l+k}}>0,
$$

represents the hypothesis that lower accumulated pressure reduces the need for additional funds to be supplied to reduce the market interest rate. In each period, the Desk bases its decision on the forecast of demand pressure and the mandate from the FOMC. Higher unsatisfied demand for additional funds supplied by OMOs is measured by the cumulative demand pressure metric. Larger open market operations correspond to periods following, and coinciding with, periods of increased demand pressure. Hypothesis 1 tests if periods when pressure is high (or has been increasing), correspond with periods of high open market operations.

The tendency for target changes to occur in the direction of the measure of accumulated demand provides support of the interest rate smoothing hypothesis. The pressure metric $\Omega$ need not perform as a predictive explanatory variable for target changes. The Fed may decide to change the target rate in an opposite direction than that predicted by the direction of pressure on the rate. However, the comovement of the backwards-looking pressure metric and the FOMC target change decisions can be estimated using an ordered discrete choice 
model to find the marginal effects of higher accumulated demand pressure as of FOMC meetings or decisions.

Hypothesis 2: Accumulated upward pressure a the time of FOMC meetings increases the likelihood of increases in the target rate.

During the sample period, target changes are announced as discrete incremental changes, and thus models for ordered discrete choice are well suited to the examination of the relationship between the accumulated pressure and the future decisions on the funds rate target. The marginal effects derived from ordered probit models test the hypothesis that a higher demand pressure metric increases the likelihood of a change to a higher target rate. This hypothesis can be expressed as

$$
\begin{aligned}
& \frac{\partial \operatorname{Pr}\left(\Delta f f r^{*}<0 \mid \Omega_{l+k_{l}}\right)}{\partial \Omega_{l+k_{l}}}<0 \\
& \frac{\partial \operatorname{Pr}\left(\Delta f f r^{*}>0 \mid \Omega_{l+k_{l}}\right)}{\partial \Omega_{l+k_{l}}}>0
\end{aligned}
$$

the probability of a target change conditioned upon the value of $\Omega_{l+k_{l}}$. Higher (lower) the accumulated demand manifests as upward (downward) pressure on the rate. To relieve this pressure the fed may be inclined to adjust the target.

\subsection{Results from Tests of Pressure on the Target Rate}

Hypothesis 1 addresses the relationship between the size of open market operations needed to affect the target rate in terms of the accumulation of pressure on the federal funds rate.

An alternative statement of hypothesis 1 is that open market operations are larger during periods when the accumulated pressure on the target is positive, and lower when negative. Constructing a dummy variable $D_{t}=\{0,1\}$ for the state of the pressure metric, and find- 
ing the relationship between average open market operations in either regime provides a straightforward test. Table 3.2 shows the results for the model

$$
\Delta R_{t}=a D_{t}+b\left(1-D_{t}\right)
$$

where

$$
D_{t}= \begin{cases}0, & \Omega_{t} \leq 0 \\ 1, & \Omega_{t}>0 .\end{cases}
$$

The parameter estimate $\hat{a}$ equals the mean of open market operations when the pressure is positive, and $\hat{b}$, when pressure is negative. The statistically significant at the $5 \%$ level parameter estimate $\hat{b}=2.013$ suggests that the mean open market operation is higher when pressure is high, and a Wald statistic $15.858 \sim \chi_{1}^{2}$ rejects the null hypothesis that $\hat{a}=\hat{b}$, the subsample means equal 2.013, during positive pressure periods, and -0.35 during negative pressure periods, are not equal. This result is in favor of hypothesis 1, that the size of open market operations are positively related to the metric of demand pressure accumulation.

A less general specification of the hypothesis is written as

$$
\Delta R_{t}=\alpha_{0}+\alpha_{1} \Omega_{t}+\alpha_{2} \Omega_{t}^{2} \cdot\left(\operatorname{sign}\left(\Omega_{t}\right)\right) .
$$

The dependent variable equals the week- $t$ change in $R_{t}$ the total of all open market operations in that period. The explanatory variable, $\Omega_{t}$ equals the accumulated pressure since the last FOMC meeting, and $\Omega_{t}^{2} \operatorname{sign}\left(\Omega_{t}\right)$ is the square of the accumulated pressure, multiplied the sign of $\Omega_{t}$ in that period.

$$
\operatorname{sign}\left(\Omega_{t}\right)=\left\{\begin{array}{rr}
-1, & \Omega_{t} \leq 0 \\
1, & \Omega_{t}>0 .
\end{array}\right.
$$

The quadratic term attempts to capture the possible of non-linear relationships while accounting for the direction of the pressure. 
Ordinary least square estimates for parameters (3.23) finds the relationship between the accumulated pressure on the target and the open market operations in that period. The estimates fail to reject the hypothesis of a positive correlation between accumulating demand pressure and open market operations with a positive point estimate for $\alpha_{1}$. Table 3.3 displays results from this specification. The statistically significant parameter estimate $\hat{\alpha}=0.2679$ implies that an additional $\$ 1$ billion in demand pressure, the Fed will supply approximately $\$ 270$ million in additional reserves via open market operations. The quadratic term is insignificant at the $5 \%$ level.

\subsubsection{FOMC Meetings and Demand Pressure}

Most target adjustments occur at the time of scheduled FOMC meetings. In the period between 2000 and 2008, four target changes occur at unscheduled meetings: two 50-basispoint reductions in 2001, on January 3 and April 18, one 50-basis-point reduction after the attacks on the World Trade Center in September of 2001, and the other just five days before a scheduled meeting in December of 2007. Table 3.1 displays the dates of the 68 FOMC meetings ${ }^{4}$ ordered in terms of the accumulated demand pressure $\Omega_{l+k_{l}}$ the value of the pressure metric during the week before the FOMC meeting, along with the direction and size of the target change. Of meetings ranked the highest positive quartile for the pressure metric, seven of 11 target changes are to higher rates, four to lower rates. The 17 meetings occurring in lowest value quartile, six occur with changes to a lower target announced and two to a higher rate. Figure 3.3 shows a scatter plot of target changes against the value of the preceding week's pressure metric. The average value for $\Omega_{l+k_{l}}$ at FOMC meetings with

\footnotetext{
${ }^{4}$ The first meeting of the sample on $2 / 2 / 2000$ not included due to incomplete data from the period between the previous meeting.
} 
positive changes equals 3.8659 with a standard error of 2.11. For changes down, average $\Omega_{l+k_{l}}$ equals -2.166 with standard error of 2.30 .

The relationship between the pressure metric and subsequent target changes at an FOMC meeting can be investigated following the approach of Estrella and Mishkin (1998), Estrella and Hardouvelis (1991), and in particular Hausman et al. (1992). Work of Estrella, Mishkin and Hardouvelis examines measures of the term structure to inform the likelihood of a recession being declared in upcoming quarters. Hausman et al. (1992) employ an ordered probit model to estimate forecasts of (then) discrete tick-by-tick changes of NYSE equity prices.

\subsubsection{General Specification}

Hausman et al. (1992) use an ordered probit model to study discrete changes in stock prices. This section describes the method and application to the funds rate target. Equation (3.25) describes the latent regression model

$$
P_{t}^{*}=\mathbf{w}_{t}^{\prime} \gamma+\epsilon_{t},
$$

with $P^{*}$, an unobserved continuous random variable, conditioned upon the vector $\mathbf{w}$. The model assumption is that the change in target is related to the variable $P$ according to the following schedule:

$$
P_{t}= \begin{cases}s_{1}, & P_{t}^{*} \in A_{1} \\ s_{2} & P_{t}^{*} \in A_{2} \\ \vdots & \vdots \\ s_{k}, & P_{t}^{*} \in A_{k}\end{cases}
$$

where, $A_{j k}$ partitions the state-space $S^{*}$ of $P^{*}$ where $S^{*}=\bigcup_{j=1}^{m} A_{j}$, and $A_{i} \bigcap A_{j}=\emptyset$, for 
$i \neq j$, with

$$
\begin{aligned}
A_{1} & \equiv\left(-\infty, \alpha_{1}\right] \\
A_{2} & \equiv\left(\alpha_{1}, \alpha_{2}\right] \\
A_{i} & \equiv\left(\alpha_{i-1}, \alpha_{i}\right] \\
\vdots & \\
A_{m} & \equiv\left(\alpha_{m-1}, \infty\right),
\end{aligned}
$$

where the boundaries $\alpha_{k}$ depend on $\mathbf{w}$.

The conditional distribution of target changes conditioned on the regressors $\mathbf{w}$ are determined by the partition boundaries:

$$
\begin{aligned}
\operatorname{Pr}\left(P_{t}^{*}=\right. & \left.s_{j} \mid \mathbf{w}_{t}\right)=\operatorname{Pr}\left(P_{t}^{*} \in A_{j k}\right)=\operatorname{Pr}\left(\mathbf{w}_{t}^{\prime} \boldsymbol{\gamma}+\epsilon_{t} \in A_{j k} \mid \mathbf{w}_{t}^{\prime}\right) \\
= & \begin{cases}\Phi\left(\alpha_{1}-\mathbf{w}_{t}^{\prime} \boldsymbol{\gamma}\right), & i=1 \\
\Phi\left(\alpha_{i}-\mathbf{w}_{t}^{\prime} \boldsymbol{\gamma}\right)-\Phi\left(\alpha_{i-1}-\mathbf{w}_{t}^{\prime} \boldsymbol{\gamma}\right), & 1<i<m \\
1-\Phi\left(\alpha_{m-1}-\mathbf{w}_{t}^{\prime} \boldsymbol{\gamma}\right), & i=m .\end{cases}
\end{aligned}
$$

where $\Phi()$ is the standard normal cumulative distribution function. Let $V_{i t}$ equal one for realization of observation $t$ in the $i-t h$ state $s_{i}$ and zero otherwise. Maximization of the $\log$ likelihood function

$$
\begin{aligned}
L(P \mid \mathbf{w})= & \sum_{t=1}^{n}\left[V_{1 t} \cdot \log \left(\Phi\left(\alpha_{1}-\mathbf{w}_{\mathbf{t}}{ }^{\prime} \boldsymbol{\gamma}\right)\right)\right. \\
& +\sum_{k=1}^{n} V_{k t} \cdot \log \left(\Phi\left(\alpha_{k}-\mathbf{w}_{\mathbf{t}}{ }^{\prime} \boldsymbol{\gamma}\right)-\Phi\left(\alpha_{k-1}-\mathbf{w}_{\mathbf{t}}{ }^{\prime} \boldsymbol{\gamma}\right)\right) \\
& \left.+V_{m t} \cdot \log \left(1-\Phi\left(\alpha_{m-1}-\mathbf{w}_{\mathbf{t}}{ }^{\prime} \boldsymbol{\gamma}\right)\right)\right]
\end{aligned}
$$

provides the parametric estimates for $\alpha_{k}$ and $\gamma$ conditional on the explanatory variable $\mathbf{w}$. 


\subsubsection{Specification and Results}

Let $P_{t}=s_{j} \in\{-1,0,1\}$ where values of $s_{j}$ correspond to the target being lowered, held constant, or increased at an FOMC meeting, and $w_{t} \gamma=\Omega_{l+k_{l}} \gamma$. Table 3.4 displays maximum likelihood estimates of model parameters relating demand pressure one week before FOMC meetings to subsequent target changes. The parameter estimate for the pressure metric $\Omega_{l+k_{l}}$ are positive and significant at the $5 \%$ level, although magnitude and sign are not interpretable in this context. The lower frames of Table 3.4 show the marginal effects of a change in $\Omega_{l+k_{l}}$ evaluated at the mean of -0.212 . These marginal effects equal

$$
\begin{aligned}
\frac{\partial \operatorname{Pr}\left(P_{t}=-1 \mid \Omega_{l+k_{l}}\right)}{\partial \Omega_{l+k_{l}}}=-\phi\left(\alpha_{1}-\Omega_{l+k_{l}} \gamma\right) \boldsymbol{\gamma} \\
\frac{\partial \operatorname{Pr}\left(P_{t}=0 \mid \Omega_{l+k_{l}}\right)}{\partial \Omega_{l+k_{l}}}=\left[\phi\left(\alpha_{1}-\Omega_{l+k_{l}} \gamma\right)-\phi\left(\alpha_{2}-\Omega_{l+k_{l}} \gamma\right)\right] \boldsymbol{\gamma} \\
\frac{\partial \operatorname{Pr}\left(P_{t}=1 \mid \Omega_{l+k_{l}}\right)}{\partial \Omega_{l+k_{l}}}=\phi\left(\alpha_{2}-\Omega_{l+k_{l}} \gamma\right) \boldsymbol{\gamma} .
\end{aligned}
$$

The sign and significance of the marginal effects on the probability of increasing or decreasing the target rate fail to reject hypothesis 2 . At the average value of $\Omega_{l+k_{l}}$, the marginal effect of a one-unit increase in the pressure metric has a significant, positive effect, increasing the probability of a positive change in the target rate by 1.06 percent.

Lines drawn in Figure 3.4 graph the probability of target changes predicted by the model by pressure metric $\Omega_{l+k_{l}}$. On each of the curves, symbols show individual FOMC meetings for each of the three possible outcomes. For example, diamonds drawn on the curve showing the probability of an increase in the target rate represent values of $\Omega_{l+k_{l}}$ when the target was increased. The crosses on the curve showing the probability of lower rates mark FOMC meetings when the target is adjusted lower.

Figure 3.5 shows marginal effects of a one-unit change in the pressure metric across levels 
of $\Omega_{l+k_{l}}$. The estimated increase in probability that the FOMC will lower the target rate when the one-unit increase in $\Omega_{l+k_{l}}$ probability to a lower target equals $1 \%$. Higher values of $\Omega_{l+k_{l}}$ increase the probability of a change to a higher rate at all levels, and exceed the increase in likelihood of no change.

This result supports the hypothesis that the pressure as measured by the accumulation of unanticipated demand shocks between FOMC meetings is related to subsequent target changes. The metric $\Omega_{l+k_{l}}$ measures the accumulated forecast miss of expected demand for additional base money, and the relationship between this metric and subsequent target changes demonstrates the correlation of the accumulation of unanticipated shifts in demand with subsequent changes in the target rate.

\subsection{Limitations}

Pressure on the federal funds rate target may be the result of anticipated changes in the target rate. For example, an anticipated increase in the target may increase present demand. However, $\Omega_{l+k_{l}}$ is defined as the cumulative sum of demand forecast errors in the week before FOMC meetings, and potential arbitrage opportunities are limited by the short-term nature of the federal funds transactions.

The ordered choice procedure does not produce forecasts of future target changes, but relates a measure of unsatisfied demand for funds to target changes. High values for the pressure metric suggest increased demand for federal funds. The results imply a relationship exists between demand for funds and subsequent target changes. The federal funds futures contracts provide a market-derived value for the probability of a change in the target rate, and while these implied probabilities measure markets expectations of an FOMC decision, 
they similarly cannot determine the directional relationship between pressure being exerted on the funds rate market and policy. A direction for future research is to examine the causal relationship between policy and demand pressure, including implications and relationships between anticipated target changes and demand pressure on the target rate.

\subsection{Conclusion}

Market pressure exerted on the target rate measured by the accumulated forecast miss of the Desk to achieve the target is correlated with subsequent target change decisions in the direction predicted by the model. Higher pressure in the weeks preceding the FOMC meeting increases the probability of a change in the target to a higher rate, and higher pressure on the target rate is accompanied by larger net open market operations. This result provides support in favor of the interest rate smoothing hypothesis, and that the assumption of exogenous funds rate target changes may not always be appropriate. 


\section{Figure 3.1: Diagram Showing Net Negative OMO to Maintain Target.}

This figure shows how an OMO at the beginning of period $t+1$ with a net negative impact, lowering reserves from $R_{t}$ to $R_{t+1}$, may be conducted to maintain the target funds rate.

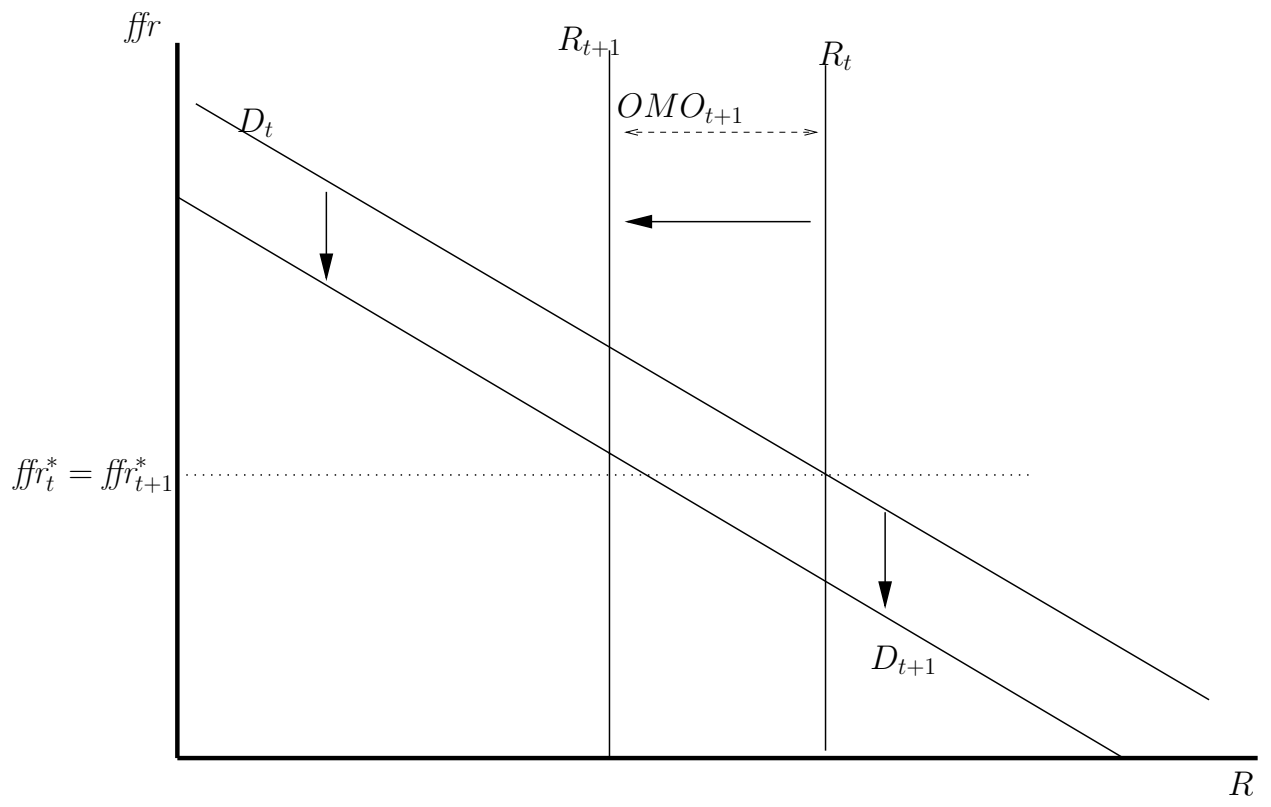

Figure 3.2: Weekly Open Market Operations and Demand Pressure.

This figure shows the timing of the accumulation of demand pressure on the federal funds rate target. The difference $\delta_{t}-E_{t-1} \delta_{t}$ equals the periodic component of unexpected demand. Between two FOMC meetings which occur at time $t$ and $t+k_{l}$, each period's demand forecast miss sums to a measure of the level of pressure relevant at the $l^{\text {th }}$ meeting, the amount of pressure accumulated between $t$ and $t+k_{l}-1$.

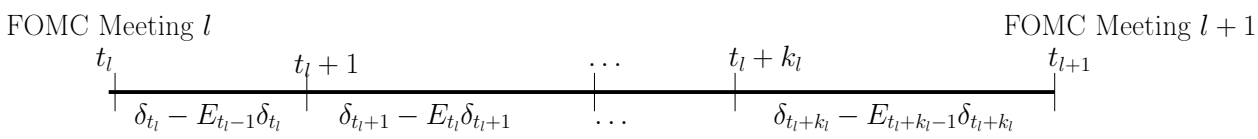

$$
\begin{aligned}
& \Omega_{l+k}=\sum_{i=0}^{k_{l}}\left(\xi_{t_{l}+i}+\varepsilon_{t_{l}+i}\right)
\end{aligned}
$$

where $k=\left\{1 . . k_{l}\right\}$ for each value of $l$.

The timing in terms of $\Omega_{l+k}$,

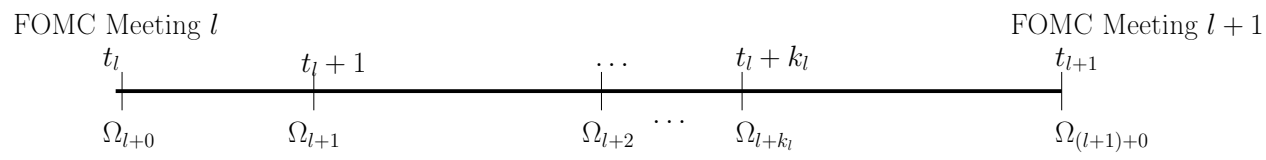


Table 3.1: FOMC Meetings Sorted by Accumulated Pressure on the Target Rate

The table below shows the measure of inter-FOMC period pressure, $\Omega$, as of the period before the FOMC meeting, the last day of the week the FOMC meeting occurs, and the announced change in the target rate, if any. The table is ordered by size of the pressure metric, from low to high. Dates marked with asterisks for weeks including unscheduled meetings of the FOMC.

\begin{tabular}{|c|c|c|c|c|c|}
\hline FOMC MEETING & $\bar{\Omega}$ & "Target Change & ב FOMC MEETING & $\overline{\bar{\Omega}}$ & Target Change \\
\hline $7 / 4 / 2007$ & -27.69656072 & & $7 / 5 / 2006$ & 0.08305454 & 0.25 \\
\hline $8 / 13 / 2003$ & -17.8858496 & & $10 / 25 / 2006$ & 0.25552607 & \\
\hline $11 / 7 / 2001$ & -14.45208478 & -0.5 & $7 / 6 / 2005$ & 0.30395736 & 0.25 \\
\hline $12 / 12 / 2001$ & -14.23031143 & -0.25 & $2 / 1 / 2006$ & 0.65155743 & 0.25 \\
\hline $1 / 31 / 2001$ & -13.8673797 & -0.5 & $6 / 27 / 2001$ & 1.26859924 & -0.25 \\
\hline $3 / 17 / 2004$ & -12.29148691 & & $5 / 8 / 2002$ & 1.33114837 & . \\
\hline $11 / 6 / 2002$ & -10.76504889 & -0.5 & $12 / 11 / 2002$ & 1.40583522 & . \\
\hline $5 / 10 / 2006$ & -10.67685224 & 0.25 & $8 / 23 / 2000$ & 1.73772135 & . \\
\hline $11 / 2 / 2005$ & -9.63227977 & 0.25 & $8 / 22 / 2007^{*}$ & 2.05493661 & . \\
\hline $3 / 21 / 2001$ & -9.01155476 & -0.5 & $5 / 9 / 2007$ & 2.32853421 & . \\
\hline $3 / 20 / 2002$ & -7.92849656 & & $12 / 10 / 2003$ & 2.82226154 & \\
\hline $6 / 25 / 2003$ & -7.57241829 & -0.25 & $5 / 17 / 2000$ & 3.77767698 & 0.5 \\
\hline $9 / 20 / 2006$ & -7.45221586 & & $9 / 17 / 2003$ & 4.05281133 & . \\
\hline $10 / 29 / 2003$ & -7.24407483 & & $5 / 5 / 2004$ & 4.55340794 & . \\
\hline $8 / 14 / 2002$ & -6.53722243 & & $8 / 9 / 2006$ & 5.18603815 & \\
\hline $3 / 19 / 2003$ & -5.48943037 & & $9 / 21 / 2005$ & 5.39157431 & 0.25 \\
\hline $1 / 31 / 2007^{*}$ & -5.36338312 & & $8 / 10 / 2005$ & 5.57121628 & 0.25 \\
\hline $9 / 19 / 2001$ & -5.16360758 & -0.5 & $6 / 26 / 2002$ & 5.79975596 & . \\
\hline $1 / 28 / 2004$ & -5.08143766 & & $9 / 19 / 2007^{*}$ & 5.81438558 & -0.5 \\
\hline $8 / 8 / 2007$ & -4.9633373 & & $5 / 7 / 2003$ & 6.94293336 & . \\
\hline $9 / 25 / 2002$ & -4.84789234 & & $8 / 22 / 2001$ & 8.05299907 & -0.25 \\
\hline $2 / 2 / 2005$ & -4.8374898 & 0.25 & $10 / 4 / 2000$ & 9.78622802 & 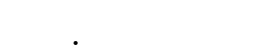 \\
\hline $6 / 28 / 2000$ & -3.86574951 & & $3 / 21 / 2007$ & 10.71673603 & . \\
\hline $3 / 23 / 2005$ & -3.75264231 & 0.25 & $1 / 3 / 2001$ & 11.08608383 & -0.5 \\
\hline $1 / 30 / 2002$ & -2.33947941 & & $12 / 20 / 2000$ & 11.19765056 & . \\
\hline $5 / 16 / 2001$ & -1.81160545 & -0.5 & $12 / 13 / 2006$ & 12.09295775 & . \\
\hline $4 / 18 / 2001^{*}$ & -1.65581229 & -0.5 & $3 / 29 / 2006$ & 12.76180575 & 0.25 \\
\hline $10 / 31 / 2007$ & -1.59224534 & -0.25 & $12 / 15 / 2004$ & 14.7614316 & 0.25 \\
\hline $11 / 10 / 2004$ & -1.55364739 & 0.25 & $12 / 14 / 2005$ & 15.99713624 & 0.25 \\
\hline $6 / 30 / 2004$ & -1.47732876 & 0.25 & $9 / 22 / 2004$ & 16.7576113 & 0.25 \\
\hline $8 / 15 / 2007$ & -1.35086927 & & $10 / 3 / 2001$ & 19.88234022 & -0.5 \\
\hline $11 / 15 / 2000$ & -1.23394901 & & $3 / 22 / 2000$ & 30.51765755 & 0.25 \\
\hline $5 / 4 / 2005$ & -0.9443041 & 0.25 & & & \\
\hline $1 / 29 / 2003$ & -0.93638864 & & & & \\
\hline $12 / 12 / 2007^{*}$ & -0.63435321 & -0.25 & & & \\
\hline $8 / 11 / 2004$ & -0.24758731 & 0.25 & & & \\
\hline
\end{tabular}


Table 3.2: Ordinary Least Squares Estimates Binary Pressure Specification Model.

The table below displays OLS estimates for the specification

$$
\Delta R_{t}=a D_{t}+b\left(1-D_{t}\right) .
$$

The right hand side, the binary variable equals 1 when $\Omega_{t}$, the accumulated pressure since the FOMC meeting is positive, and zero otherwise. The dependent variable equals the week $t$ change in $R_{t}$ the sum of average open market operations. The sample includes the 413 weeks ending between January 26, 2000, the first FOMC meeting in the study sample period, and the last FOMC meeting of 2007, December 19, 2007.

\begin{tabular}{lrrrl}
\hline \multicolumn{5}{c}{$R^{2}=0.0347, N=413$} \\
VARIABle & Estimate & ST.ERR. & \multicolumn{1}{c}{$t$-stat } & $p$-VALUE \\
\hline \hline$D_{t}$ & 2.013725 & 0.421452 & 4.778063 & 0.0000 \\
$\left(1-D_{t}\right)$ & -0.354072 & 0.419421 & -0.844193 & 0.3991 \\
\hline
\end{tabular}


Table 3.3: Least Squares Estimates for Nonlinear Pressure Specification Model. The table below displays OLS estimates for the specification

$$
\Delta R_{t}=\gamma_{0}+\gamma_{1} \Omega_{t}+\gamma_{2} \Omega_{t}^{2} \operatorname{sign}\left(\Omega_{t}\right)
$$

The dependent variable equals the week- $t$ change in $R_{t}$ the total of all open market operations in that period. The explanatory variable, $\Omega_{t}$ equals the accumulated pressure since the last FOMC meeting, and $\Omega_{t}^{2} \operatorname{sign}\left(\Omega_{t}\right)$ equals the square of the accumulated pressure, multiplied the sign of $\Omega_{t}$ in that period.

$$
\operatorname{sign}\left(\Omega_{t}\right)=\left\{\begin{array}{rr}
-1, & \Omega_{t} \leq 0 \\
1, & \Omega_{t}>0
\end{array}\right.
$$

The sample includes the 413 weeks ending between January 26, 2000, the first FOMC meeting in the study sample period, and the last FOMC meeting of 2007, December 19, 2007.

\begin{tabular}{lrrrl}
\hline \multicolumn{5}{c}{$R^{2}=0.0401, N=413$} \\
VARIABle & Estimate & St.ERR. & \multicolumn{1}{c}{-stat } & $p$-VALUE \\
\hline \hline$C$ & 0.844014 & 0.298362 & 2.828827 & 0.0049 \\
$\Omega$ & 0.267964 & 0.073703 & 3.635726 & 0.0003 \\
$\Omega^{2} \operatorname{sign}(\Omega)$ & -0.006992 & 0.003637 & -1.922516 & 0.0552
\end{tabular}




\section{Figure 3.3: Scatter Plot of Pressure Metric $\Omega$ and Target Changes.}

The horizontal axis shows the target changes in basis points. The vertical axis, the value of $\Omega_{l+k_{l}}$, the value of the metric for accumulated pressure on the target rate as of the week preceding each of the 68 FOMC meetings between $3 / 22 / 2000$ and 12/31/2007.

To illustrate the relationship between this and Table 3.1 the end of week date is displayed near the largest magnitude observations of $\Omega$ in each class.

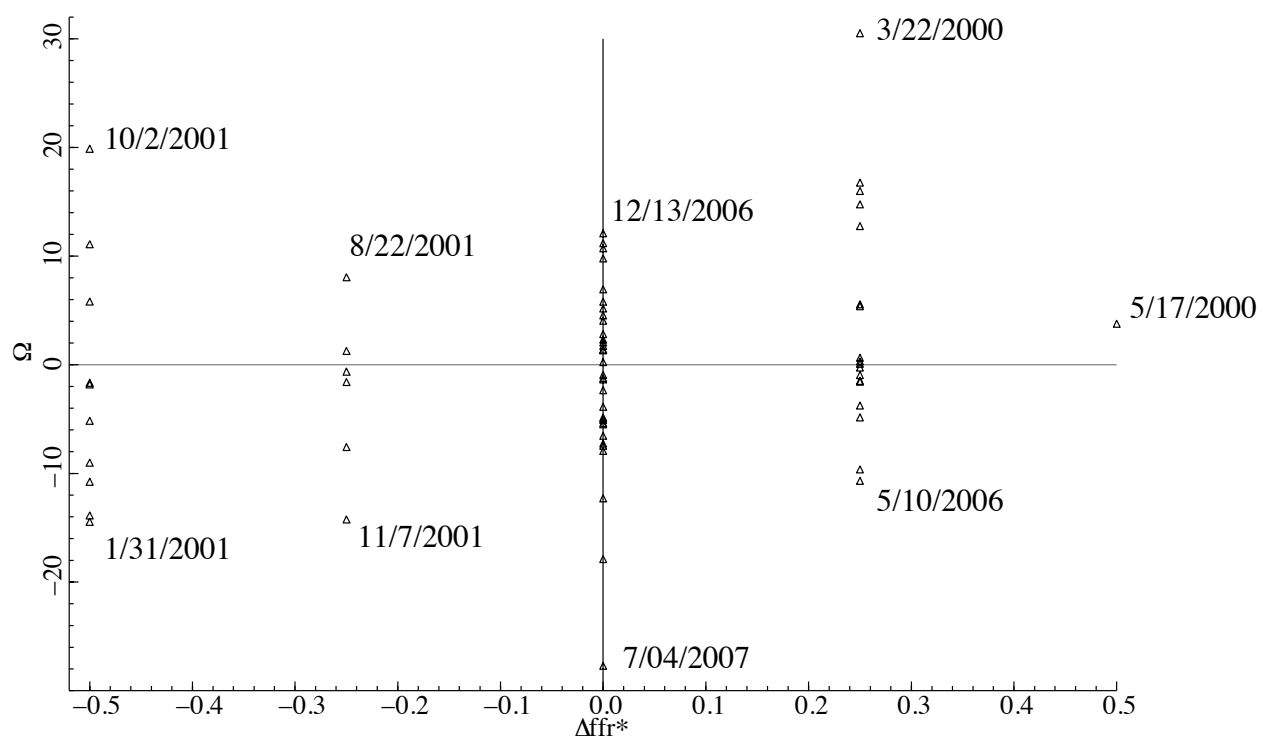




\section{Table 3.4: Ordered Probit Model. Dependent Variable Equals $\{-1,0,1\}$}

The dependent variable corresponds to FOMC meetings where lower $(-1)$, unchanged $(0)$, and higher (1) target changes are announced. The explanatory variable $\Omega_{t}$ equals the accumulated demand pressure as of the week prior to the period including the FOMC meeting. Marginal effects are calculated at the sample average of $\Omega_{l+k_{l}}=-0.0212$

$$
\begin{gathered}
\operatorname{Pr}\left(P_{t}^{*}=s_{j} \mid \Omega_{l+k_{l}}\right)=\operatorname{Pr}\left(P_{t}^{*} \in A_{j k}\right)=\operatorname{Pr}\left(\Omega_{l+k_{l}} \gamma+\epsilon_{t} \in A_{j k} \mid \Omega_{l+k_{l}}\right) \\
\operatorname{Pr}\left(P_{t}^{*}=s_{j} \mid \Omega_{l+k_{l}}\right)= \begin{cases}\Phi\left(\alpha_{1}-\Omega_{l+k_{l}} \gamma\right), & i=1 \\
\Phi\left(\alpha_{i}-\Omega_{l+k_{l}} \gamma\right)-\Phi\left(\alpha_{i-1}-\Omega_{l+k_{l}} \gamma\right), & 1<i<m \\
1-\Phi\left(\alpha_{m-1}-\Omega_{l+k_{l}} \gamma\right), & i=m .\end{cases} \\
\frac{\partial \operatorname{Pr}\left(P_{t}=-1 \mid \Omega_{l+k_{l}}\right)}{\partial \Omega_{l+k_{l}}}=-\phi\left(\alpha_{1}-\Omega_{l+k_{l}} \gamma\right) \gamma \\
\frac{\partial \operatorname{Pr}\left(P_{t}=0 \mid \Omega_{l+k_{l}}\right)}{\partial \Omega_{l+k_{l}}}=\left[\phi\left(\alpha_{1}-\Omega_{l+k_{l}} \gamma\right)-\phi\left(\alpha_{2}-\Omega_{l+k_{l}} \gamma\right)\right] \gamma \\
\frac{\partial \operatorname{Pr}\left(P_{t}=1 \mid \Omega_{l+k_{l}}\right)}{\partial \Omega_{l+k_{l}}}=\phi\left(\alpha_{2}-\Omega_{l+k_{l}} \gamma\right) \gamma .
\end{gathered}
$$

\begin{tabular}{|c|c|c|c|c|}
\hline \multicolumn{5}{|c|}{$\operatorname{Pr}\left(\Delta f f r^{*}<0\right)=0.22564$} \\
\hline VARIABLE & Estimate & $z$-stat & $P>z$ & $\leftarrow 95 \%$ C.I. $\rightarrow$ \\
\hline$\overline{\Omega_{l+k_{l}}}$ & $\begin{array}{ll}-0.0095561 & 0.00462\end{array}$ & -2.07 & 0.039 & $\begin{array}{ll}-0.018608 & -0.000504\end{array}$ \\
\hline \multicolumn{5}{|c|}{$\operatorname{Pr}\left(\Delta f f r^{*}=0\right)=0.50168$} \\
\hline VARIABLE & Estimate St.ERR & $z$-stat & $P>z$ & $\leftarrow 95 \%$ C.I. $\rightarrow$ \\
\hline$\overline{\Omega_{l+k_{l}}}$ & $\begin{array}{ll}-0.0010143 & 0.00193\end{array}$ & -0.53 & 0.599 & $\begin{array}{ll}-0.0048 & .002771\end{array}$ \\
\hline \multicolumn{5}{|c|}{$\operatorname{Pr}\left(\Delta f f r^{*}>0\right)=0.27268$} \\
\hline VARIABLE & Estimate ST.ERR. & $z$-stat & $P>z$ & $\leftarrow 95 \%$ C.I. $\rightarrow$ \\
\hline$\Omega_{l+k_{l}}$ & 0.0105704 & 2.07 & 0.039 & $\begin{array}{ll}0.000554 & 0.020587\end{array}$ \\
\hline
\end{tabular}

\begin{tabular}{lrccccc}
\hline \multicolumn{7}{c}{ PSEUdo $R^{2}=0.0314, N=68$} \\
VARIable & Estimate & St.ERR. & $z$-stat & $P>z$ & \multirow{2}{*}{$\leftarrow 95 \%$ C.I. $\rightarrow$} \\
$($ Threshold $)$ & & & & & & \\
\hline \hline$\Omega_{l+k_{l}}$ & 0.0318119 & 0.0152386 & 2.09 & 0.037 & 0.0019449 & 0.061679 \\
$\alpha_{1}$ & -0.7515942 & 0.1701431 &. &. & -1.085068 & -0.4181199 \\
$\alpha_{2}$ & 0.6064166 & 0.1653387 &. &. & 0.2823588 & 0.9304744
\end{tabular}

Marginal effects calculated at the sample average of $\Omega_{l+k_{l}}=-0.0212$ 


\section{Figure 3.4: Ordered Probit Model. Dependent Variable Equals $\{-1,0,1\}$}

The figure below shows the estimated probability of announcements of target rate changes at FOMC meetings.

$$
\begin{aligned}
& \operatorname{Pr}\left(f f r_{t_{l}}^{*}<0 \mid \Omega_{l+k_{l}}\right)=\Phi\left(\alpha_{1}-\Omega_{l+k_{l}} \gamma\right) \\
& \operatorname{Pr}\left(f f r_{t_{l}}^{*}=0 \mid \Omega_{l+k_{l}}\right)=\Phi\left(\alpha_{i}-\Omega_{l+k_{l}} \gamma\right)-\Phi\left(\alpha_{i-1}-\Omega_{l+k_{l}} \gamma\right), \\
& \operatorname{Pr}\left(f f r_{t_{l}}^{*}>0 \mid \Omega_{l+k_{l}}\right)=1-\Phi\left(\alpha_{m-1}-\Omega_{l+k_{l}} \gamma\right) .
\end{aligned}
$$

Lines graph the probability of target changes predicted by the model by pressure metric $\Omega_{l+k_{l}}$. On each of the curves, symbols show individual FOMC meetings for each of the three possible outcomes. For example, diamonds drawn on the curve showing the probability of an increase in the target rate represent values of $\Omega_{l+k_{l}}$ when the target was increased. The crosses on the curve showing the probability of lower rates mark FOMC meetings when the target is adjusted lower.

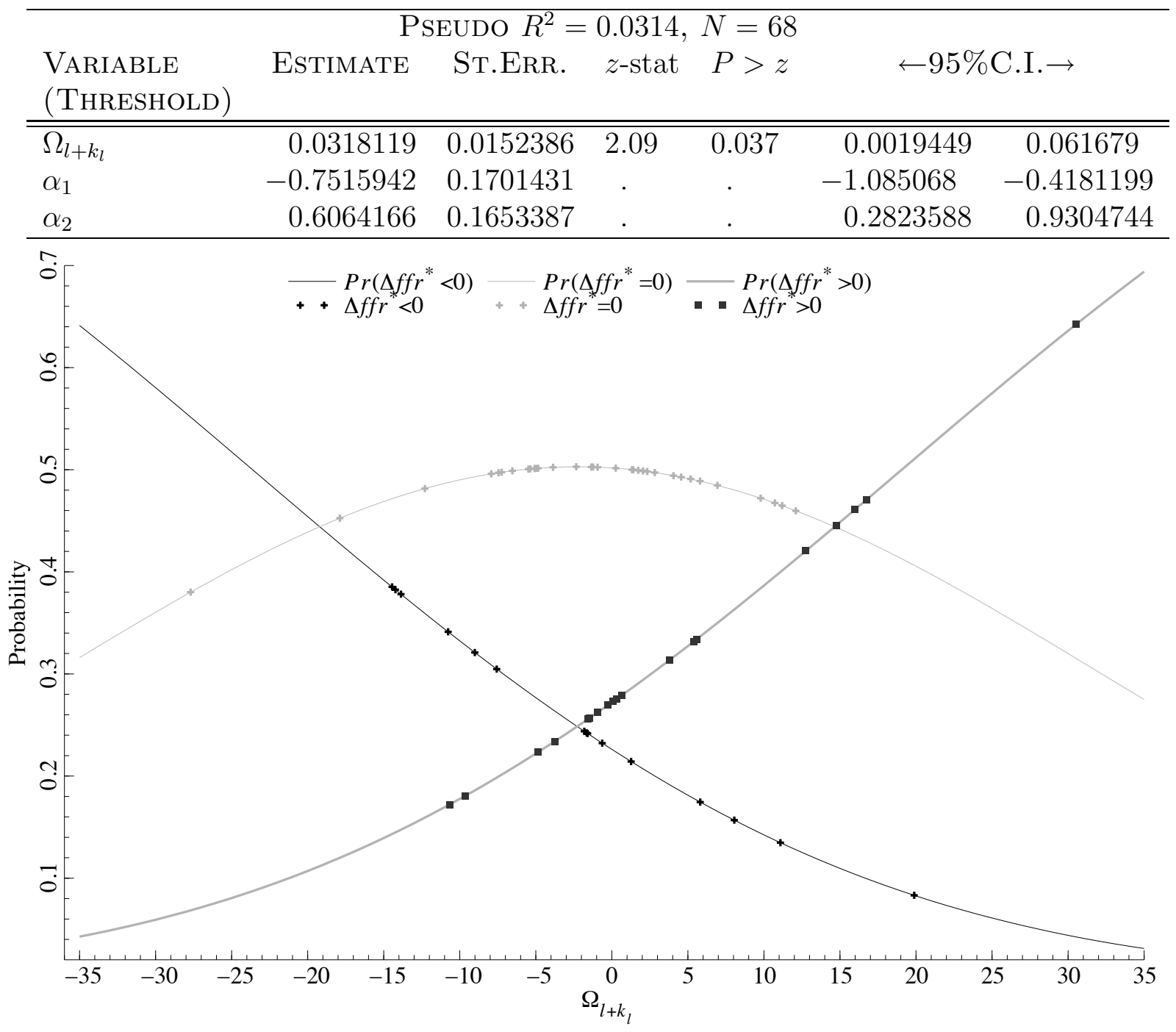




\section{Figure 3.5: Marginal Effects of Ordered Probit Model.}

The figure below shows marginal effects of a change in the pressure metric at each level of $\Omega_{l+k_{l}}$.

$$
\begin{aligned}
& \frac{\partial \operatorname{Pr}\left(\Delta f f r^{*}<0 \mid \Omega_{l+k_{l}}\right)}{\partial \Omega_{l+k_{l}}}=-\phi\left(\alpha_{1}-\Omega_{l+k_{l}} \gamma\right) \gamma \\
& \frac{\partial \operatorname{Pr}\left(\Delta f f r^{*}=0 \mid \Omega_{l+k_{l}}\right)}{\partial \Omega_{l+k_{l}}}=\left[\phi\left(\alpha_{1}-\Omega_{l+k_{l}} \gamma\right)-\phi\left(\alpha_{2}-\Omega_{l+k_{l}} \gamma\right)\right] \gamma \\
& \frac{\partial \operatorname{Pr}\left(\Delta f f r^{*}>0 \mid \Omega_{l+k_{l}}\right)}{\partial \Omega_{l+k_{l}}}=\phi\left(\alpha_{2}-\Omega_{l+k_{l}} \gamma\right) \gamma .
\end{aligned}
$$

Marginal effects calculated at the sample average of $\Omega_{l+k_{l}}=-0.0212$

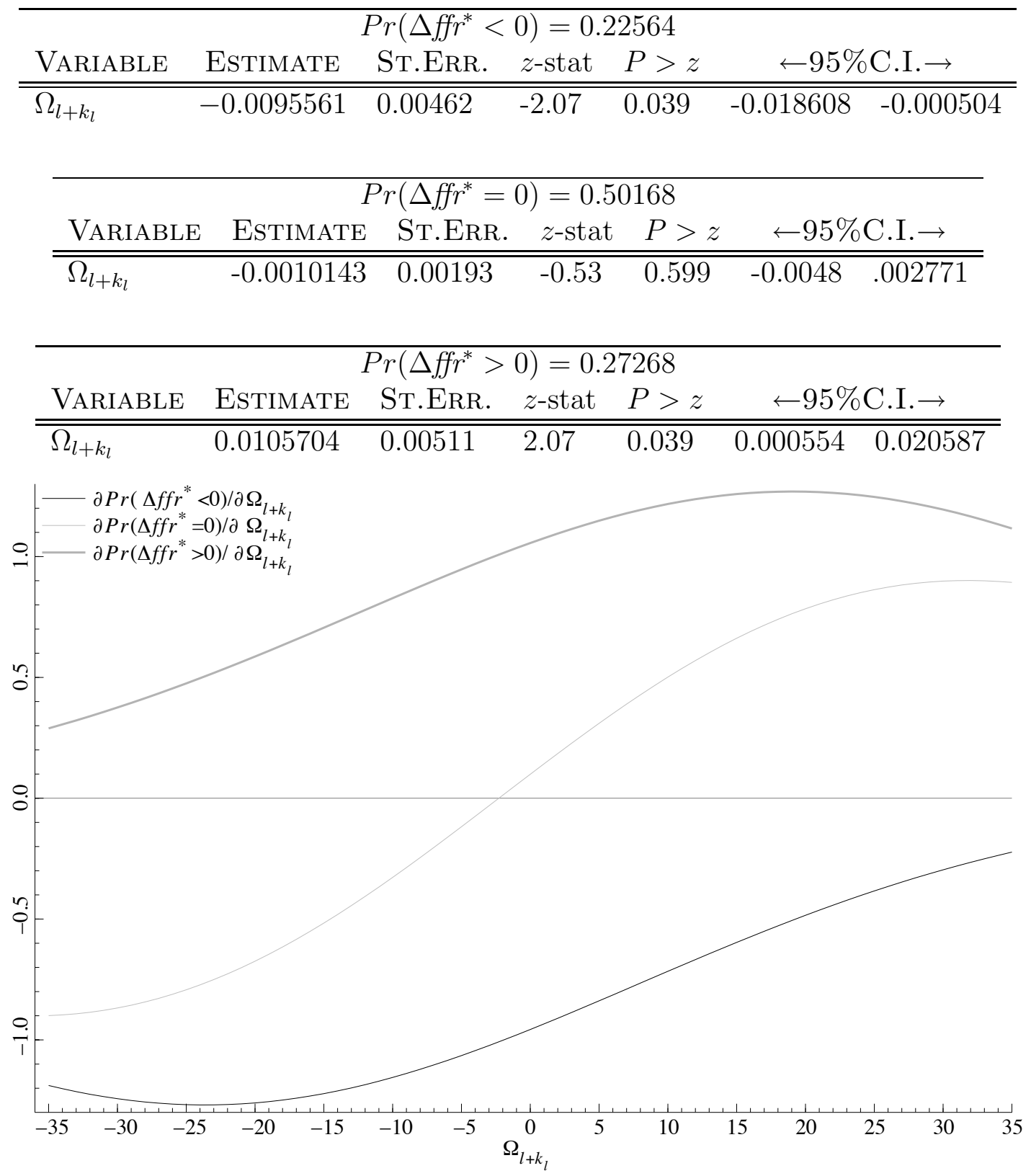




\section{Chapter 4}

\section{The Impact of U.S. Treasury Auctions on Discount Yields}

\subsection{Introduction}

The discount function is an integral component in the study of financial market phenomena. Default-free zero-coupon rates, derived from prices of U.S. Treasury securities, deliver benchmark yields of uniform risk across the term structure. The Treasury's debt management policy, informing the size and maturity of treasury auctions, must balance the government's objective to finance spending at the lowest cost, while satisfying market participant's demand for risk-free securities. Auctions increase the nominal supply of interest and principal cashflows to be paid on the federal debt, and at the auctioned issue's maturity horizon, this increase in cashflows is most significant.

This paper examines discount yields constructed from off-the-run bond prices. Since prices of newly issued, on-the-run bonds are not included in the determination of the discount yields, the effect of auction events can be related directly to the absorption effect. The effect of a change in the supply of cashflows on these discount rates are not directly related to changes in liquidity of the underlying assets, since the yields are constructed using twice offthe-run bond prices. An event study approach finds a positive relationship between auction 
events and the change in relative yields at one, two, three, four, and seven-year horizons. While short-lived, the effect on relative yields at the horizons of auction events is positive and independent of the size of the auction. The auction event transmits no new information regarding size, since announcements occurring days or weeks before the auction report an anticipated subscription amount. By comparison, event study results using a set of yields constructed primarily from the on-the-run issues display a more persistent liquidity-premium effect at the five, ten, and thirty-year horizons.

Since 1982, the announcement and auction of U.S. Treasury debt with maturity one year and greater occurs on a fairly regular schedule. Garbade (2007) cites reduction of market uncertainty and lower borrowing costs among the reasons for Treasury's abandonment of irregular, or tactical debt issuance. Auctions of additional default-free cashflows can be associated with two distinct effects: (1) A "liquidity-premium effect" due to the fact that new issues are more liquid thus requiring a lower return; and (2) An "absorption effect" associated with the additional supplies of cashflows inducing lower prices.

Goldreich et al. (2005) find the premium for off-the-run over on-the-run 2-year notes to be approximately 1.5 basis points at the issue date of a new security, declining as the on-the-run bonds transition to the first off-the-run status. Warga (1992) studies bonds with maturity greater than one year, finding constant duration portfolios composed of on-the-run issues earn a premium of 55 basis points per year over a similarly constructed portfolio of off-the-run bonds.

An absorption effect occurs through the market segmentation channel. Downward sloping demand curves for bonds of a particular maturity require lower prices with higher supplies. Seligman (2006) and Simon $(1991,1994)$ examine unscheduled auctions of short-term cash- 
management bills and provide evidence of this effect at the short end of the term structure. By examining the yield differentials relative to neighboring maturity instruments over auction events, Seligman finds that the positive price effect of increased liquidity is dominated by other factors at the short end of the yield curve. The size of the yield differential for cashmanagement bills equals 31.24 basis points between the auction and announcement date. Simon (1991) finds a 20 basis point average change in the spread between cash-management and adjacent-maturity bill rates. These large differences can be attributed in part to the nature of cash management bills, typically unscheduled, very short-term operations. In contrast to these results from the short-term yield curve, this study characterizes the impact of auction events at longer-term horizons using zero-coupon yields of Gürkaynak et al. (2007). These yields, constructed prices for bonds at least twice off-the-run, provide daily data on zero-coupon rates for maturities of one through 30 years at annual increments. Gürkaynak et al. (2007) argue that the use of off-the-run bonds in construction of discount yields sidesteps the problematic liquidity-premium implications encountered in other yield data, including the Treasury's constant-maturity series. The newly issued instruments are excluded from the sample of treasuries used to estimate the yields for an appropriate risk-free zero-coupon discount function.

The following section describes the background and testable hypothesis. Sections 4.2.1 and 4.3 describe the data and empirical method of the study, Section 4.5 presents results. Section 4.6 describes extensions to the model and Section 4.7 concludes.

\subsection{Background and Hypothesis}

Scholes (1972) presents the theoretical motivation for the negative price effect of a firm mak- 
ing additional shares available. If securities have close substitutes, an increase in the supply of additional shares will have no price effect, since those new shares will be sold at the market price for similar income streams. If a firm's shares do not have close substitutes in the market, then the cashflows cannot be matched well with other assets, and the demand elasticity for a stock will determine lower prices when supply increases. An implied alternative possibility is that changes in the supply of equity shares, affected, for example, by secondary distributions or large block trades of institutional investors, are related to other information such as the firm's fundamental value. Asquith and Mullins (1986) find prices adjust quickly and negatively to information of seasoned equity offerings in support of Scholes' price pressure hypothesis. Fama et al. (1969) find stock splits serve as events which trigger repricing of expected income streams shortly after the split announcement. Holthausen et al. (1987) examine block trades, finding a distinction between buyer and seller initiated transactions. The uniform risk profile, relatively more complete markets due to the consistent treatment of principal and interest payments, existence of the STRIPS ${ }^{1}$ program, and implications of the expectations hypothesis, suggest that a change in the supply of cashflows should not impact market prices for treasuries.

Much of the event study research on United States Treasury prices focuses on the bill market. Hughes et al. (2008) examine the volatility effects corresponding to treasury bill auction events, finding that volatility is high as a bond moves from on-the-run to off-the-run status. Fleming (2002) shows that Treasury bill reopenings occur with lower prices, finding the effect of greater supply dominates the possible liquidity benefit that might drive prices

\footnotetext{
${ }^{1}$ Acronym for Separate Trading of Registered Interest and Principal of Securities. The STRIPS program designates securities which may be divided or stripped by financial institutions into separately traded zerocoupon instruments representing single principal or interest payments from a note or bond.
} 
higher. This result suggests that additional supply of a perfect substitute, that is, additional supplies of identical cashflows, lower the market price of the existing securities. Balduzzi et al. (2009), Fleming and Remolona (1999), Babbel et al. (2004), each use intraday data to study the effects of macroeconomic announcements, orderflow, and transactions size on bond prices.

This paper employs interday data describing an alternative measure of the yield curve. Gürkaynak et al. (2007) construct the zero-coupon yield curve from bonds at least twice off-the-run so that yield changes related to the liquidity premium for on-the-run bonds do not contaminate measurement. These discount yields provide information on the prices of less liquid but otherwise substitutable cashflows. Evidence of the effect of auctions on the off-the-run discount yields shows that the change in the relative supply of cashflows drives relative prices for seasoned treasuries down, but only in the short term. The result differs from previous research of off versus on-the-run yields since the supply effect originates from additional cashflows available at the maturity horizon, and the yields are constructed from a set of assets with uniform liquidity. Since the yields are constructed from the universe of treasuries excluding bonds which are on-the-run or first-off-the-run, the auction effect is not attributable to a liquidity premium.

Hypothesis: An increase in the supply of cashflows at a particular maturity reduces relative prices, and increases relative yields at that horizon.

Well documented Treasury auction events mark changes in the supply of bonds. Examination of the simultaneous effects on the yield curve through use of event study methodology provides a measure of the effect.

Since auctions increase the supply of cashflows at the auction maturity horizon, prices 
for substitutes, the existing matching-maturity cashflows, fall. This effect manifests as a statistically significant increase of change of relative yields. These changes in relative yield measure the extent to which the price of bonds at the auction horizon are driven down with an increase in the supply of close substitutes, relative to changes in prices of less perfect substitutes - alternative maturity cashflows.

The time series of discount yields across the available term structure permits the examination of this effect. Letting $\mathbf{Y}_{t}^{(n)}$ equal the relative yield at maturity horizon $n$, the general hypothesis can be written as:

$$
\frac{\partial \mathbf{Y}^{(n)}}{\partial \mathbf{X}^{(n)}}>0
$$

where $\mathbf{X}^{(n)}$ equals the supply of cashflows at maturity horizon $n$. Specifically, defining $\mathbf{A}$ to be the set of dates $k$ when auction events occur, the hypothesis can be stated as:

$$
\Delta \mathbf{Y}_{t}^{(n)}>0, \text { where } t \in\{\mathbf{A}\}
$$

Results of hypothesis tests appear in section 4.5 utilizing data and methods described in sections 4.2 .1 and 4.3 .

\subsubsection{Event Definition and Data}

\section{Yield Curve:}

The empirical methodology used by Gürkaynak et al. (2007) provides discount yields derived from the prices of off-the-run Treasury bonds at annual increments. The data spans 1961 to the recent past.

The maturity structure of the debt limits the horizons for which the discount yield curve can be estimated. Figure 4.1 displays a sample of the yield curve data employed in this study. Vertical lines show the date of inclusion for 16 to 20 and 21 through 30-year yields. 
In the period under study, prices of off-the-run treasuries determine the discount rates for one to 15 years over the first seven months of 1981, at one to 20-year horizons until 1985 , and after November of 1985, one to 30 years.

\section{Auction Distribution:}

The U.S. Treasury website treasurydirect.org provides detailed auction data since 1980. Figure 4.2 shows the size, timing, and maturity for the Treasury auctions of securities with maturity of at least one year for the period between January 1, 1981 and December 31, 2007. The top frame displays the timing of auction events against maturity, the bottom frame the face value of the auction.

Figure 4.2 demonstrates that the distribution and frequency of auctions exhibits considerable variation over the sample period. Figure 4.3 summarizes the schedule of auction events by month, across maturity horizons. In general, auctions for 52 -week bills occur every four weeks. Two-year notes are typically auctioned in the second half of each month, three and ten-year note and thirty-year bond auctions typically occur in the first half of the month, quarterly, on a February-May-August-November schedule. Five-year note auctions occur in the second half of the month on the same (February-May-August-November) quarterly schedule until 1991 when the frequency increases and auctions are conducted monthly. Beginning in 1998 the schedule for five-year auctions returns to midquarters, but shifts to the first half of the month.

Until discontinued in 1991, four-year notes are auctioned on a quarterly schedule beginning in March. Twenty-year notes were on a similar schedule. These March-June-SeptemberDecember auctions occur in the second half of the month. Seven-year auctions occur on an approximately quarterly schedule, beginning either in January or March each year. 
The top frame of Figure 4.4 shows the total value of accepted offers at auction across all maturity horizons, by month, between January 1981 and December 2007. The lower frame shows detail from a subsample of the data. The subperiod of detail includes March of 1996, when no securities were auctioned due to the debt ceiling legislation debate. Auction face values are high in February, May, August, and November due to the three, five, ten, and thirty-year auctions which occur in those months.

Figure 4.5 shows a subsample of the data from Figure 4.2 detailing the distribution of auctions by maturity and the face value at auction over one year, between 1990 and 1991 . During this period, auctions for one, two, three, five, ten and thirty-year maturities occur in each of the months of February, May, August, and November. This subperiod also shows the transition from quarterly to monthly five-year note auctions.

The top frame of Figure 4.6 shows a scatter diagram of years to maturity against days between announcement and auction. The lower frame shows the days between announcement and issuance against days between announcement and auction. Most very short-term cashmanagement bills are announced only a few days before the auction, and longer-term notes and bonds generally have longer periods between announcement and auction. Exceptions include a nine year 11 month note announced and auctioned on the same day in October of 2001, and issued the next day. Two five-year notes were announced one day before the auction in 2005, although, like the three and four-year notes announced one day before their auctions in 1987 and 1985, respectively, weren't issued until the following week. Since the present study examines the longer-term treasury market, and Gürkaynak et al. (2007) construct the discount-yield curve excluding short-term bills in their estimation, cash-management and other short-term bill auctions are not shown in the figures for the good of clarity. 


\subsection{Empirical Method}

This section describes the event study methodology employed to address auction effects on the yield curve. The procedure is adapted from the treatment of Campbell et al. (1997) and MacKinlay (1997). For adaptability to other cases, their procedure, outlined here, uses the $\mathbf{v}$ for the response vector under study.

Let $\tau=0$ denote the date of the event, and define $\tau=T_{1}+1$ to $\tau=T_{2}$ the event window.

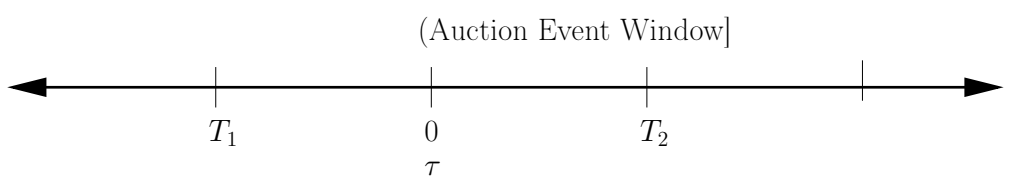

Date $T_{1}$ represents the eve of the event, $T_{2}$ the end of the event window. Each date $t$ can be referenced in terms of its distance from an auction event. For this type of ordering, the index $\tau$ is used with reference to a particular auction event.

Let the difference between the observed and expected value of $\mathbf{v}$ be defined as $\boldsymbol{\xi}$. For each priced asset $i$, let the $T_{2} \times 1$ vector, $\hat{\xi}_{i}^{(N)}$ with $k^{\text {th }}$ element, equal to

$$
\hat{\xi}_{i k}=v_{i k}-E\left(v_{i k}\right)
$$

represent the "abnormal return" over the event window. The appropriate model for expectations over the event window is informed by the question under study. Candidates include CAPM or APT for equity returns, constant mean, or other model.

In general, the model expressed in terms of linear regression as:

$$
\mathbf{v}_{i}=\mathbf{X}_{i} \boldsymbol{\delta}_{i}+\boldsymbol{\epsilon}_{i}
$$

with the usual implications of ordinary least squares estimation; $\hat{\boldsymbol{\delta}}_{i} \in \mathbb{R}^{k \times 1}, \mathbf{X}_{i} \in \mathbb{R}^{n \times k}$, and 
$\mathbf{v}_{i} \in \mathbb{R}^{n \times 1}$.

$$
\begin{aligned}
\hat{\boldsymbol{\delta}}_{i} & =\left(\mathbf{X}_{i}^{\prime} \mathbf{X}_{i}\right)^{-1} \mathbf{X}_{i}^{\prime} \mathbf{v}_{i} \\
\hat{\boldsymbol{\epsilon}}_{i} & =\mathbf{v}_{i}-\mathbf{X}_{i} \hat{\boldsymbol{\delta}}_{i} \\
\hat{\sigma}_{\epsilon_{i}}^{2} & =\frac{1}{n-k} \hat{\boldsymbol{\epsilon}}_{i}^{\prime} \hat{\boldsymbol{\epsilon}}_{i} \\
\operatorname{Var}\left(\hat{\boldsymbol{\delta}}_{i}\right) & =\left(\mathbf{X}_{i}^{\prime} \mathbf{X}_{i}\right)^{-1} \sigma_{\boldsymbol{\epsilon}_{i}}^{2},
\end{aligned}
$$

The conditional expectation and variance of (4.3), where $\mathbf{X}_{i}^{*}$ holds the observed explanatory variables over the event period, $\mathbf{X}_{i k}^{*}=\mathbf{X}_{i k}$ when $k \in\left[\tau_{1}, \tau_{2}\right]$ equals

$$
\begin{gathered}
E\left(\hat{\xi}_{i k}\right)=0 \\
\mathbf{V}_{i}=E\left(\hat{\xi}_{i} \hat{\xi}_{i}^{\prime}\right)=\mathbf{I} \sigma_{\boldsymbol{\epsilon}_{i}}^{2}+\mathbf{X}_{i}^{*}\left(\mathbf{X}_{i}^{\prime} \mathbf{X}_{i}\right)^{-1} \mathbf{X}_{i}^{* \prime} \sigma_{\epsilon_{i}}^{2} .
\end{gathered}
$$

The second term of (4.10) equals the variance contribution of the uncertainty of parameter estimation from (4.4) which decreases to zero with increasing sample period length.

Over the event window, the cumulative abnormal return for each security equals the deviation from the expected value of the market model in the interval $\left[\tau_{1}, \tau_{2}\right]$, where $T_{1}<$ $\tau_{1}, \leq \tau_{2} \leq T_{2}$

$$
\widehat{C A R}_{i}\left(\tau_{1}, \tau_{2}\right)=\sum_{\tau=\tau_{1}}^{\tau_{2}} \hat{\xi}_{i \tau}
$$

The average of $\widehat{C A R}$, over each of the $N$ events, equals

$$
\overline{C A R}\left(\tau_{1}, \tau_{2}\right)=\frac{1}{N} \sum_{i=0}^{N} \widehat{C A R}_{i}\left(\tau_{1}, \tau_{2}\right) .
$$

Defining the variance of $\widehat{C A R}_{i}\left(\tau_{1}, \tau_{2}\right)$ as

$$
\operatorname{Var}\left(\widehat{C A R}_{i}\left(\tau_{1}, \tau_{2}\right)\right)=\sigma_{i}^{2}\left(\tau_{1}, \tau_{2}\right)=\left(\tau_{2}-\tau_{1}+1\right) \sigma_{\xi_{i}}^{2},
$$


and

$$
\operatorname{Var}\left(\overline{C A R}\left(\tau_{1}, \tau_{2}\right)\right)=\bar{\sigma}_{i}^{2}\left(\tau_{1}, \tau_{2}\right)=\frac{1}{N^{2}} \sum_{i=1}^{N} \sigma_{i}^{2}\left(\tau_{1}, \tau_{2}\right)
$$

it follows that under the null hypothesis, the event having no impact on the mean or variance of $\xi_{i}$, (from (4.9) and (4.10)), $\xi_{i} \sim N\left(0, \mathbf{V}_{i}\right)$. Therefore,

$$
\widehat{C A R}_{i}\left(\tau_{1}, \tau_{2}\right) \sim N\left(0, \sigma_{i}^{2}\left(\tau_{1}, \tau_{2}\right)\right)
$$

and

$$
\overline{C A R}_{i}\left(\tau_{1}, \tau_{2}\right) \sim N\left(0, \bar{\sigma}_{i}^{2}\left(\tau_{1}, \tau_{2}\right)\right)
$$

The test statistic for the effect on $v_{i t}$ in response to an event equals

$$
\theta=\frac{\overline{C A R}\left(\tau_{1}, \tau_{2}\right)}{\sqrt{\operatorname{Var}\left(\overline{C A R}\left(\tau_{1}, \tau_{2}\right)\right)}}
$$

where $\theta$ is distributed as Student's $t$ with $T$, degrees of freedom, where $T$ corresponds to the size of the estimation window for computing variance estimate $\sigma_{\xi_{i}}^{2}$.

MacKinlay (1997) describes a modification of the null hypothesis which uses the sample estimate for $\operatorname{Var}(\overline{C A R})$, dependent on the cross section of cumulative abnormal returns.

$$
\theta^{\prime}=\frac{\overline{C A R}\left(\tau_{1}, \tau_{2}\right)}{\sqrt{\widehat{\operatorname{Var}}\left(\overline{C A R}\left(\tau_{1}, \tau_{2}\right)\right)}}
$$

where

$$
\widehat{\operatorname{Var}}=\frac{1}{N^{2}} \sum_{i=1}^{N}\left(\widehat{C A R}_{i}\left(\tau_{1}, \tau_{2}\right)-\overline{C A R}\left(\tau_{1}, \tau_{2}\right)\right)^{2}
$$

The null hypothesis in this specification, that the event has no effect on mean returns, in contrast to the hypothesis stated above that the event has no effect on either mean or variance of returns. 


\subsection{Specification}

Notation throughout sets $y_{t}^{(N)}$ equal to the discount rate at time $t$ for cashflows which occur at time $t$ plus $N$ years. The relative yield to maturity at time $t$ equals,

$$
\mathbf{Y}_{t}^{(N)}=y_{t}^{(N)}-\frac{1}{T} \sum_{k=1}^{T} y_{t}^{(k)}
$$

the difference between the yield to maturity and the average yield over the $T$ maturity horizons across the term structure at time $t$. Auctions within six months of a particular maturity horizon are classified with the nearest maturity class. For example, 29-year 6month auctions are included within the 30-year category.

The normalization of yields using the average across the term structure is motivated by the desire to smooth effects which may be related to a particularly active maturity, while capturing the relationship between auction events and relative yields. For example, since the one-year horizon has an auction every four weeks, examining the change in the term premium at horizon $n, y_{t}^{(n)}-y_{t}^{(1)}$, as associated with $n$-year auctions, would introduce noise particularly related to the 1-year auction schedule.

Changes in relative yields are measured using a fixed maturity horizon. The distinction between yield changes expressed this way, and the price of the corresponding synthetic discount bond to changes in the price or holding period return of an actual discount bond is that the maturity horizon is unchanged. $\Delta y_{t}^{(N)}$ equals the change in yield on a discount bond of a maturity $N$, between $t=k$ and $t=k+1$. That is, for both observations, $y_{k}^{(N)}$ and $y_{k+1}^{(N)}$, the term to maturity of each yield equals $N$ years. The series $\mathbf{Y}_{t}^{(N)}$ is centered around the average curvature of the yield curve by subtracting off the average level of yields at each time $t$. Figure 4.7 shows the levels and first differences of two, seven, and thirty-year 
discount yields to maturity in excess of the average.

Modeling the expected value of the change in $\mathbf{Y}_{j \tau}^{(N)}$ equal to zero, where $\tau$ measures the time of the observation with respect to an auction $j$,

$$
\widehat{C A R}_{j}^{(N)}\left(\tau_{1}, \tau_{2}\right)=\sum_{\tau=\tau_{1}}^{\tau_{2}} \Delta \mathbf{Y}_{j \tau}^{(N)}
$$

The specification is equivalent to that in (4.11), setting

$$
\hat{\xi}_{j \tau}^{(N)}=\Delta \mathbf{Y}_{j \tau}^{(N)}
$$

An estimate of the population variance of abnormal returns, in this case deviations from the zero-mean expectations of changes in relative yields, is estimated from the subset of business days without an auction event occurring in any maturity tranche two days before or after the auction event. For each horizon $N$,

$$
\operatorname{Var}\left(\widehat{C A R}^{(N)}\left(\tau_{1}, \tau_{2}\right)\right)=\left(\tau_{2}-\tau_{1}+1\right) \sigma_{\xi_{i}^{(N)}}^{2}
$$

which, for the one day event window, equals $\operatorname{Var}\left(\Delta \mathbf{Y}^{(N)}\right)$. Estimation of variance occurs over a subsample of the data constructed by eliminating observations within two business days of an auction at any horizon. This procedure determines the sample for estimation of variance which equals 3768 observations, 53.5 percent of the sample for yields on maturities between one and 15 years. Maturity horizons 16 through 20 years supply 3711 observations, and maturities between 21 and 31 years the variance estimate comes from a subset of 3210 observations.

Let $\overline{\mathbf{Y}}_{\tau}^{(N)}$ equal the average deviation from mean across the $K$ auctions of maturity horizon $N$,

$$
\overline{\Delta \mathbf{Y}}_{\tau}^{(N)}=\frac{1}{K} \sum_{j=1}^{K} \Delta \mathbf{Y}_{j \tau}^{(N)}
$$


The subscript $\tau$ represents the observation date with respect to auction event centered at $\tau=0$. For example, $\Delta \mathbf{Y}_{k 0}^{(3)}$ equals the change in $\mathbf{Y}$ between the day before and of the $k$ th auction at the three-year horizon. Equation (4.24) shows the average of changes in relative yield at the $K$ auction events for maturity horizon $N$. This notation agrees with (4.21) where each $\widehat{C A R}_{j}^{(N)}$ measures the cumulative abnormal returns over one auction event, such that the change at the date of the auction equals

$$
\overline{C A R}^{(N)}(0,0)=\overline{\Delta \mathbf{Y}}_{\tau=0}^{(N)}=\frac{1}{K} \sum_{i=1}^{K} \Delta \mathbf{Y}_{i 0}^{(N)}
$$

\subsection{Results}

Figure 4.8 displays the average cumulative changes in relative yield to maturity, for a 10 business-day window centered around the auction event,

$$
\overline{C A R}^{(N)}(-5, m)=\sum_{\tau=-5}^{m}\left(\overline{\Delta \mathbf{Y}}_{\tau}^{(N)}\right) \text {, for } m \in\{-5 . .4\}
$$

The horizontal axis of Figure 4.8 shows periods before and after the date of the auction event, marked by a vertical line, at $\tau=0$. The vertical axis measures the average over auctions cumulative abnormal return based on the zero-mean expectations model. Each point on the curve measures the cumulative change in the deviation from average yield to maturity starting five days before the auction event until four days after.

The peaks at $\tau=0$ show high cumulative changes in relative yields centered at auction events at most maturities. This graphical summary of the event study suggests a positive relationship between the auction event and the relative off-the-run Treasury yields. For example, average prices of cashflows at horizons other than two years are relatively more expensive when new two-year cashflows are made available. The decline observed in the 
subsequent periods shows that the effect on these relative yields is temporary.

Figure 4.9 shows the results from a specification of the event study procedure described in section 4.3. The procedure tests for significance of the slope of the peaks shown in Figure 4.8 between periods $\tau=-1$ and $\tau=0$, the change in relative yield at the auction event.

In addition to tests of the relationship between the event at the auction horizon and relative yields at that maturity, Figure 4.9 shows test statistics calculated against maturities other than the auction horizon. For instance, Figure 4.8 does not show the behavior of relative yields at the 4 -year horizon at windows centered at auctions of 2 -year notes. The curves in Figure 4.9 show results of hypothesis tests that auctions of the maturity noted in the caption have no effect on neighboring or more distant relative yields, measured across the horizontal axis. The solid line displays the $t$-statistic measured on the vertical axis against the null hypothesis of no change in either the mean or variance,

$$
\begin{aligned}
\theta_{1} & =\frac{\overline{C A R}^{(N)}(-1,0)}{\sqrt{\operatorname{Var}\left(\overline{C A R}^{(N)}(-1,0)\right)}} \\
& =\frac{\frac{1}{K} \sum_{i=1}^{K} \Delta \mathbf{Y}_{i 0}^{(N)}}{\sqrt{\operatorname{Var}\left(\overline{C A R}^{(N)}(-1,0)\right)}}
\end{aligned}
$$

where $\operatorname{Var}\left(\overline{C A R}^{(N)}(-1,0)\right)$ is estimated using the variance of yield in excess of the average for each day in the sample at least 2 days before or after any auction - of any maturity.

The dotted lines in each frame of Figure 4.9 show the test statistic against the null of no 
change in the mean,

$$
\begin{aligned}
\theta_{1}^{\prime} & =\frac{\overline{C A R}^{(N)}\left(\tau_{1}, \tau_{2}\right)}{\sqrt{\widehat{\operatorname{Var}}\left(\overline{C A R}^{(N)}\left(\tau_{1}, \tau_{2}\right)\right)}} \\
& =\frac{\frac{1}{k} \sum_{i=1}^{k} \mathbf{Y}_{i}^{(N)}}{\sqrt{\frac{1}{N^{2}} \sum_{h=1}^{N}\left(\mathbf{Y}_{h}^{(N)}-\frac{1}{l} \sum_{i=1}^{l} \mathbf{Y}_{l}^{(N)}\right)^{2}}} .
\end{aligned}
$$

The test statistic $\theta_{1}^{\prime}$ does not rely on the subsample of dates outside two days of the auction event to produce an estimate of the variance. Solid horizontal lines represent test statistics equal to positive or negative 1.96. The sample size for estimating the variance of $\overline{C A R}$ exceeds 2000 for each horizon and thus the test statistic is approximately normally distributed.

The null hypothesis is rejected against the hypothesis that auctions have no impact on relative yields of the auction's maturity for horizons of one, two, three, four, and seven years in favor of the hypothesis that the own maturity effect on relative yields is positive. The effect of 20-year auctions on the discount yields of 20 years and greater are not calculated since the availability of these long-term discount yields does not overlap the period when 20-year auctions are conducted.

Additionally, auction horizons which exhibit a positive effect on own-maturity relative yields show pattern of influence over neighboring maturities. For example, the four-year auction frame in Figure 4.9 shows the test statistic against the hypothesis that the auction of four-year bonds has no effect on the relative yield of the five-year relative discount yield. This hypothesis is rejected at the $5 \%$ level. 


\subsubsection{Auction Size and Yield Effects}

Table 4.1 shows ordinary least squares estimates for the parameters of

$$
\Delta \mathbf{Y}_{k}^{(N)}=\alpha^{(N)}+\beta^{(N)}\left(S_{k}^{(N)}-\bar{S}_{k}^{(N)}\right)+\varepsilon_{k},
$$

where $\Delta \mathbf{Y}_{k}^{(N)}$ equals the change in relative yield at horizon $N$ for each of $k$ auctions. The right-hand-side variable $S^{(N)}-\bar{S}^{(N)}$ equals the size of auction $k$ less the average auction size at horizon $N$. The deviation from mean of the right-hand side clarifies the intuition of the model, as an auction of size zero is undefined. The parameter estimate for the effect of the size of auction is insignificant at each horizon. The insignificance of parameter estimates for the relative size suggest auctions influence relative yields at their maturities regardless of size. However, the auction event itself contains little new information with regard to the face value of the issue, since auction announcements occurring days or weeks before the auction report an anticipated subscription amount. Participants in the auction determine the market price for the new debt, information which would not be fully reflected in market prices until the auction takes place. An analogous event study procedure testing the relationship of relative yields to announcement dates fails to reject the hypothesis of no effect on relative yields the $5 \%$ level for all maturities.

\subsubsection{Expanded Window Surrounding Auction Events}

The results of tests reported in Section 4.5 report a significant change in relative yields on the date of the auction event. The upward slope of cumulative relative yields at the auction events shown in Figure 4.8 is significant at the one day horizon for each of the shorter term instruments, except for five-year notes.

The results of tests from expanding the window over differences produces a different 
picture of the effect of auction events. Figure 4.10 shows the test statistics for significance of changes in yields between dates two days previous and the auction event. The sample from which variance of the response variable is estimated is reduced to include observations from dates not within three business days of an auction event at any maturity. Figure 4.11 shows the test statistics for significance of changes in yields between dates three days previous and the auction event. The sample from which variance of the response variable is estimated is reduced to include observations from dates not within four business days of an auction event at any maturity.

These two tests reveal the peaks in the five-year maturity are significant in the days before the auction event. Unlike the other maturities which demonstrate significant increases in relative yields between auction and the date preceding the auction event, the five-year yields show a significant increase during the period between the date of an auction announcement leading up to the auction date.

The results discussed in the one day change in relative yields are generally reflected in the results addressing the change in relative yield between two and three days before the auction event. The substantive differences are in the three and five-year events. The five-year yields show a significant positive relationship between auctions and the change in yields for a two or three-day horizon. The three-year auctions do not demonstrate a positive relationship between relative yields at any horizon for the two or three-day change in relative yields.

Figure 4.12 shows the test statistics against the null hypothesis of no effect on the change in relative yield over the period one day before until one day after the auction event. Only in the one and two-year case do the statistics reject the null of no effect on relative yields at the maturity of the auction events. In these tests the variance estimator is taken from 
observations without an auction event at any maturity within two business days. The test statistics reported in Figures 4.12 and 4.13 show equivalent and essentially identical results as to those found by expanding the event window by an additional day using the formulation given by equation (4.14), where

$$
\operatorname{Var}(\overline{C A R}(-1,1))=\bar{\sigma}_{i}^{2}(-1,1)=\frac{1}{k^{2}} \sum_{i=1}^{k} \sigma_{i}^{2}(-1,1)
$$

and

$$
\operatorname{Var}(\overline{C A R}(-1,2))=\bar{\sigma}_{i}^{2}(-1,2)=\frac{1}{k^{2}} \sum_{i=1}^{k} \sigma_{i}^{2}(-1,2)
$$

provide variance estimates.

Figure 4.13 shows the test statistics against the null hypothesis of no effect on the change in relative yield over the period one day before until two days after the auction event. For these tests the variance estimator is taken from observations without an auction event at any maturity within four business days. These results, along with the tests finding a significant effect at the one day change horizon, suggest that the impact of additional supplies of cashflows at a maturity horizon exert a short-term effect on the relative discount yields. The three-day change in relative yields straddling the auction event between one day preceding until two days following the auction are not significantly different from similar three-day periods across the sample.

\subsubsection{Cross-Maturity Auction Effects}

A central issue regarding the impact of auction events and yields is related to the regularity of the auction schedule. Figure 4.15 displays the average cumulative changes in relative yield 
to maturity for a 50 business-day window before and after an auction event,

$$
\overline{C A R}^{(N)}(-50, m)=\sum_{\tau=-50}^{m}\left(\overline{\Delta \mathbf{Y}}_{\tau}^{(N)}\right) \text {, for } m \in\{-50,49\} .
$$

Vertical bold, light, and dashed lines show the date of auctions, announcements, and issuance respectively. One and two-year auctions display the most easily recognized pattern, consistent with the fact that both maturities exhibit significant positive effects on changes in relative yields and are auctioned on a regular schedule throughout the sample. Two-year notes auctions occur each month, and one-year bills every four weeks.

The fact that three-year auctions occur only in the months of February, May, August, and November allows for a straightforward interpretation of the off-auction event peaks exhibited by the three-year cumulative abnormal returns. Figure 4.16 shows only the three-year frame from Figure 4.15. Inspection reveals off-auction peaks in cumulative changes in relative yields around three-year auctions occur 30 days before the auction date and 35 days after. The solid line marks these peaks between auctions in Figure 4.16.

Three-year auctions occur during the first half of February, May, August, or November. The average day of the auction is the $7.16 t h$, with standard deviation of 3.16 days. The graphic of Figure 4.16 shows the relationship of maturity events having an effect across maturities. The pattern marked by dark vertical bars corresponds to periods 30 days before and 35 days after three-year auction events. Thirty business days before three-year auction dates correspond on average to the 25.42th day in December, March, June, and September. The average day of the month for the 35th business day after three-year auctions equals the 24.99th day of March, June, September, and December. These dates align approximately to the auctions of two-and four-year notes, shown to exhibit a positive association with relative yields at the three-year horizon. Two-year auctions occur at the end of every month on 
average date of the 23.89th. Four-year auctions occur almost always on the March-JuneSeptember-December schedule, with the average date of the 23.44th of the month.

\subsubsection{Summary of Results Evidence of a Positive Relationship with Auction Events:}

The following subsections describe results from tests of cross and own-maturity effects between auctions and relative yields for a one-day event window. Equation (4.28) shows the test statistic for the hypothesis of no change in mean or variance, and (4.30) tests the hypothesis of no change in mean of relative yields at auction events. Test statistics greater than 1.96 suggest rejection of the null at the $5 \%$ level. The two tests statistics are in agreement in every case excluding the relationship between seven-year auctions and six-year yields.

First, the maturities where a positive relationship is observed are discussed, followed by a discussion of the results at horizons where the results do not show a clear relationship.

\section{One-year Relative Yields}

Relative yields at the one-year horizon show a statistically significant positive relationship with the 254 one-year treasury auctions held between 1981 and 2001. The average change in relative yield equals 0.81 basis points between the day before and of the auction. Auctions of one-year treasuries have a significant and positive effect on two-year relative yields corresponding with a 0.585 basis point increase in two-year yields relative to the average.

\section{Two-year Auctions}

The 323 two-year auctions events demonstrate positive own maturity effects, yielding an average increase in two-year relative yields equal to 0.5 basis points. A cross maturity effect is not observed with significance against the one-year relative yields, although two-year 
auctions are associated with significantly higher three and four-year relative yields of 0.49 and 0.36 basis points respectively.

\section{Three-year Auctions}

Eighty-seven auctions of three-year notes correspond to an average of 0.83 basis point increases in three-year relative yields, along with 1.6 and 1.3 basis point increases in the one and two-year relative yields respectively.

\section{Four-year Auctions}

Forty-one four-year auctions occur in the sample period between 1981 and 1991. The average increase in relative yields on the dates of four-year auctions equals 0.94 basis points. The auctions correspond with positive changes in five and six-year relative yields equal to 0.92 and 0.8 basis points respectively.

\section{Seven-year Auctions}

Forty-nine seven-year auctions occur during the sample period between 1981 and 1993. The auctions exhibit significant effects at the six through 15-year horizons. At each horizon the effect measures approximately one basis point of increase in the relative yield.

\section{Summary of Positive Relationship Results:}

The descriptions above describe the effect of one, two, three, four, and seven-year auctions on relative yields at own and neighboring maturities. In these five cases, auctions correspond with positive changes in relative yields, both at the maturity tranche of the auction and neighboring horizons. The results suggest a significant decrease in relative prices for existing bonds when new instruments providing similar cashflows are issued. 
A notable relationship exists between the four and seven-year horizons. Both maturities show strong own-horizon effects, with auctions affecting neighboring relative yields. Cross effects involving relative yields at the four-year horizon include the positive effect associated with three and two-year auctions. Both seven and four-year notes are auctioned almost exclusively in months other than the February, May, August, and November. Only one fouryear auction occurred in the first days of February. The relative isolation of these auctions helps explain the strong relationship with relative yields.

\section{Summary of Tests which Fail to Reject Null:}

Auctions at the five, ten, twenty, and thirty-year horizons do not correspond with significant increases in relative yields at auction maturity horizons.

In the case of the 20-year yields, a possible explanation is the small sample size and the period over which auctions occur. Only 16 auctions overlap with the sample availability of 20-year yields. The dates spanned by the sixteen 20-year auctions, 1981 through 1986, exhibit yields unrepresentative of the remainder of the sample. Monetary policy changes, a period of dramatically decreasing inflation rates, and declining interest rates may be a source of bias.

Another explanation for the failure to identify supply effects at the five, ten, and thirtyyear horizons is the effect of the auction calendar. Auctions for each of these three maturities occur primarily in February, May, August, or November. These months correspond to the majority of auction activity, where the size of auctions are dominated by the issues in the one, two, and three-year maturity horizons. Significant negative effects on the ten-year yields from auctions of one and three-year treasuries might contaminate the measurement of own price effects from the smaller in face value ten-year auctions. Of the 129 ten-year auctions, 
only 45 occur outside two business days of a three-year auction, and only 13 outside of two business days of an auction at either the three or five-year horizon.

The 30-year relative yields are subject to a combination of possible influences. First, each auction takes place during the busy February-May-August-November schedule. Second, since the 30-year bond is the longest maturity instrument issued, the discount cashflows matching the principal of the newly issued bonds do not exist. Third, the schedule of 30year auctions is far less regular than the other maturities. Between 1986 and 1994 auctions occur in each month in the February-May-August-November schedule. Between 1994 and 2006 the schedule decreases to include only February and August, adding November in 1996 through 1999, and returning to a schedule including both May and November in 2007. This irregularity suggests that the thirty-year schedule may retain some tactical component not obviously reflected in the schedules of other maturities. It is possible that measurement error from estimating these zero-coupon rates, the fact direct substitutes are unavailable, and the possibility that the auctions are more tactical than those at other maturities explains the absence of a clear relationship in the case of thirty-year relative yields.

\subsubsection{Non-parametric Test Statistics}

The empirical procedure outlined in Section 4.3 requires assumptions about the distribution and model of expected returns. Campbell et al. (1997) describe a nonparametric test based on the sign of the abnormal return.

Let $N$ equal the total number of events and $N^{+}$the number of cases where the $\widehat{C A R}$ is positive. Under the null hypothesis, that with equal probability $\widehat{C A R}$ will be positive or 
negative, the test statistic

$$
\theta^{*}=\left(\frac{N^{+}}{N}-0.5\right) \frac{N^{1 / 2}}{0.5}
$$

is asymptotically distributed $\mathcal{N}(0,1)$ as $N$ increases. The null hypothesis $H_{0}: p \leq 0.5$ where $p=\operatorname{Pr}(\widehat{C A R}>0)$ is rejected in favor of the alternative $H_{A}: p>0.5$ for a test of size $\alpha$ if $\theta^{*}>\Phi^{-1}(\alpha)$. Figure 4.17 shows nonparametric test statistics from equation (4.35) for tests of one-day changes in relative yields. The results compare with test statistics shown in Figure 4.9. The nonparametric statistics either rejects or fails to reject the null hypothesis for own maturity horizons in agreement with the parametric statistics at each of the nine auction horizons.

\subsection{Extensions}

\subsubsection{Auction Impact on Yields Adjusted for Expected Inflation}

It is clear from Figure 4.1 that yields across all maturity horizons have fallen considerably and fairly consistently between 1981 and 2008. This pattern can be explained in part by the change in expected inflation between 1981 and 2008.

Letting expectations of yields be modeled using ex post realized changes in the inflation rate,

$$
E_{t}\left(\Delta y_{t+1}^{(N)}\right)=\Delta \hat{\pi}_{t}
$$

equation (4.36) shows the expected change in the $N$-year yield as the change in ex post expected inflation between dates $t$ and $t+1$. The value of $\Delta \hat{\pi}_{t}$ equals the incremental change, or share of the change in expected inflation between the first and last date in the 
sample. Defining

$$
\hat{\pi}_{t}=\frac{1}{M}\left(\pi_{0}^{e}-\pi_{M}^{e}\right)
$$

with $t=0$ corresponding to January 1,1981 and $M=9861$, December $31,2007 .^{2}$ The annualized inflation rate, constructed from the All Urban Consumers CPI (CPIAUCNS) series at the St. Louis FRED, equals the change in log value of the non-seasonally adjusted consumer price index of all urban consumers reported each month. Expected inflation $\pi^{e}$ equals the geometric average of inflation over the previous year.

$$
1+\pi_{t}^{e}=\left(\prod_{i=0}^{11}\left(1+\pi_{t-i}\right)\right)^{\frac{1}{12}}
$$

Figure 4.18 summarizes the data on yields, inflation, and changes in discounted yields including an expected inflation risk adjustment. The top frame shows the discount yields for the two, ten, and thirty-year maturities, the 12-month rolling-average inflation rate as described in equation (4.38) and the trend in inflation between January 1981 and December 2007, the known rate of change in expected inflation over the sample period. The lower frame shows the difference between the yields at the two, ten, and thirty-year horizons and the maturity adjusted inflation rate,

$$
\mathbf{Y}(\pi)_{t}^{(N)}=y_{t}^{(N)}-\hat{\pi}_{t}
$$

Figure 4.19 shows the average cumulative changes in the inflation corrected yield curve, $\Delta \mathbf{Y}(\pi)_{t}^{(N)}$ for a 50 day window around each auction event. Cyclical patterns are evident surrounding the auction events, although a similar technique examining abnormal returns

\footnotetext{
${ }^{2}$ There are 9861 days between 1-1-1981 and 12-31-2007. The data for the study uses only business days, while the change in expected inflation is modeled as continuous over all days. The effect of this adjustment is that the change between Friday and Monday includes the correction for the preceding weekend.
} 
based on a zero-expected-mean specification

$$
\begin{gathered}
E\left(\Delta \mathbf{Y}(\pi)_{t}^{(N)}\right)=0 \\
\hat{\xi}_{t}^{(N)}=\Delta \mathbf{Y}(\pi)_{t}^{(N)}
\end{gathered}
$$

shows insignificance in tests at horizons. As in the relative yield specification, the variance estimator is the subsample variance from all days without an auction event within two business days. Figures 4.20 through 4.25 show results from an analogous set of tests examining the two and three-day changes in inflation corrected yields, along with tests for the change between days previous and subsequent to the auction event. These results do not suggest a strong relationship between auction events and yields corrected for inflation using the average decrease in the inflation rate.

Alternative specifications employing inflation expectations from the University of Michigan or Philadelphia Federal Reserve Bank find similar results. A plausible explanation is the frequency and precision mismatch of both the reported survey data and the mechanism by which market participants update their expectation of future inflation rates. The significant effect of auctions on relative yields is short lived and relatively small in comparison to the correction derived from monthly observations of consumer prices. The term structure of inflation expectations cannot be completely observed from the one or five year survey data, and derived daily changes in inflation expectation may be subject to measurement error larger than the observable effect of the auction event on yields. The average standard deviation of Michigan survey respondents estimates between 1979 and 2009 equals 4.64\%, with an average inter-quartile range of $3.5 \%$.

The use of TIPS zero-coupon yields in an effort to remove the inflation expectation 
approach is complicated by a number of factors. The sample for one through thirty-year TIPS yields begins in 2004, and differences between these real yields and the nominal offthe-run rates may not be interpreted as breakeven inflation due to considerable differences in liquidity between bonds trading in these separate markets. Additional robustness checks of the off-the-run results using alternate subsets or individual yields as level corrections produce results similar (and often stronger) than those from Section 4.5. The normalization by the average yields is favored for its parsimony and avoidance of maturity specific effects which would be encountered using yields of a specific instrument or horizon. As liquidity in the TIPS market becomes better understood, the real yields may provide an additional avenue for analysis.

\subsubsection{On-the-run Zero-Coupon Yields}

Bloomberg Professional supplies a collection of zero-coupon yields constructed from a sample of on and off-the-run treasury prices for the one, two, three, four, five, six, seven, eight, nine, ten, fifteen, twenty, and thirty-year maturity horizons. The daily coverage of the on/off-therun zero-coupon curve begins April 28, 1989, with spot rates calculated using the on-the-run issue for each maturity, where available, and off-the-run issues with nearest maturity for those horizons where on-the-run issues do not exist. Auction events of neighboring maturities correspond to changes in which off-the-run bond is used in the construction of the curve. Figure 4.26 show a subset of the available yields over the sample period, along with the distribution and size of auction events. There are zero twenty-year auctions during this period, and only seven and 16 auctions at the four and seven-year horizons respectively.

The zero-coupon yields are constructed from the par coupon curve using a proprietary 
algorithm. The documentation on zero-coupon yield curves in the Bloomberg documentation describe the procedure for the construction. The par coupon curve is put into a canonical form by fitting yields at 6-month intervals across the 30-year span of the yield curve. The canonical coupon curve is stripped into a spot curve specified in bond-equivalent yields. While the exact methodology of the construction of this off-the-run curve is unavailable, the relationship between the continuously compounded yields of Gürkaynak et al. (2007) and on/off-the-run (converted to continuously compounded rates) shown in Figure 4.27 exhibits properties in line with expectations and previous research. Figure 4.28 shows the available data for the ten-year horizon, along with a closer detail of the premium between the on and off-the-run yields, with auction events marked by vertical lines.

Figure 4.29 shows the cumulative change of relative yields,

$$
\overline{C A R}^{(N)}(-5, m)=\sum_{\tau=-5}^{m}\left({\overline{\Delta^{o} \mathbf{Y}}}_{\tau}^{(N)}\right) \text {, for } m \in\{-5 . .4\} .
$$

for this off/on-the-run series, where

$$
{ }^{o} \mathbf{Y}_{t}^{(N)}={ }^{o} y_{t}^{(N)}-\frac{1}{10} \sum_{k=1}^{10}{ }^{o} y_{t}^{(k)},
$$

and ${ }^{o} y_{t}^{(N)}$ is the yield constructed from the benchmark off/on-the-run curve. Figure 4.30 shows the cumulative change over a 50 day window.

One through ten-year yields construct the average level of interest rates. Coverage of the on/off-the-run yields does not include the 11 through 14 or 21 through 29-year rates, and the 20-year on/off-the-run rate exhibits a jump in 1999 where additional bond prices are included in the estimation data used to construct the yields. This choice is not particularly disruptive since zero twenty-year auctions occur during the subsample. ${ }^{3}$

\footnotetext{
${ }^{3}$ The empirical results from studies of the Gürkaynak et al. (2007) off-the-run yield curve using relative yields constructed from only the one through ten-year rates produce nearly identical results as those using the entire available yield curve.
} 
Figures 4.31, 4.32, and 4.33 show results for hypothesis tests on the one, two, and threeday changes in relative yields from the on/off-the-run curve. The one-day change at auction fails to reject the null of no effect on relative yields at the two, four, and ten-year horizon. In contrast to the off-the-run results, the five-year relative yields display a significantly negative relationship with five-year auctions, and the thirty-year rate is positively related to auctions for the off/on-the-run curve where no relationship is detected for off-the-run yields.

\subsubsection{Departures from Off-the-run Results}

The first three tests, against the null hypothesis of no effect on relative yields at auction horizons over the one, two, and three-day changes leading up to the auction event, are considerably different from the off-the-run results. Where the off-the-run yields show a positive difference at the shorter-term horizons leading up to the auction, this effect is largely unobserved in the on/off-the-run data. Only one and thirty-year relative yields are significantly higher between three days before and the day of the auction. For off-the-run bonds, this relationship is evident at the one, two, four, five, and seven-year horizons.

Figures 4.34 and 4.35 show test results using off/on-the-run relative yields at auction horizons. Relative yields are significantly lower than the day before the auction event at the five, ten, and thirty-year horizons. These results contrast the off-the-run results, where yields demonstrated no significant difference for changes between one day previous and one or more days following the auction. The results based on the curve derived from mainly on-the-run bonds shows a significant negative relative yield effect between the previous and two days following the auction, suggesting the liquidity premium paid for newly issued five, ten, and thirty-year bonds is more persistent than the absorption effect observed in the off-the-run 
study. As Figure 4.37 shows, the change in relative yields between the previous and four days following the auction event is significantly negative for the five, ten, and thirty-year horizon. The positive relationship of the three-year yields at that interval may be explained by the same cross-maturity effect observed from the off-the-run results.

Comparing the on and off-the-run yields directly is problematic due to the differences in construction of the data. However, the implications of these two sets of results will be reflected in direct estimation of the effect of auction events on the on and off-the-run yield spread. A similar battery of tests finds the own-maturity effect of auctions to be significantly negative at the one-year horizon over the preceding and several days following the auction event. This effect suggests that the positive relationship observed of one-year auctions on the one-year rates dominates the same positive relationship observed in the off-the-run yield data. One explanation for this effect is the segmentation of the treasury bill and longer term instrument market. The one-year bonds are issued once every four weeks, and the treasury bill auction schedule is much more closely linked to these short-term instruments. While a ten or thirty-year instrument will be on-the-run for several months, the one-year bond's status will be quickly downgraded, and the instrument will be exposed to more activity in terms of neighboring auction events or reopenings of the same issue. Insignificance of oneday changes in the on and off-the-run spread at all horizons other than one and two years is consistent with the effect of the liquidity premium and absorption effect working in opposite directions.

At the five, ten, and thirty-year horizons, the effect on the spread between the off and onthe-run yields is positive and the effect persists comparably to the results from on/off-the-run relative yield tests, consistent from the implications of the independent results above. 


\subsection{Conclusion}

A set of high-frequency discount yields, spanning the term structure serves an invaluable function in economic research. Results reported here show that relative discount yields, derived from prices of at least twice off-the-run U.S. Treasuries are not insulated from the institutional effects of the auction calendar. The cycles of the institutional framework correspond to a statistically significant pattern of variation in relative yields affecting every maturity horizon. Additionally, the results suggest an absorption effect related to the increase in cashflows at auction horizons at most maturities. Although the effect is short lived, the impact could exert unexpected influence on empirical results, especially for phenomenon which are associated with the auction schedule either through design or by coincidence.

Additionally, an analogous event study addresses yields constructed from a smaller collection of primarily on-the-run treasuries. These yields exhibit a different relationship with auction events. Similar to the evidence from the off-the-run yields, the days preceding an auction event correspond to significant increases in relative yields at most horizons, the relative yields at the benchmark five, ten, and thirty-year horizons exhibit significant declines in the period following the auction event. In contrast, relative yields derived from the offthe-run curve do not exhibit changes in relative yields significantly different from zero two or three days after the auction events at all but the seven-year horizon. The influence of auction events has a temporary and significant effect on the off-the-run yield curve. 


\section{Figure 4.1: Yield Curve Data Sample}

The top frame shows a sample of data on daily discount yields of Gürkaynak et al. (2007). These continuously compounded zero-coupon discount rates are computed using off-the-run treasuries. The two vertical lines show the periods where 16 through 20-year rates (in 1981), and where 21 through 30-year rates are included (in late 1985).

The bottom frame shows the difference between the one and 2,7,10,20, and 30-year rates.
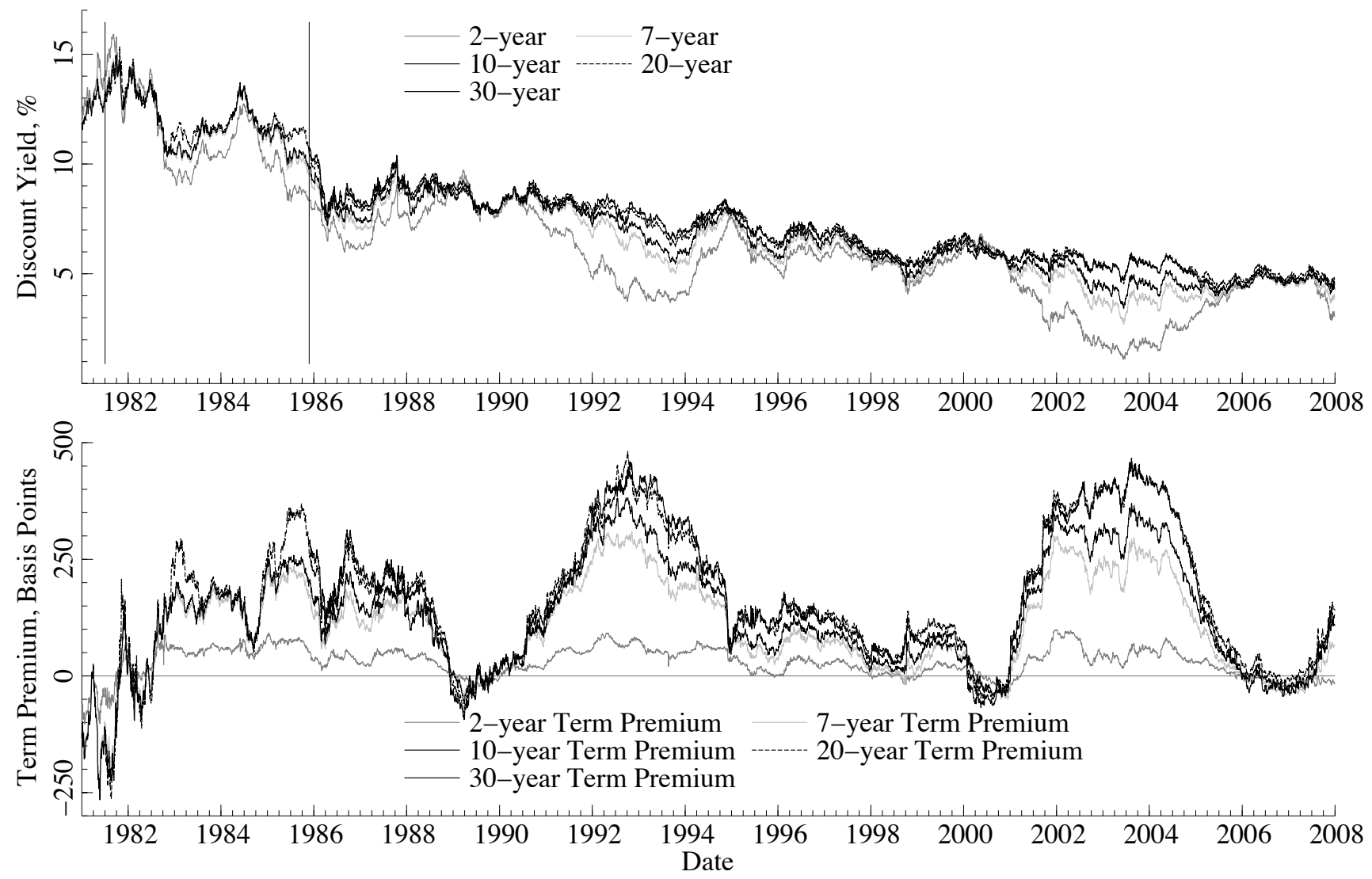


\section{Figure 4.2: Auction Event Timing Across Maturity Horizons.}

The figure below shows the timing of Treasury Auctions between January 1981 and 2008. Each symbol in the top frame represents an auction at the maturity horizon shown in the vertical axis. The bottom frame shows the total quantity accepted in each auction, in billions of dollars. The symbols in the lower frame correspond to symbols used for each maturity horizon shown in the top frame. The two vertical bars show the dates that coverage begins for 16 through 20-year (in 1981) and 21 through 30-year (late 1985) discount rates.

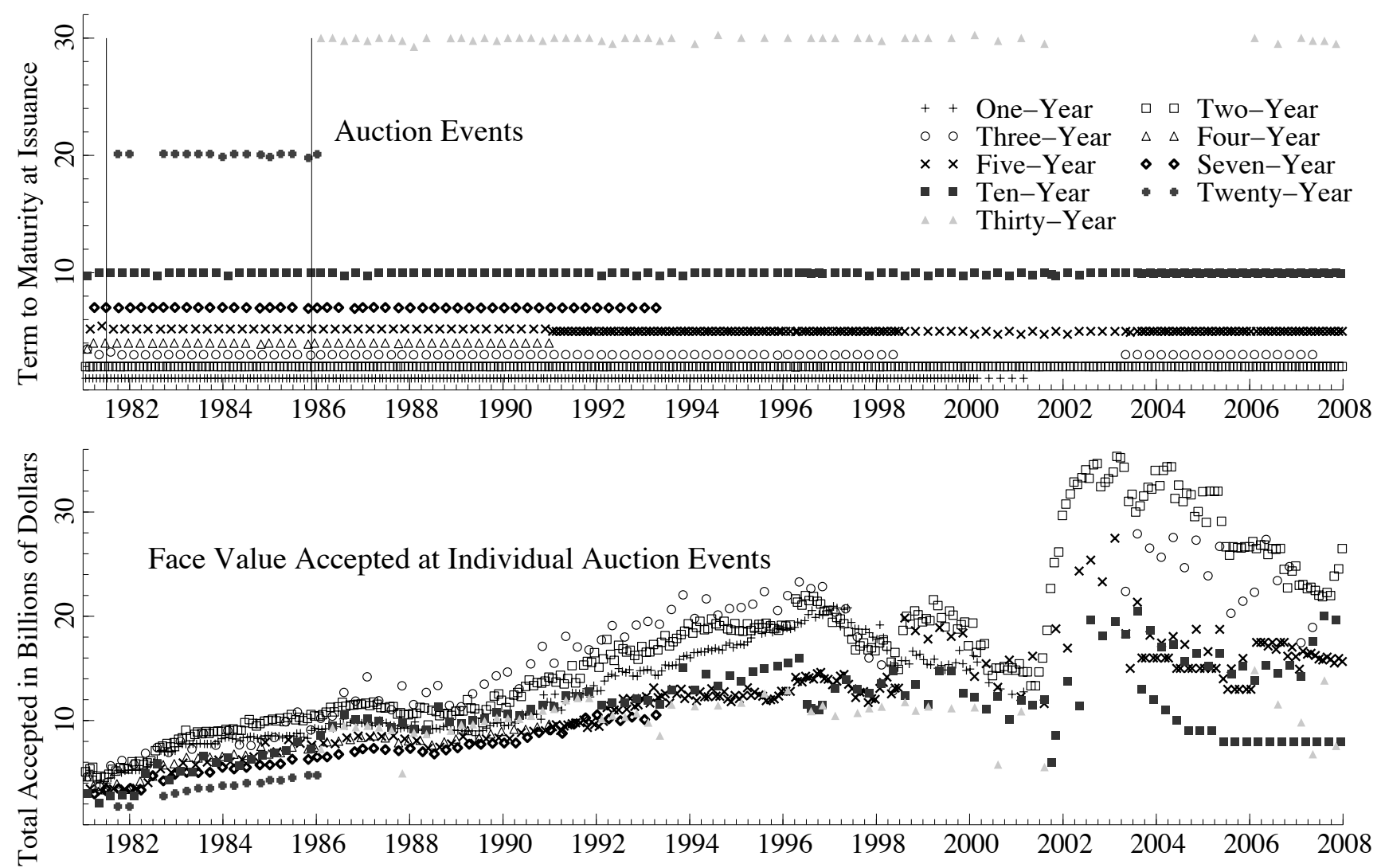




\section{Figure 4.3: Monthly Auction Distribution by Maturity Horizon.}

The figure below shows the distribution of auction events across calendar months for each maturity horizon. Each frame corresponds to a maturity horizon. The horizontal axis corresponds to the calendar month, the vertical axis, the number of auction events in the sample.
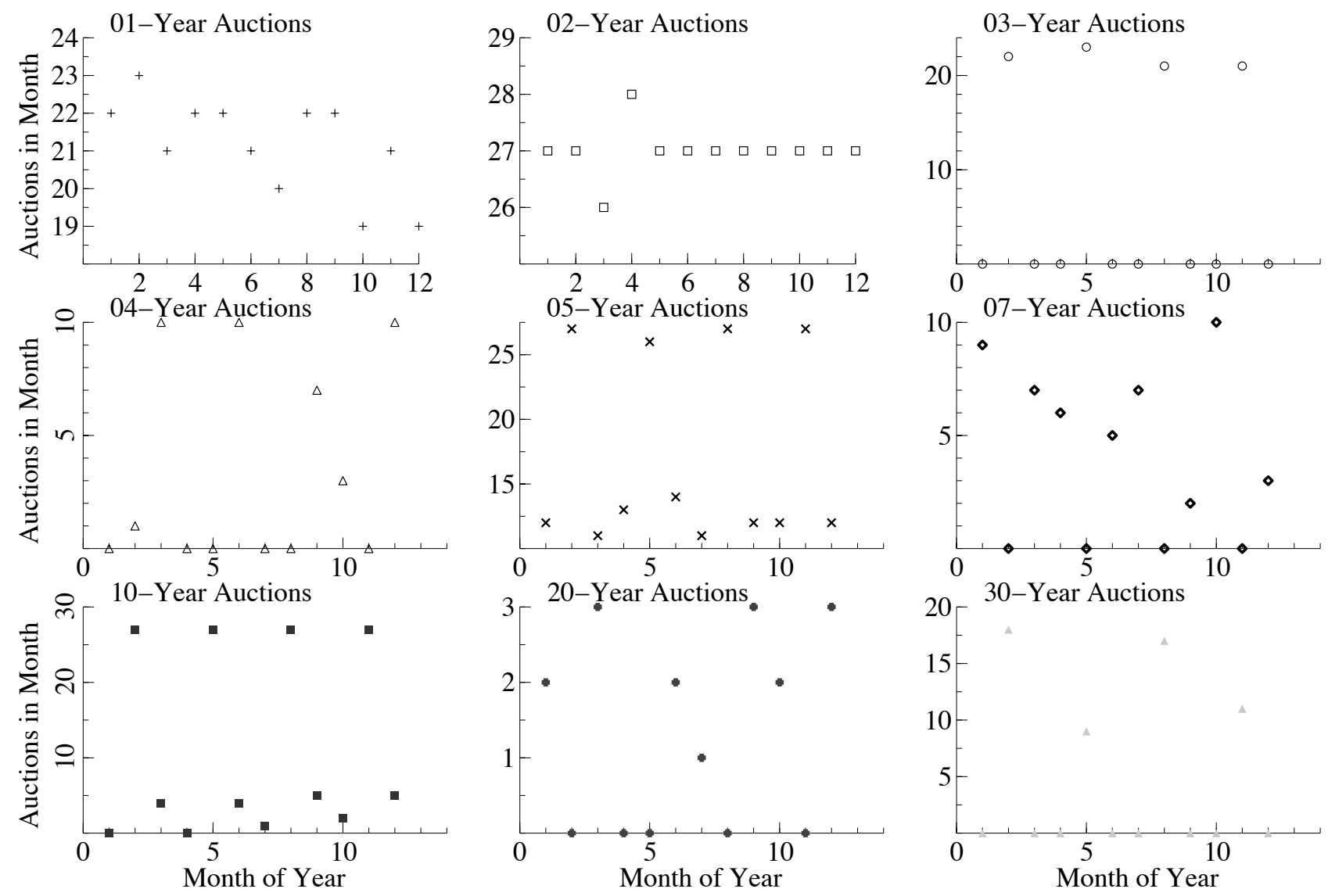
Figure 4.4: Face Value of Auction Events by Month.

The top frame shows the face value of all auctions during each month between January 1981 and December 2007. The bottom frame shows a subsample of the data for the dates between January 1993 and December 1996. Ticks on the horizontal axis correspond to end of months. Zero auctions occur in March of 1996 during due to the unfinished legislative debate to increase the Federal debt ceiling.

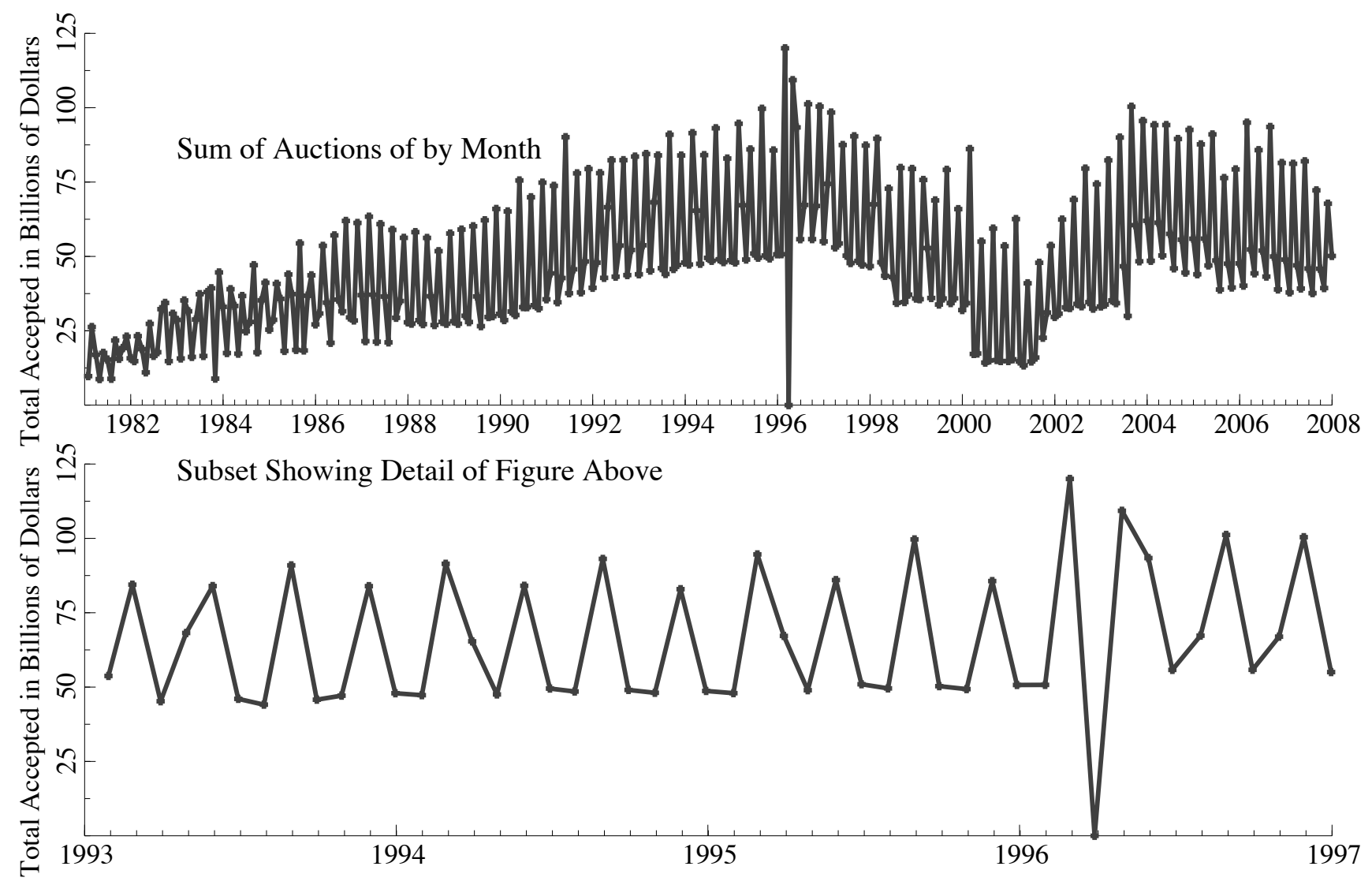




\section{Figure 4.5: Auction Event Timing Across Maturity Horizons.}

The figures below show a subsample from Figure 4.2. The top frame shows the timing of Treasury Auctions between July, 1990 and June, 1991. Each symbol in the top frame represents an auction at the maturity horizon shown in the vertical axis.

The bottom frame shows the total quantity accepted in each auction, measured on the vertical axis in billions of dollars. The symbols in the lower frame correspond to symbols used for each maturity horizon shown in the top frame.
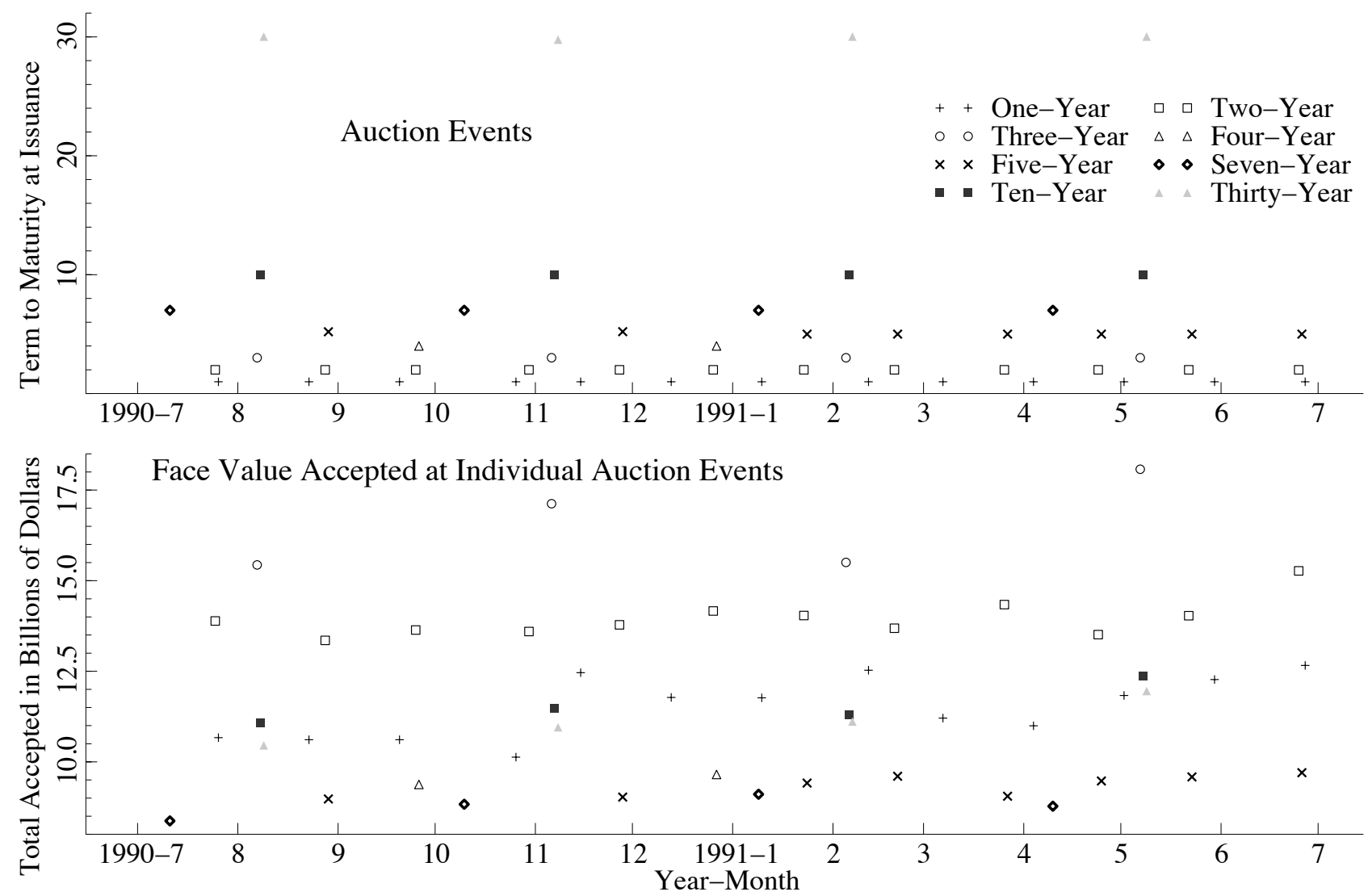


\section{Figure 4.6: Auction and Announcement Timing}

The figure below shows the time between the announcement and auctions of Treasury Auctions between January 1981 and 2008.

The top frame shows the relationship between maturity and days between announcement and auction. The vertical axis shows the maturity horizon in years, and the horizontal axis the days between announcement and auction.

The bottom frame shows the relationship of days between announcement and issuance and days between the announcement and auction. The dashed diagonal is the 45 degree line.

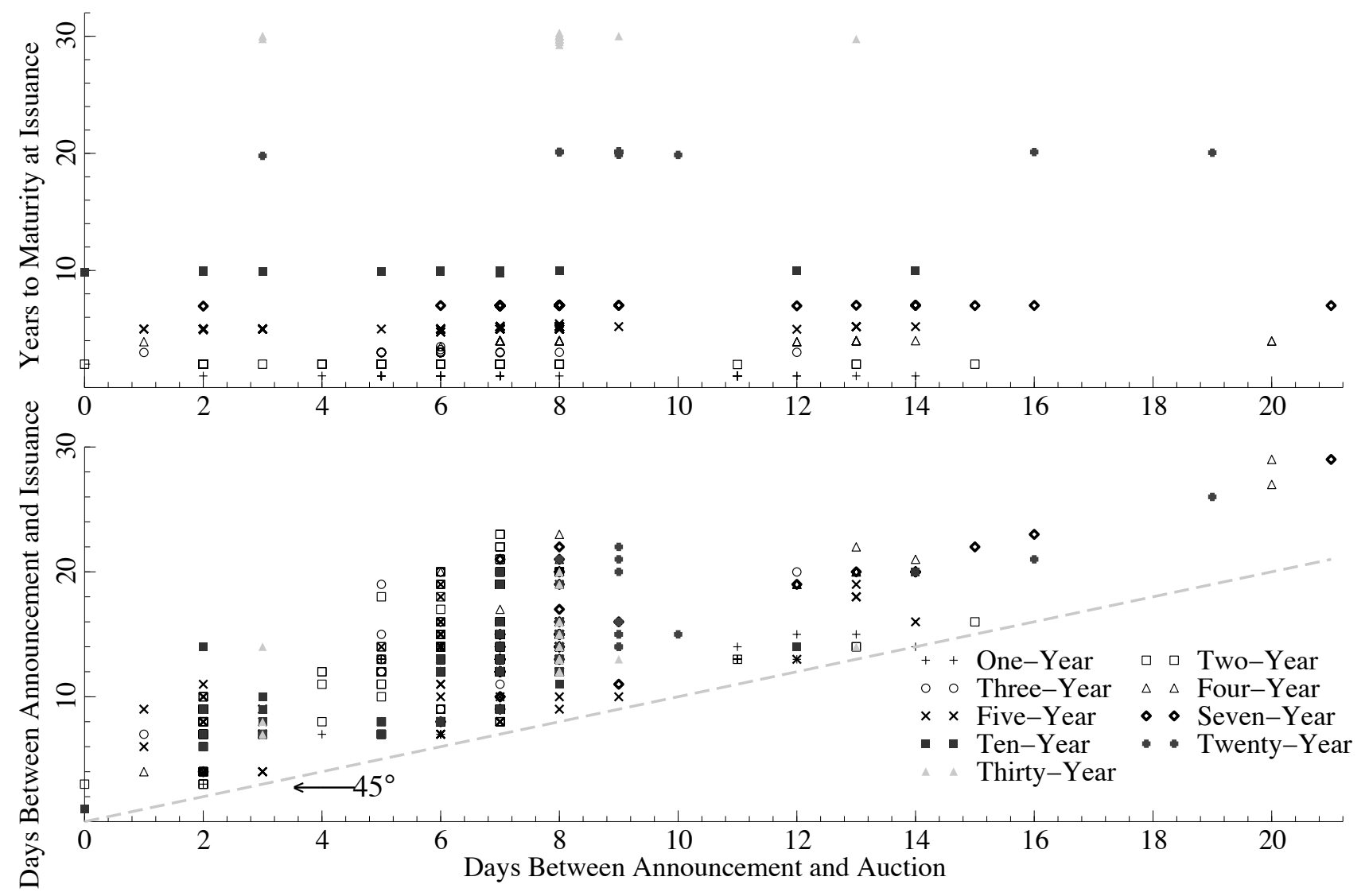




\section{Figure 4.7: Relative Yield Data}

The top frame of the figure below shows discount yield deviations from mean expressed in basis points for the daily discount yields of Gürkaynak et al. (2007). These continuously compounded zero-coupon discount rates are computed from off-the-run treasury security prices.

$$
\mathbf{Y}_{t}^{(N)}=y_{t}^{(N)}-\frac{1}{N} \sum_{k=1}^{N} y_{t}^{(k)}
$$

where $y_{t}^{(n)}$ is the $n$-period discount yield at time $t$. The average $\frac{1}{N} \sum_{k=1}^{N} y_{t}^{(k)}$, takes $N$ equal to the longest maturity available at time $t$.

The bottom frame shows first differences of the deviations from mean,

$$
\Delta \mathbf{Y}_{t}^{(N)}=\mathbf{Y}_{t}^{(N)}-\mathbf{Y}_{t-1}^{(N)}
$$

in basis points. The time series are constructed from the discount yields of Gürkaynak et al. (2007).
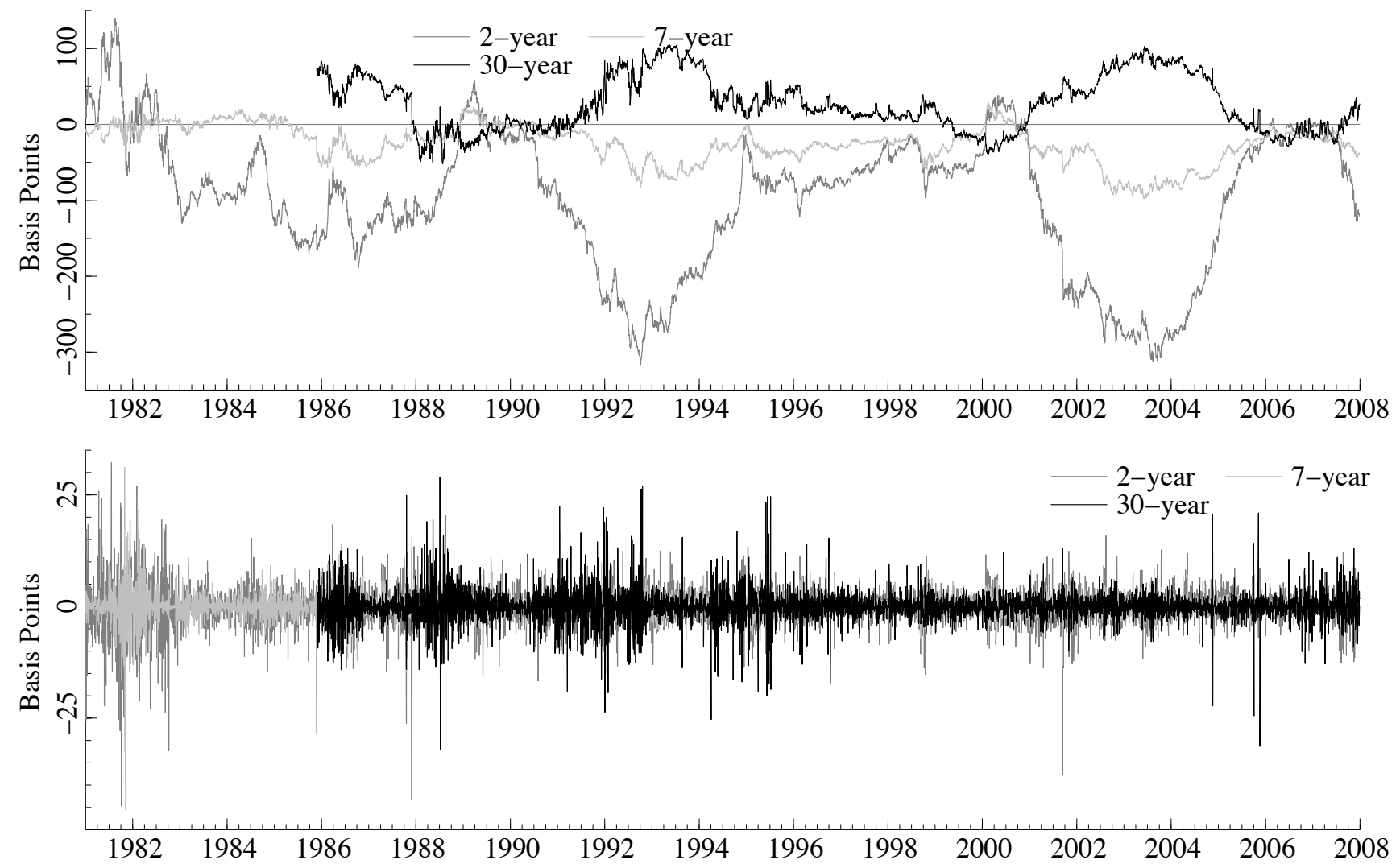


\section{Figure 4.8: Cumulative Changes in Relative Yield}

The figure shows the cumulative changes in relative yields over a period beginning 5 business days before until 4 days following an auction, expressed in basis points. Each frame shows the period around the auction event of the maturity horizon shown in the top left corner. Dark solid vertical lines represent auction events, dashed lines announcements and light solid lines issue dates after auctions.

$$
\overline{C A R}^{(N)}(-5, m)=\sum_{\tau=-5}^{m}\left(\overline{\Delta \mathbf{Y}}_{\tau}^{(N)}\right), \text { for } m \in\{-5 . .4\}
$$
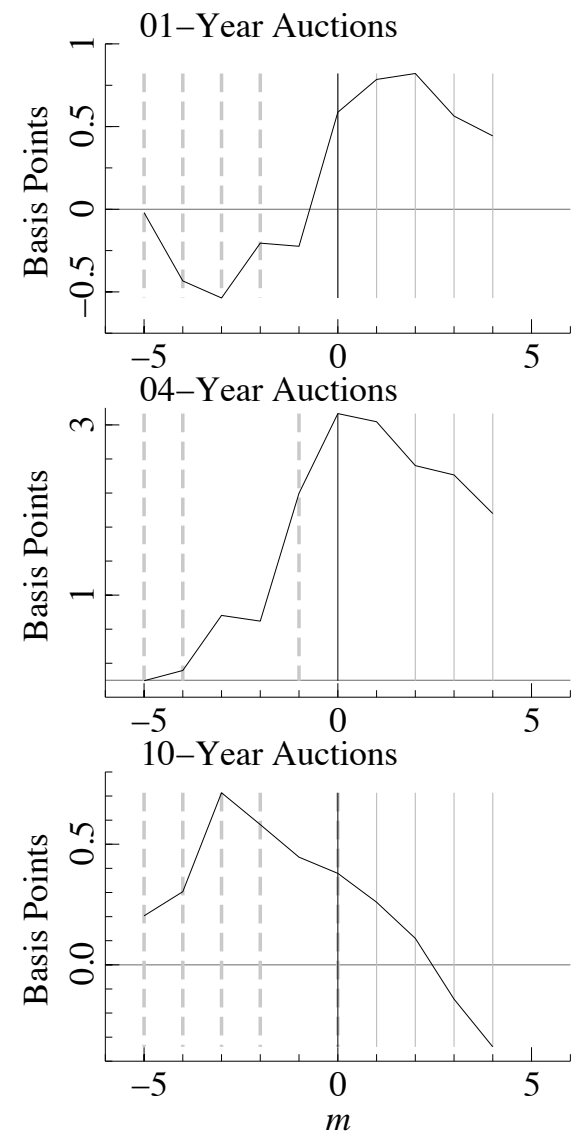
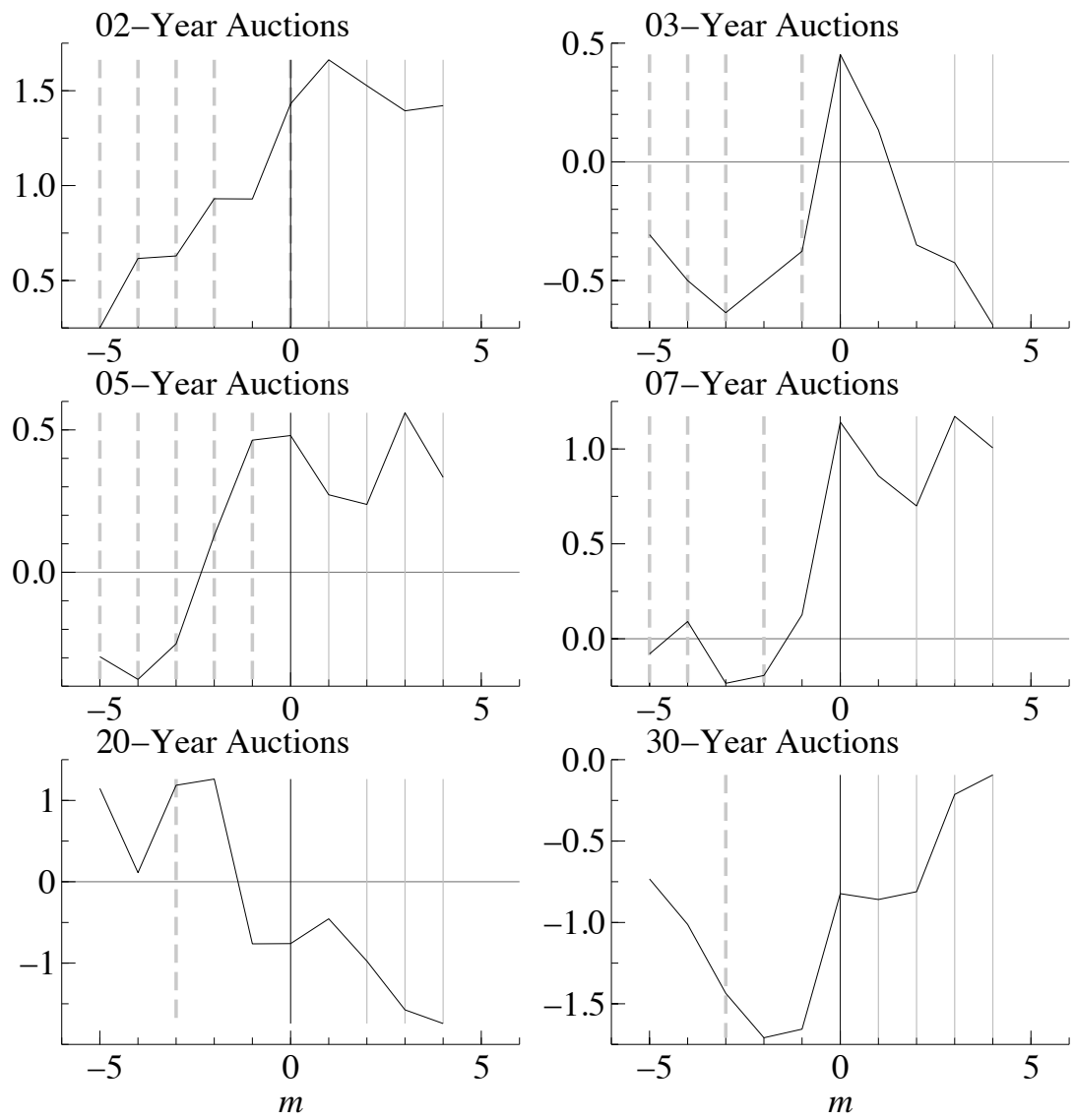


\section{Figure 4.9: Test Statistics for Auction Event Studies on Relative Yields.}

The frames below show test statistics against the null hypothesis of no effect of auctions on relative yields. Each point on the curve represents the t-statistic for the hypothesis that the auction event at the horizon shown in the top corner has no effect on the relative yields shown across the horizontal axis. The solid line shows the test against the hypothesis of no change in either the mean or variance,

$$
\theta_{1}=\frac{\frac{1}{k} \sum_{i=1}^{k} \Delta \mathbf{Y}_{i}^{(N)}}{\sqrt{\operatorname{Var}\left(\overline{\Delta \mathbf{Y}}_{j}^{(N)}\right)}}
$$

where each $\mathbf{Y}_{k}^{(N)}$ is the yield in excess of the average on the day of the auction event, and each $j$ are dates at least 3 days before or after any auction. The dotted lines in each frame show the test statistic against the null of no change in the mean

$$
\theta_{1}^{\prime}=\frac{\frac{1}{k} \sum_{i=1}^{k} \Delta \mathbf{Y}_{i}^{(N)}}{\sqrt{\frac{1}{N^{2}} \sum_{h=1}^{N}\left(\Delta \mathbf{Y}_{h}^{(N)}-\frac{1}{l} \sum_{i=1}^{l} \Delta \mathbf{Y}_{l}^{(N)}\right)^{2}}}
$$

This test does not rely on the subsample of dates not within two days of the auction event to produce an estimate of the variance. The horizontal axis shows the response horizon, each frame represents auctions in different maturity classes. Auctions within 6 months of a particular maturity horizon are considered within the nearest class. For example, 29 year 6-month auctions are included within the 30 year category.
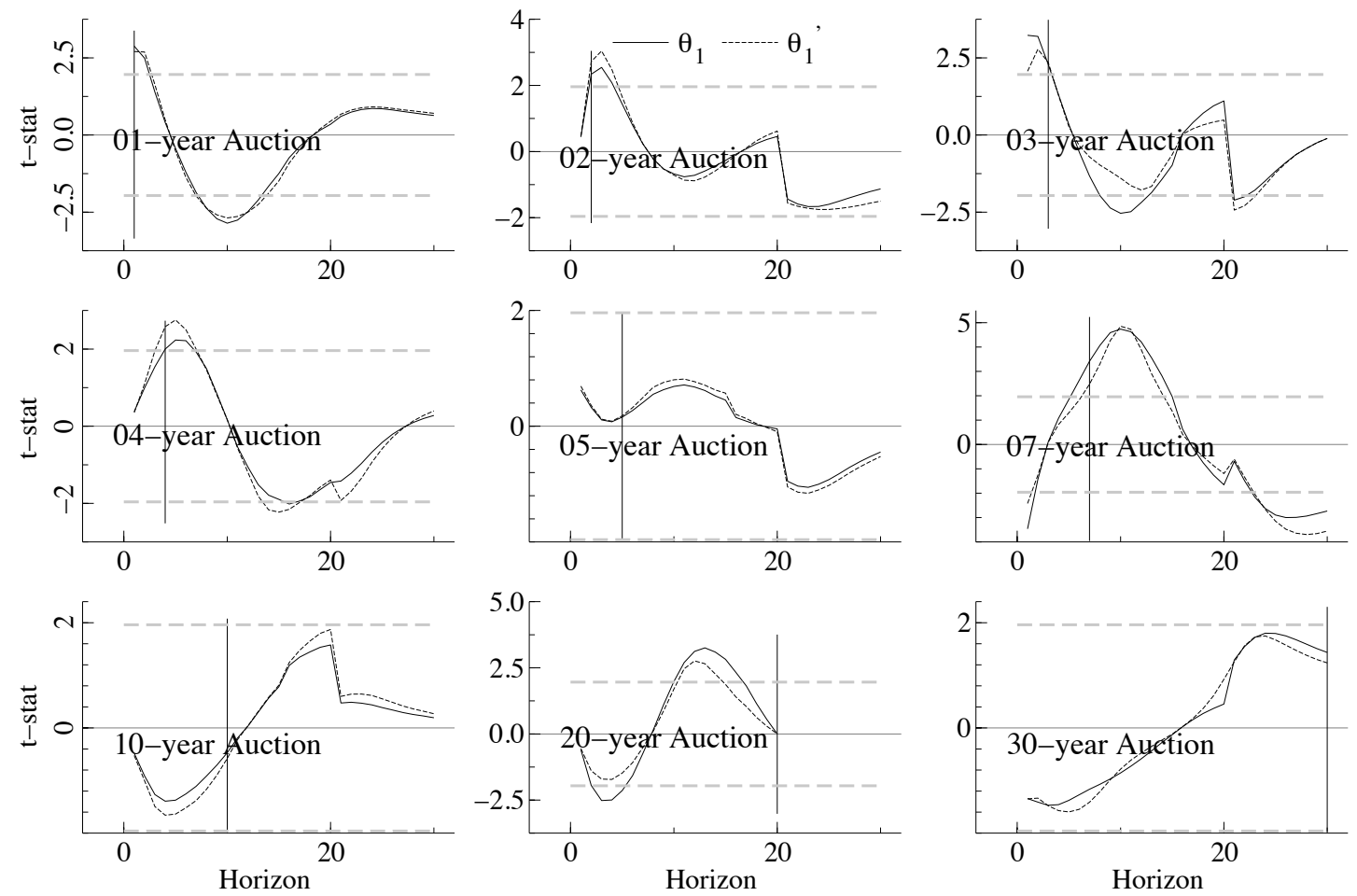
Table 4.1: Auction Size and Relative Yield OLS Results.

The table below shows the results of ordinary least squares estimates of the relationship between auction size at a particular maturity horizon and the change in relative yield.

$$
\Delta \mathbf{Y}_{k}^{(N)}=\alpha^{(N)}+\beta^{(N)}\left(S_{k}^{(N)}-\bar{S}_{k}^{(N)}\right)+\varepsilon_{k},
$$

\begin{tabular}{|c|c|c|c|c|c|c|}
\hline $\begin{array}{l}\text { AUCTION } \\
\text { HORIZON }\end{array}$ & VARIABLE & Estimate & ST.ERR. & $t$-stat & $p$-VALUE & $R^{2}$ \\
\hline \multirow{2}{*}{ 1-year } & $\overline{\alpha^{(1)}}$ & 0.00810827 & "0.00297869 & 2.72209429 & 0.00693971 & \multirow{2}{*}{0.0134} \\
\hline & $S^{(1)}-\bar{S}^{(1)}$ & -0.00123738 & 0.00082975 & -1.49127461 & 0.13714011 & \\
\hline \multirow{2}{*}{ 2-year } & $\alpha^{(2)}$ & 0.00501218 & 0.00179174 & 2.72516022 & 0.00678170 & \multirow{2}{*}{0.0011} \\
\hline & $S^{(2)}-\bar{S}^{(2)}$ & -0.00013706 & 0.00024168 & -0.56712942 & 0.57102511 & \\
\hline \multirow{2}{*}{ 3-year } & $\alpha^{(3)}$ & 0.00829705 & 0.00352987 & 2.35052232 & 0.02106282 & \multirow{2}{*}{0.0003} \\
\hline & $S^{(3)}-\bar{S}^{(3)}$ & 0.00008514 & 0.00070641 & 0.12053141 & 0.90434666 & \\
\hline \multirow{2}{*}{ 4-year } & $\alpha^{(4)}$ & 0.00936435 & 0.00362084 & 2.58623600 & 0.01355168 & \multirow{2}{*}{0.0037} \\
\hline & $S^{(4)}-\bar{S}^{(4)}$ & -0.00082795 & 0.00259242 & -0.31937336 & 0.75114791 & \\
\hline \multirow{2}{*}{ 5-year } & $\alpha^{(5)}$ & 0.00029270 & 0.00162983 & 0.17958849 & 0.85765837 & \multirow{2}{*}{0.0001} \\
\hline & $S^{(5)}-\bar{S}^{(5)}$ & -0.00005741 & 0.00053440 & -0.10742073 & 0.91456343 & \\
\hline \multirow{2}{*}{ 7-year } & $\alpha^{(7)}$ & 0.01014952 & 0.00409662 & 2.47753833 & 0.01688048 & \multirow{2}{*}{0.0001} \\
\hline & $S^{(7)}-\bar{S}^{(7)}$ & 0.00014630 & 0.00307886 & 0.04751843 & 0.96230139 & \\
\hline \multirow{2}{*}{ 10-year } & $\alpha^{(10)}$ & -0.00069413 & 0.00119819 & -0.57932000 & 0.56341585 & \multirow{2}{*}{0.0001} \\
\hline & $S^{(10)}-\bar{S}^{(10)}$ & -0.00006333 & 0.00040879 & -0.15491038 & 0.87714183 & \\
\hline \multirow{2}{*}{ 20-year } & $\alpha^{(20)}$ & 0.00002792 & 0.01426050 & 0.00195762 & 0.99846567 & \multirow{2}{*}{0.0174} \\
\hline & $S^{(20)}-\bar{S}^{(20)}$ & 0.00848717 & 0.01786987 & 0.47494280 & 0.64215176 & \\
\hline \multirow{2}{*}{ 30-year } & $\alpha^{(30)}$ & 0.00722586 & 0.00582310 & 1.24089613 & 0.22021338 & \multirow{2}{*}{0.0061} \\
\hline & $S^{(30)}-\bar{S}^{(30)}$ & 0.00181655 & 0.00291414 & 0.62335717 & 0.53577458 & \\
\hline
\end{tabular}


Figure 4.10: Auction Event Studies on Two-day Changes in Relative Yields. The frames below show test statistics against the null hypothesis of no effect of auctions on the twoday change in relative yields. Each point on the curve represents the t-statistic for the hypothesis that the auction event at the horizon shown in the top corner has no effect on the relative yields shown across the horizontal axis. The solid line shows the test against the hypothesis of no change in either the mean or variance of the relative yield between two days before and the day of the auction

$$
\theta_{1}=\frac{\frac{1}{k} \sum_{i=1}^{k} \Delta_{2} \mathbf{Y}_{i}^{(N)}}{\sqrt{\operatorname{Var}\left(\overline{\Delta_{2} \mathbf{Y}_{j}^{(N)}}\right)}}
$$

where each $\Delta_{i} \mathbf{Y}_{k}^{(N)}=\mathbf{Y}_{k}^{(N)}-\mathbf{Y}_{k-i}^{(N)}$, the change in yield in excess of the average on the day of the auction event, and each $j$ are dates at least 4 days before or after any auction. The dotted lines in each frame show the test statistic against the null of no change in the mean

$$
\theta_{1}^{\prime}=\frac{\frac{1}{k} \sum_{i=1}^{k} \Delta_{2} \mathbf{Y}_{i}^{(N)}}{\sqrt{\frac{1}{N^{2}} \sum_{h=1}^{N}\left(\Delta_{2} \mathbf{Y}_{h}^{(N)}-\frac{1}{l} \sum_{i=1}^{l} \Delta_{2} \mathbf{Y}_{l}^{(N)}\right)^{2}}}
$$

This test does not rely on the subsample of dates not within two days of the auction event to produce an estimate of the variance. The horizontal axis shows the response horizon, each frame represents auctions in different maturity classes. Auctions within 6 months of a particular maturity horizon are considered within the nearest class.
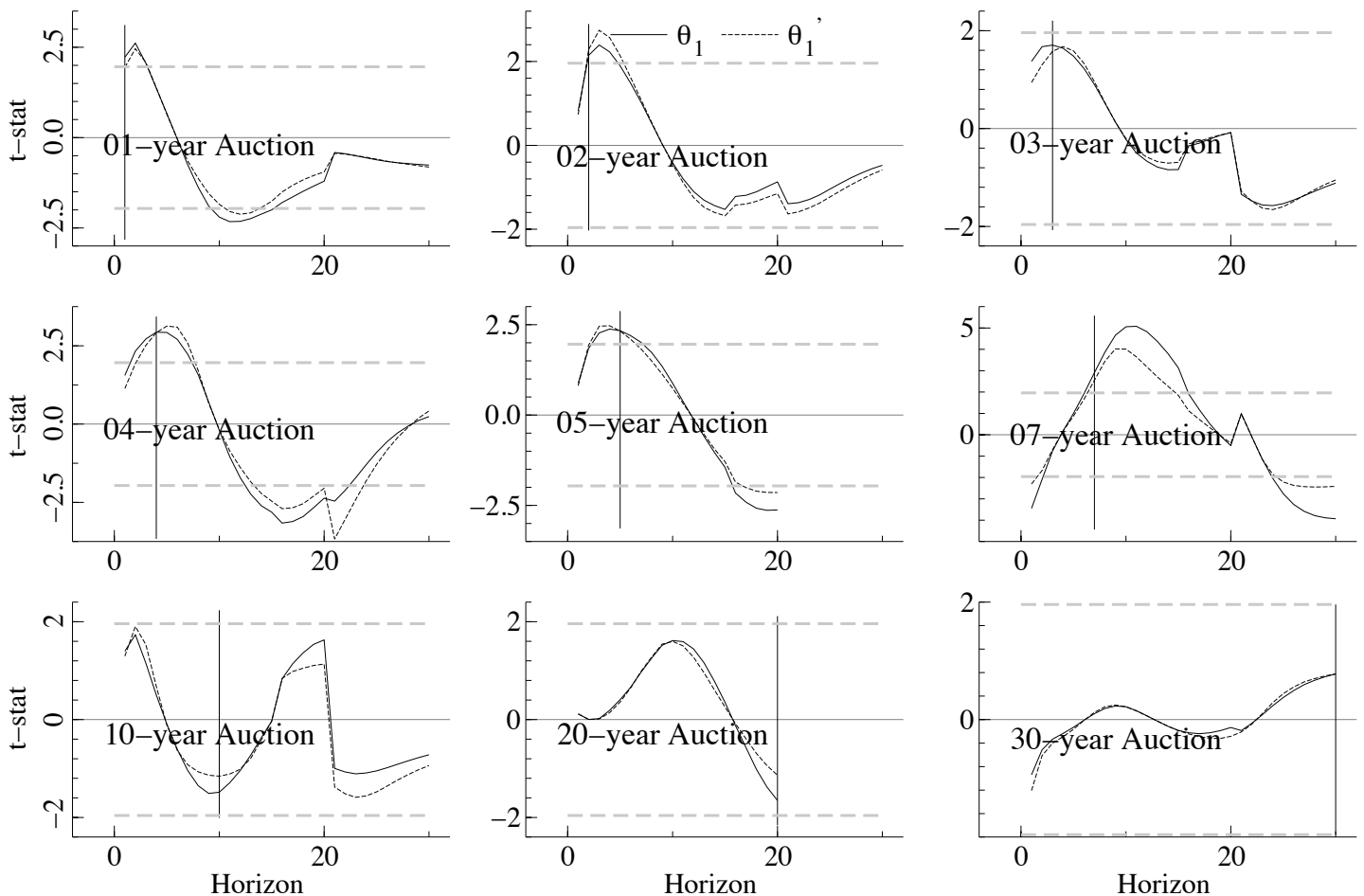


\section{Figure 4.11: Auction Event Studies on Three-day Changes in Relative Yields.} The frames below show test statistics against the null hypothesis of no effect of auctions on relative yields. Each point on the curve represents the t-statistic for the hypothesis that the auction event at the horizon shown in the top corner has no effect on the relative yields shown across the horizontal axis. The solid line shows the test against the hypothesis of no change in either the mean or variance of the change in relative yield between three days before and the day of the auction.

$$
\theta_{1}=\frac{\frac{1}{k} \sum_{i=1}^{k} \Delta_{3} \mathbf{Y}_{i}^{(N)}}{\sqrt{\operatorname{Var}\left(\overline{\Delta_{3} \mathbf{Y}_{j}^{(N)}}\right)}}
$$

where each $\Delta_{i} \mathbf{Y}_{k}^{(N)}=\mathbf{Y}_{k}^{(N)}-\mathbf{Y}_{k-i}^{(N)}$, the change in yield in excess of the average on the day of the auction event, and each $j$ are dates at least 5 days before or after any auction. The dotted lines in each frame show the test statistic against the null of no change in the mean

$$
\theta_{1}^{\prime}=\frac{\frac{1}{k} \sum_{i=1}^{k} \Delta_{3} \mathbf{Y}_{i}^{(N)}}{\sqrt{\frac{1}{N^{2}} \sum_{h=1}^{N}\left(\Delta_{3} \mathbf{Y}_{h}^{(N)}-\frac{1}{l} \sum_{i=1}^{l} \Delta_{3} \mathbf{Y}_{l}^{(N)}\right)^{2}}}
$$

The horizontal axis shows the response horizon, each frame represents auctions in different maturity classes. Auctions within 6 months of a particular maturity horizon are considered within the nearest class. For example, 29 year 6-month auctions are included within the 30 year category.
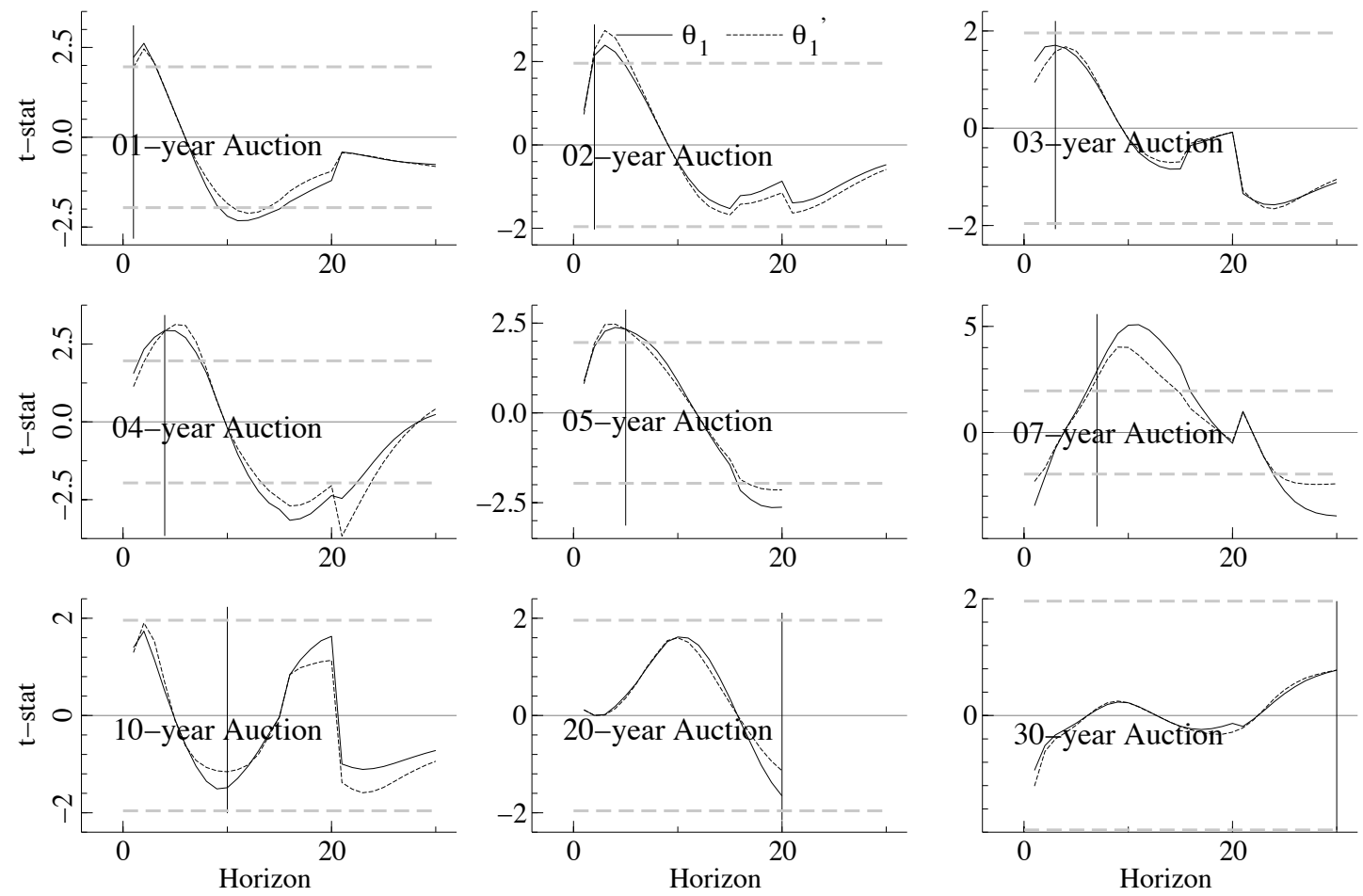
Figure 4.12: Changes in Relative Yields Between Previous and Following Day.

The frames below show test statistics against the null hypothesis of no effect of auctions on relative yields. Each point on the curve represents the t-statistic for the hypothesis that the auction event at the horizon shown in the top corner has no effect on the relative yields shown across the horizontal axis. The solid line shows the test against the hypothesis of no change in either the mean or variance of the change in relative yield between one day before until one day after the auction event.

$$
\theta_{1}=\frac{\frac{1}{k} \sum_{i=1}^{k} L^{-1}\left(\mathbf{Y}_{i}^{(N)}\right)-L\left(\mathbf{Y}_{i}^{(N)}\right)}{\sqrt{\operatorname{Var}\left(\overline{L^{-1}\left(\mathbf{Y}_{i}^{(N)}\right)-L\left(\mathbf{Y}_{i}^{(N)}\right)}\right)}}
$$

where $L(\cdot)$ is the lag operator, and each $\left.\mathbf{Y}_{k}^{(N)}\right)$ is the $k^{t h}$ auction event. $L^{-1}\left(\mathbf{Y}_{i}^{(N)}\right)-L\left(\mathbf{Y}_{i}^{(N)}\right)$ equals the change in yield in excess of the average between the day before of the auction event and the next business day. Each $j$ are dates at least 2 days before or after any auction. The dotted lines in each frame show the test statistic against the null of no change in the mean

$$
\theta_{1}^{\prime}=\frac{\frac{1}{k} \sum_{i=1}^{k} L^{-1}\left(\mathbf{Y}_{i}^{(N)}\right)-L\left(\mathbf{Y}_{i}^{(N)}\right)}{\sqrt{\frac{1}{N^{2}} \sum_{h=1}^{N}\left(L^{-1}\left(\mathbf{Y}_{h}^{(N)}\right)-L\left(\mathbf{Y}_{h}^{(N)}\right)-\frac{1}{l} \sum_{i=1}^{l}\left(L^{-1}\left(\mathbf{Y}_{i}^{(N)}\right)-L\left(\mathbf{Y}_{i}^{(N)}\right)\right)\right)}}
$$

The horizontal axis shows the response horizon, each frame represents auctions in different maturity classes. Auctions within 6 months of a particular maturity horizon are considered within the nearest class. For example, 29 year 6-month auctions are included within the 30 year category.
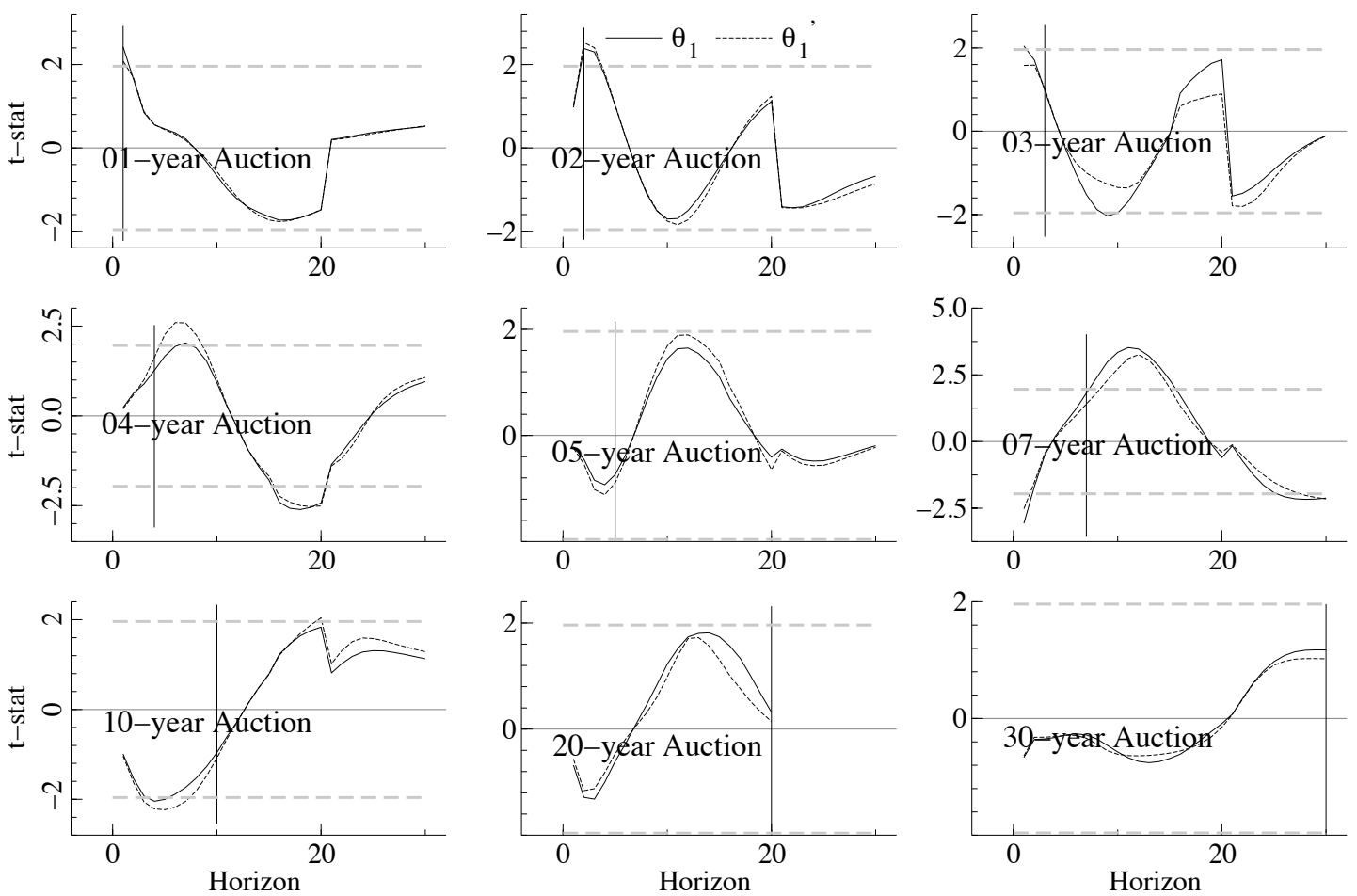
Figure 4.13: Changes in Relative Yields Between Previous and Two-Business Days Following Auction.

The frames below show test statistics against the null hypothesis of no effect of auctions on relative yields. Each point on the curve represents the t-statistic for the hypothesis that the auction event at the horizon shown in the top corner has no effect on the relative yields shown across the horizontal axis. The solid line shows the test against the hypothesis of no change in either the mean or variance of the change in relative yields, one day before and two days after the auction event.

$$
\theta_{1}=\frac{\frac{1}{k} \sum_{i=1}^{k} L^{-2}\left(\mathbf{Y}_{i}^{(N)}\right)-L\left(\mathbf{Y}_{i}^{(N)}\right)}{\sqrt{\operatorname{Var}\left(\overline{L^{-2}\left(\mathbf{Y}_{i}^{(N)}\right)-L\left(\mathbf{Y}_{i}^{(N)}\right)}\right)}}
$$

where $L(\cdot)$ is the lag operator, and each $\mathbf{Y}_{k}^{(N)}$ is the $k^{\text {th }}$ auction event. $L^{-2}\left(\mathbf{Y}_{i}^{(N)}\right)-L\left(\mathbf{Y}_{i}^{(N)}\right)$ equals the change in yield in excess of the average between the day before of the auction event and the next business day. Each $j$ are dates at least 2 days before or after any auction. The dotted lines in each frame show the test statistic against the null of no change in the mean,

$$
\theta_{1}^{\prime}=\frac{\frac{1}{k} \sum_{i=1}^{k} L^{-2}\left(\mathbf{Y}_{i}^{(N)}\right)-L\left(\mathbf{Y}_{i}^{(N)}\right)}{\sqrt{\frac{1}{N^{2}} \sum_{h=1}^{N}\left(L^{-2}\left(\mathbf{Y}_{h}^{(N)}\right)-L\left(\mathbf{Y}_{h}^{(N)}\right)-\frac{1}{l} \sum_{i=1}^{l}\left(L^{-2}\left(\mathbf{Y}_{i}^{(N)}\right)-L\left(\mathbf{Y}_{i}^{(N)}\right)\right)\right)}}
$$

The horizontal axis shows the response horizon, each frame represents auctions in different maturity classes. Auctions within 6 months of a particular maturity horizon are considered within the nearest class. For example, 29 year 6 -month auctions are included within the 30 year category.
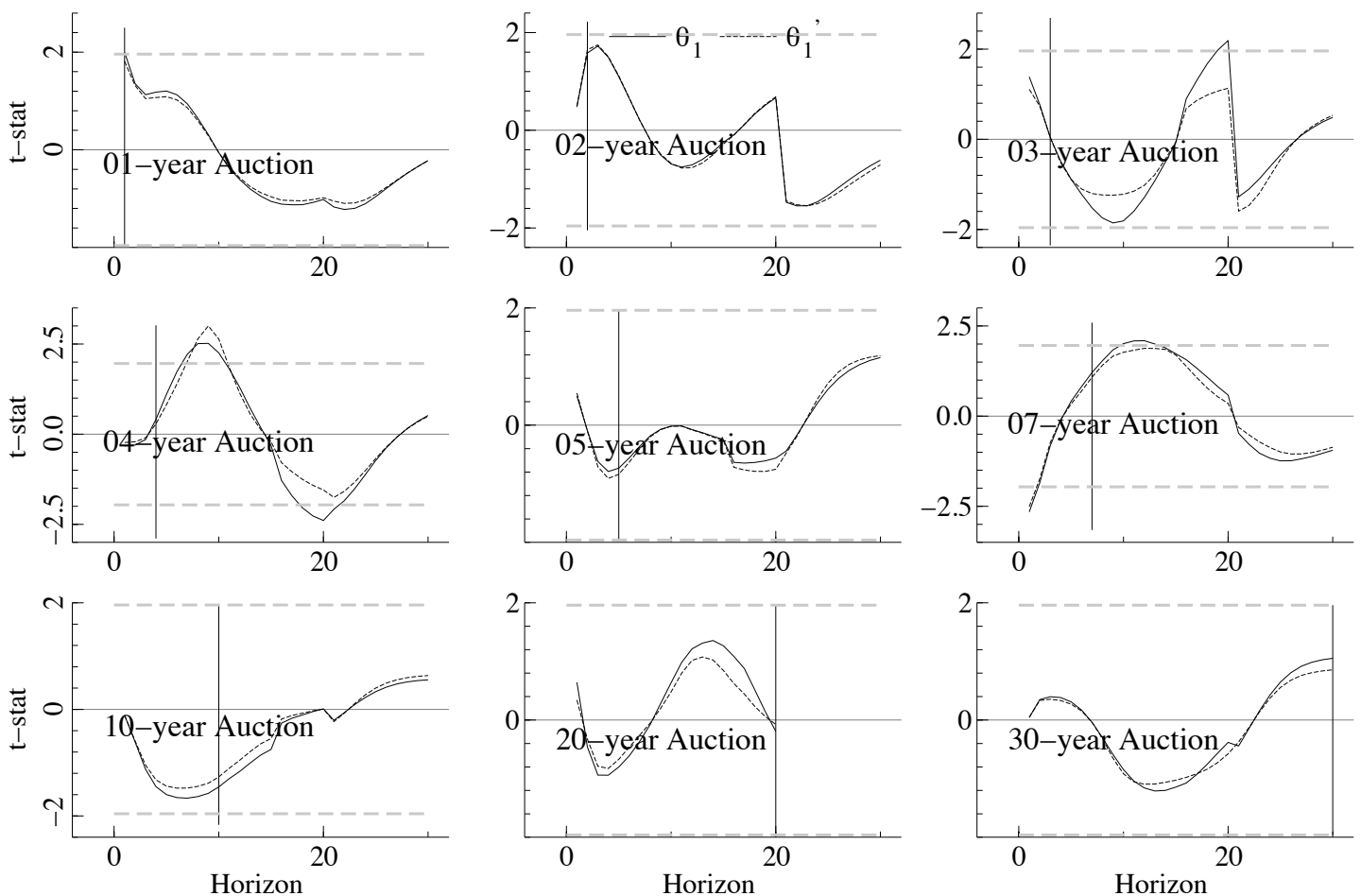
Figure 4.14: Changes in Relative Yields Between Two Days Previous and Day Following Auction.

The frames below show test statistics against the null hypothesis of no effect of auctions on relative yields. Each point on the curve represents the t-statistic for the hypothesis that the auction event at the horizon shown in the top corner has no effect on the relative yields shown across the horizontal axis. The solid line shows the test against the hypothesis of no change in either the mean or variance of the change in relative yield between one day before and two days after the auction event.

$$
\theta_{1}=\frac{\frac{1}{k} \sum_{i=1}^{k} L^{-1}\left(\mathbf{Y}_{i}^{(N)}\right)-L^{2}\left(\mathbf{Y}_{i}^{(N)}\right)}{\sqrt{\operatorname{Var}\left(\overline{L^{-1}\left(\mathbf{Y}_{i}^{(N)}\right)-L^{2}\left(\mathbf{Y}_{i}^{(N)}\right)}\right)}}
$$

where $L(\cdot)$ is the lag operator, and each $\left.\mathbf{Y}_{k}^{(N)}\right)$ is the $k^{t h}$ auction event. $L^{-1}\left(\mathbf{Y}_{i}^{(N)}\right)-L^{2}\left(\mathbf{Y}_{i}^{(N)}\right)$ equals the change in yield in excess of the average between two days before and the day after the auction event. Each $j$ are dates at least 2 days before or after any auction. The dotted lines in each frame show the test statistic against the null of no change in the mean

$$
\theta_{1}^{\prime}=\frac{\frac{1}{k} \sum_{i=1}^{k} L^{-1}\left(\mathbf{Y}_{i}^{(N)}\right)-L\left(\mathbf{Y}_{i}^{(N)}\right)}{\sqrt{\frac{1}{N^{2}} \sum_{h=1}^{N}\left(L^{-1}\left(\mathbf{Y}_{h}^{(N)}\right)-L^{2}\left(\mathbf{Y}_{h}^{(N)}\right)-\frac{1}{l} \sum_{i=1}^{l}\left(L^{-1}\left(\mathbf{Y}_{i}^{(N)}\right)-L^{2}\left(\mathbf{Y}_{i}^{(N)}\right)\right)\right)}} .
$$

The horizontal axis shows the response horizon, each frame represents auctions in different maturity classes. Auctions within 6 months of a particular maturity horizon are considered within the nearest class. For example, 29 year 6-month auctions are included within the 30 year category.
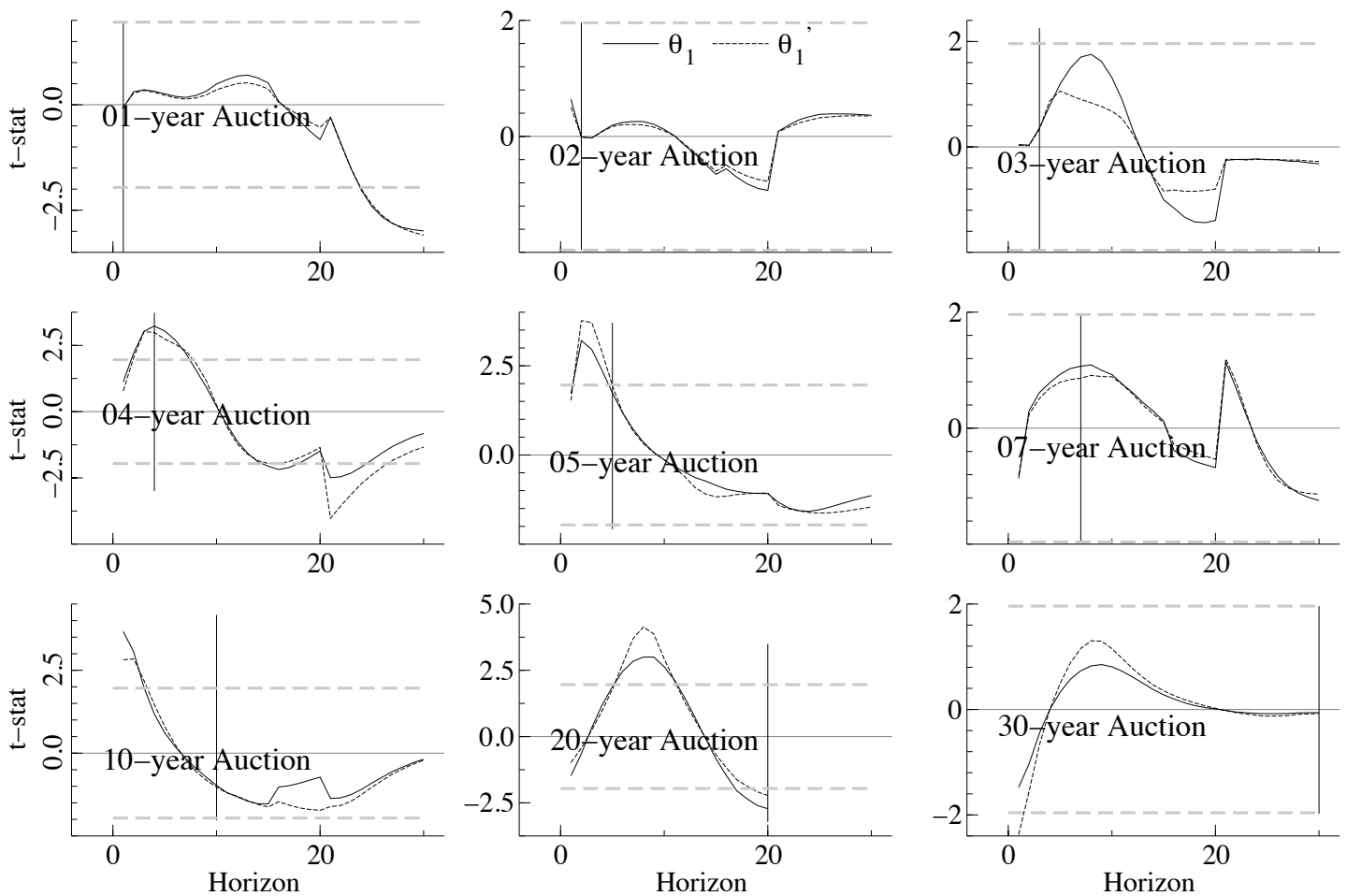


\section{Figure 4.15: Cumulative Changes in Relative Yield}

The figure shows the cumulative changes in relative yields over a period 50 business days preceding and following an auction, expressed in basis points. Each frame shows the period around the auction event of the maturity horizon shown in the top left corner. Dark solid vertical lines represent auction events, dashed lines announcements and light solid lines issue dates after auctions.

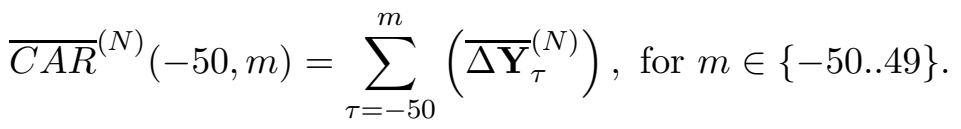
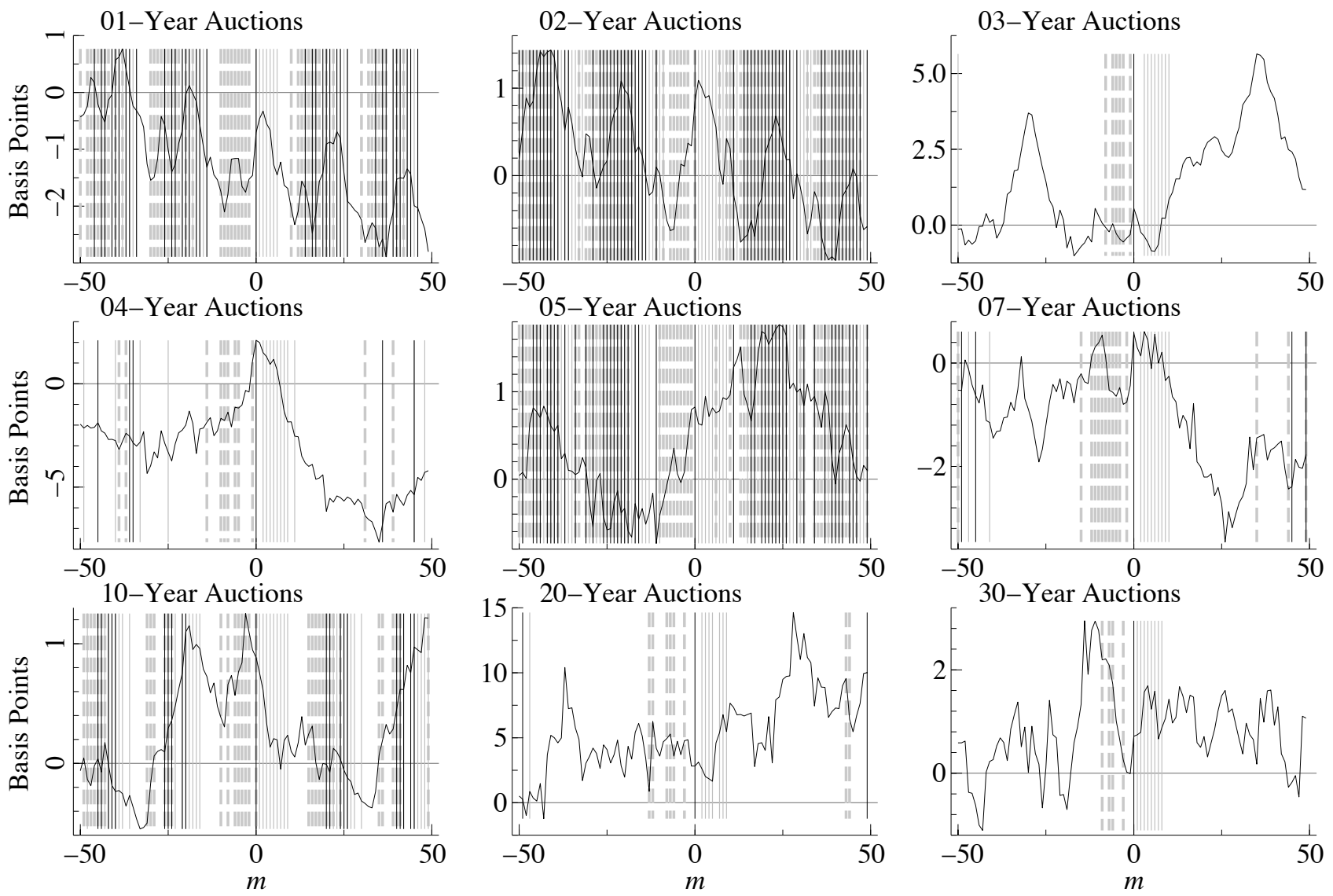


\section{Figure 4.16: Cumulative Changes in Relative Yield-Three Year Horizon}

The figure shows the cumulative changes in relative yields over a period 50 business days preceding and following an auction, expressed in basis points for three-year events. Dark solid vertical lines represent auction events, dashed lines announcements and light solid lines issue dates after auctions. Thick solid lines mark peaks at 30 days before and 35 days after auction events, corresponding approximately to auction events in the two and four-year maturity tranches.

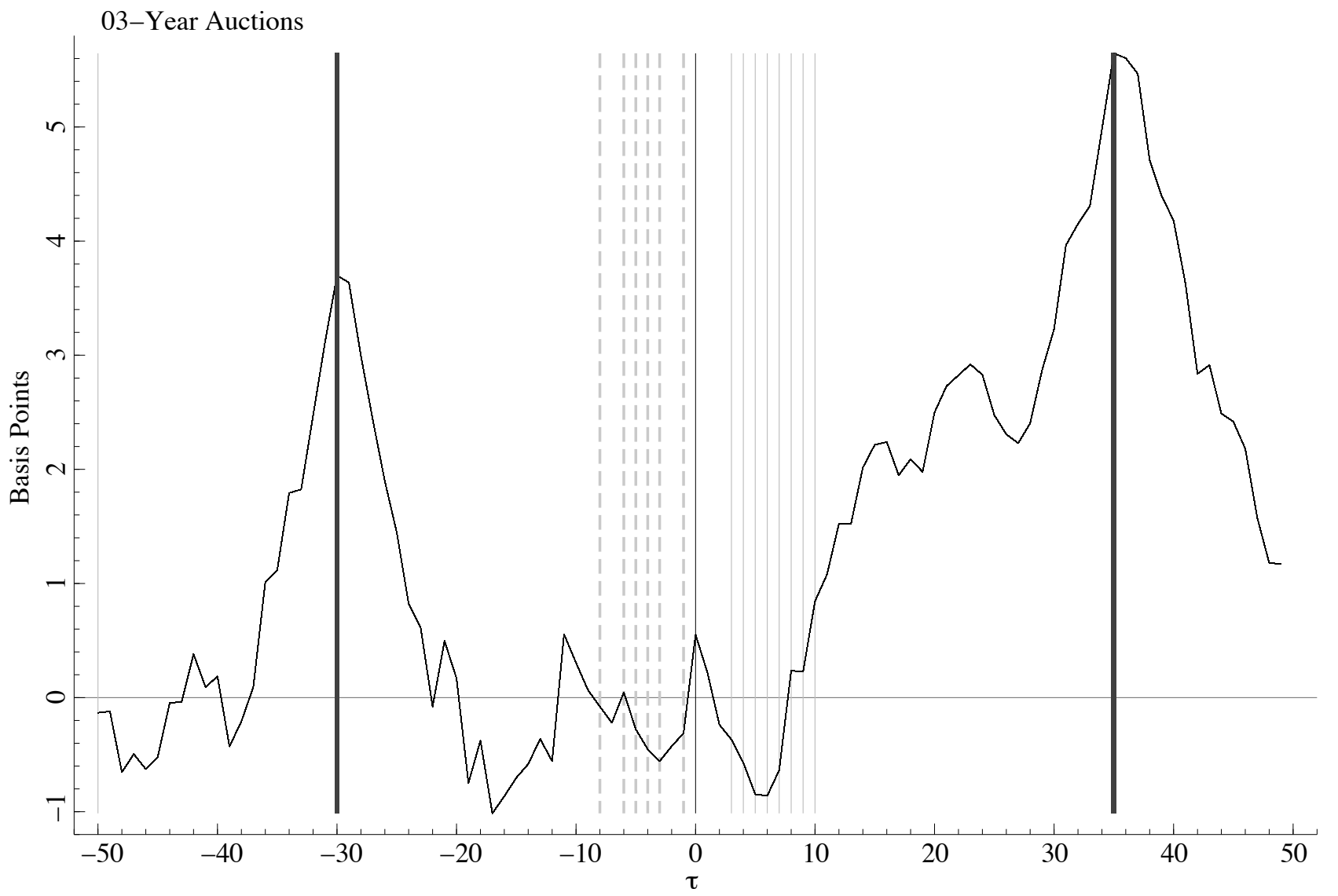


Figure 4.17: Non-Parametric Statistics for Auction Event Studies on Relative Yields.

The frames below show test statistics against the null hypothesis of no effect of auctions on relative yields. Each point on the curve represents the t-statistic for the hypothesis that the auction event at the horizon shown in the top corner has no effect on the relative yields shown across the horizontal axis. The solid line shows the test against the hypothesis of no change in either the mean or variance,

$$
\theta_{1}=\frac{\frac{1}{k} \sum_{i=1}^{k} \Delta \mathbf{Y}_{i}^{(N)}}{\sqrt{\operatorname{Var}\left(\overline{\left.\Delta \mathbf{Y}_{j}^{(N)}\right)}\right.}}
$$

where each $\mathbf{Y}_{k}^{(N)}$ is the yield in excess of the average on the day of the auction event, and each $j$ are dates at least 3 days before or after any auction. The dotted lines in each frame show the test statistic against the null of no change in the mean

$$
\theta_{1}^{\prime}=\frac{\frac{1}{k} \sum_{i=1}^{k} \Delta \mathbf{Y}_{i}^{(N)}}{\sqrt{\frac{1}{N^{2}} \sum_{h=1}^{N}\left(\Delta \mathbf{Y}_{h}^{(N)}-\frac{1}{l} \sum_{i=1}^{l} \Delta \mathbf{Y}_{l}^{(N)}\right)^{2}}}
$$

This test does not rely on the subsample of dates not within two days of the auction event to produce an estimate of the variance. The horizontal axis shows the response horizon, each frame represents auctions in different maturity classes. Auctions within 6 months of a particular maturity horizon are considered within the nearest class. For example, 29 year 6-month auctions are included within the 30 year category.

Let $N$ equal the total number of events and $N^{+}$the number of cases where the $\widehat{C A R}$ is positive. Under the null hypothesis, that with equal probability $\widehat{C A R}$ will be positive or negative. The test statistic

$$
\theta^{*}=\left(\frac{N^{+}}{N}-0.5\right) \frac{N^{1 / 2}}{0.5}
$$

is asymptotically distributed $\mathcal{N}(0,1)$ as $N$ increases. The null hypothesis $H_{0}: p \leq 0.5$ where $p=\operatorname{Pr}(\widehat{C A R}>0)$ is rejected in favor of the alternative $H_{A}: p>0.5$ for a test of size $\alpha$ if $\theta^{*}>\Phi^{-1}(\alpha)$.
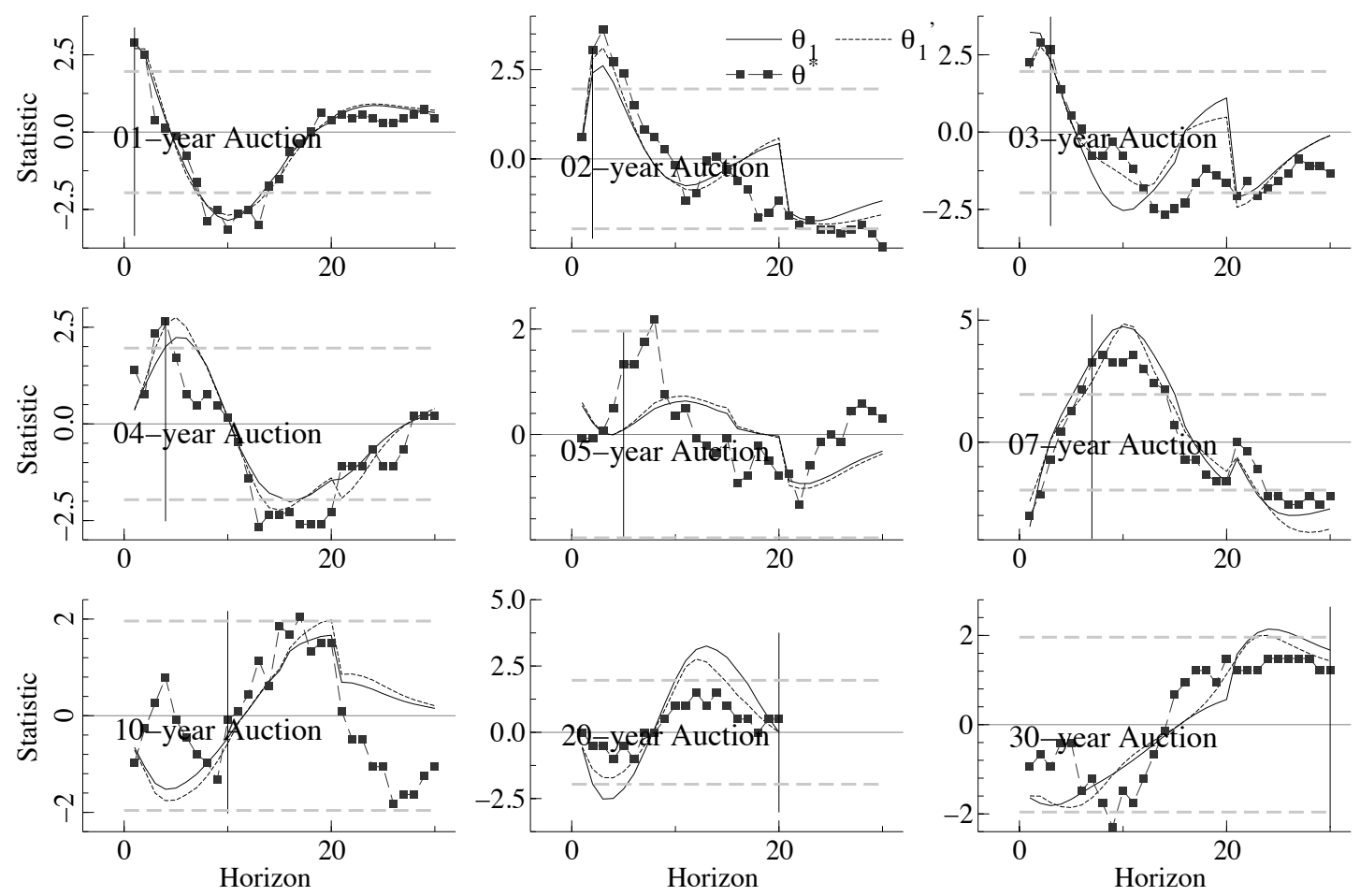


\section{Figure 4.18: Yield Curve and Inflation}

The top frame of the figure below shows a sample from the daily discount yields of Gürkaynak et al. (2007) and inflation measures.

The straight diagonal line represents the incremental change in ex post expected inflation over the sample period. The expected inflation rate defined as the geometric mean of the previous twelvemonth's inflation rate equals $10.73 \%$ on January 1, 1981 and $4.12 \%$ December 31,2007 . The daily expected inflation rate $\pi^{e}$ drawn with a dashed line takes the same value for each day of the month, equal to the 12-month rolling geometric mean of inflation rates.

The lower frame shows the series

$$
\mathbf{Y}(\pi)_{t}^{(N)}=y_{t}^{(N)}-\hat{\pi}_{t}
$$

where $\hat{\pi}_{t}$ equals the period $t$ value for expected ex post inflation.
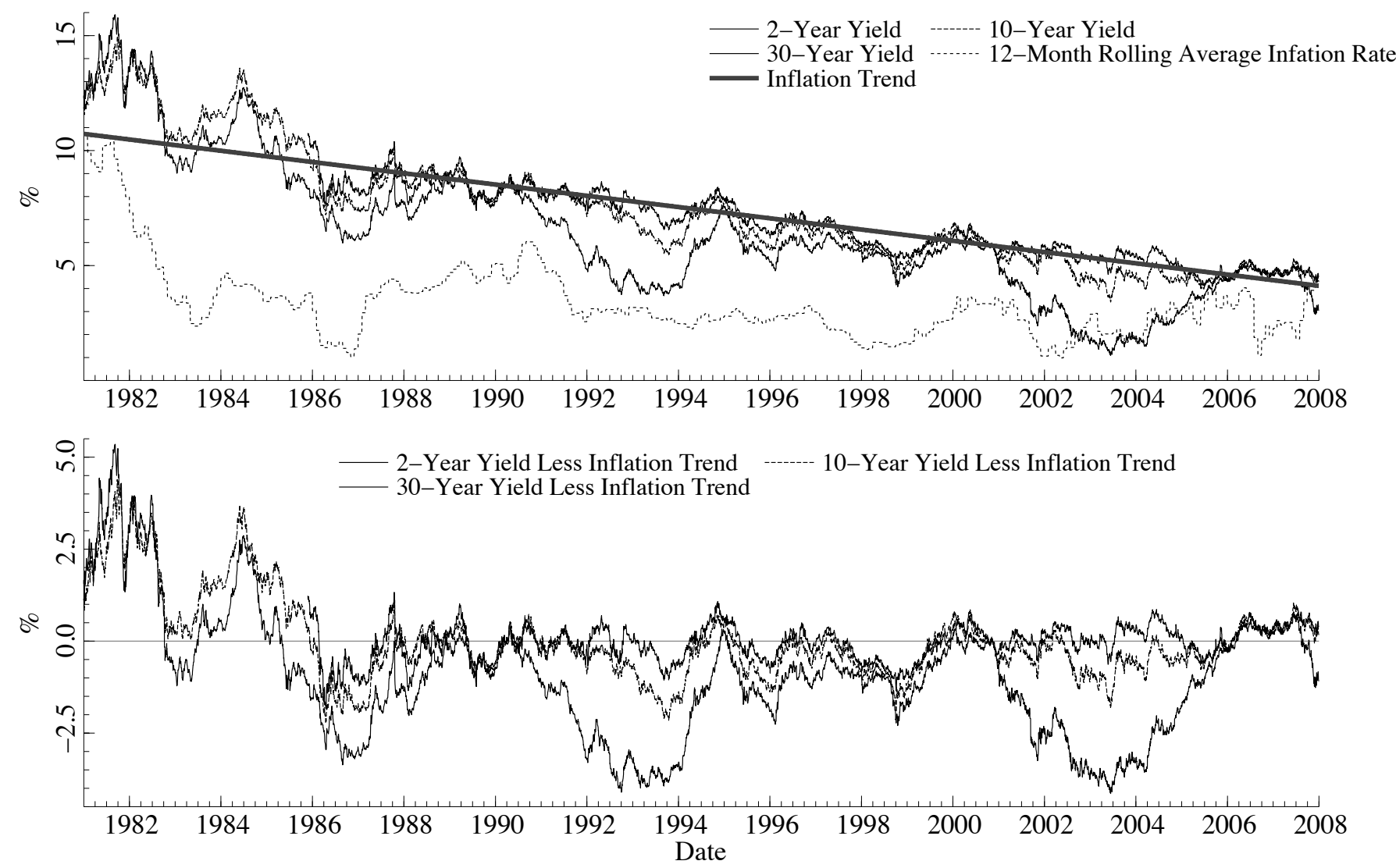


\section{Figure 4.19: Cumulative Changes in Expected Inflation Corrected Yields}

The figure shows the cumulative changes in expected inflation corrected yields over a period 50 business days preceding and following an auction, expressed in basis points. Each frame shows the period around the auction event of the maturity horizon shown in the top-left corner. Dark solid vertical lines represent auction events, dashed lines announcements and light solid lines issue dates after auctions.
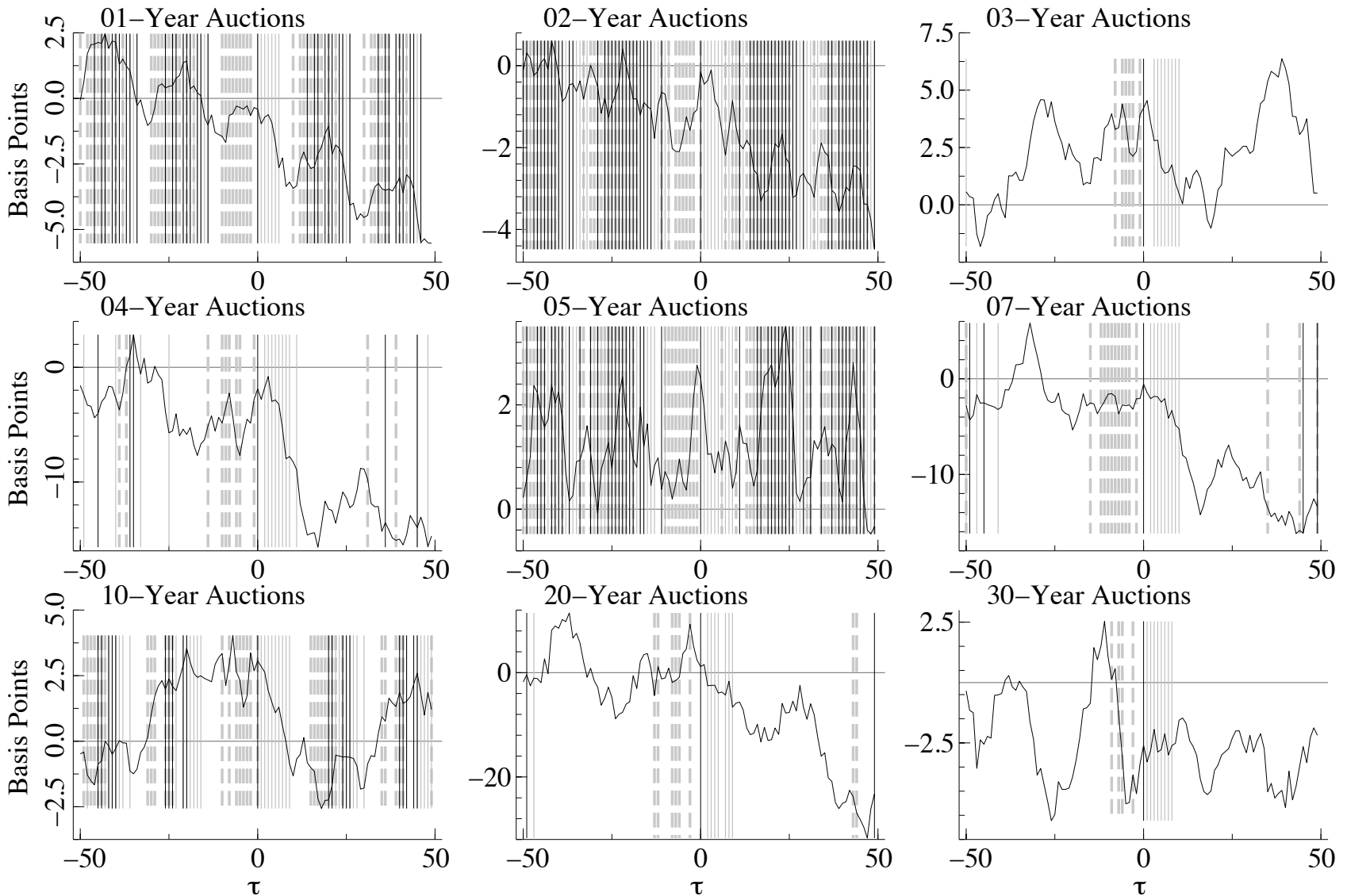


\section{Figure 4.20: Test Statistics for Auction Event Studies on Inflation Corrected} Yields.

The frames below show test statistics against the null hypothesis of no effect of auctions on expected inflation corrected yields. Each point on the curve represents the t-statistic for the hypothesis that the auction event at the horizon shown in the top corner has no effect on the relative yields shown across the horizontal axis. The solid line shows the test against the hypothesis of no change in either the mean or variance,

$$
\theta_{1}=\frac{\frac{1}{k} \sum_{i=1}^{k} \mathbf{Y}(\pi)_{i}^{(N)}}{\sqrt{\operatorname{Var}\left(\Delta \mathbf{Y}_{j}(\pi)^{(N)}\right)}},
$$

where each $\mathbf{Y}(\pi)_{k}^{(N)}$ is the yield in excess of the expected inflation rate on the day of the auction event, modeled as the incremental change in realized inflation rate over the sample period. The dotted lines in each frame show the test statistic against the null of no change in the mean

$$
\theta_{1}^{\prime}=\frac{\frac{1}{k} \sum_{i=1}^{k} \mathbf{Y}(\pi)_{i}^{(N)}}{\sqrt{\frac{1}{N^{2}} \sum_{h=1}^{N}\left(\mathbf{Y}(\pi)_{h}^{(N)}-\frac{1}{l} \sum_{i=1}^{l} \mathbf{Y}(\pi)_{l}^{(N)}\right)^{2}}} .
$$

This test does not rely on the subsample of dates not within two days of the auction event to produce an estimate of the variance. The horizontal axis shows the response horizon, each frame represents auctions in different maturity classes. Auctions within 6 months of a particular maturity horizon are considered within the nearest class. For example, 29 year 6 -month auctions are included within the 30 year category.
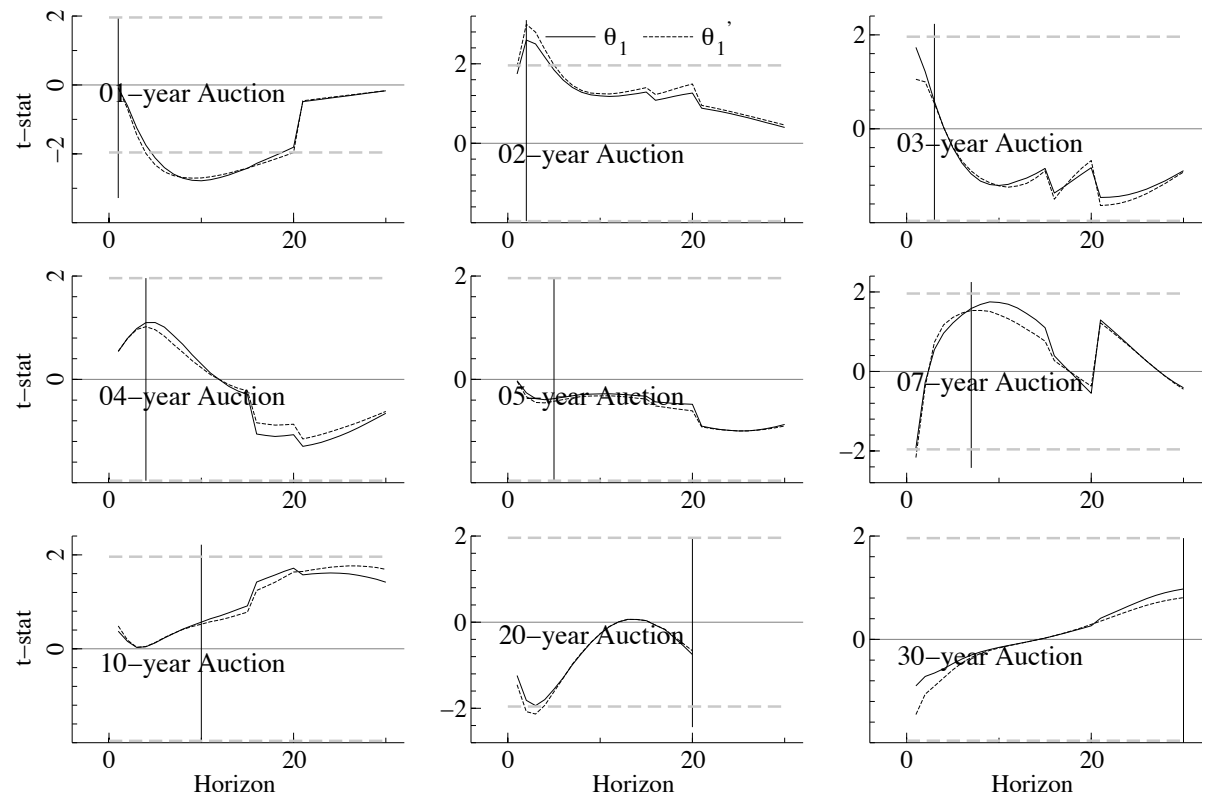
Figure 4.21: Auction Event Studies on Two-day Changes in Inflation Corrected Yields.

The frames below show test statistics against the null hypothesis of no effect of auctions on inflation corrected yields. Each point on the curve represents the t-statistic for the hypothesis that the auction event at the horizon shown in the top corner has no effect on the relative yields shown across the horizontal axis. The solid line shows the test against the hypothesis of no change in either the mean or variance, between two days before and the day of the auction,

$$
\theta_{1}=\frac{\frac{1}{k} \sum_{i=1}^{k} \Delta_{2} \mathbf{Y}(\pi)_{i}^{(N)}}{\sqrt{\operatorname{Var}\left({\overline{\Delta_{2} \mathbf{Y}(\pi)}}_{j}^{(N)}\right)}},
$$

where each $\Delta_{i} \mathbf{Y}(\pi)_{k}^{(N)}=\mathbf{Y}(\pi)_{k}^{(N)}-\mathbf{Y}(\pi)_{k-i}^{(N)}$, the change in yield in excess of the expected inflation estimate on the day of the auction event, and each $j$ are dates at least 5 days before or after any auction. The dotted lines in each frame show the test statistic against the null of no change in the mean,

$$
\theta_{1}^{\prime}=\frac{\frac{1}{k} \sum_{i=1}^{k} \Delta_{2} \mathbf{Y}(\pi)_{i}^{(N)}}{\sqrt{\frac{1}{N^{2}} \sum_{h=1}^{N}\left(\Delta_{2} \mathbf{Y}(\pi)_{h}^{(N)}-\frac{1}{l} \sum_{i=1}^{l} \Delta_{2} \mathbf{Y}(\pi)_{l}^{(N)}\right)^{2}}} .
$$

The horizontal axis shows the response horizon, each frame represents auctions in different maturity classes. Auctions within 6 months of a particular maturity horizon are considered within the nearest class. For example, 29 year 6 -month auctions are included within the 30 year category.
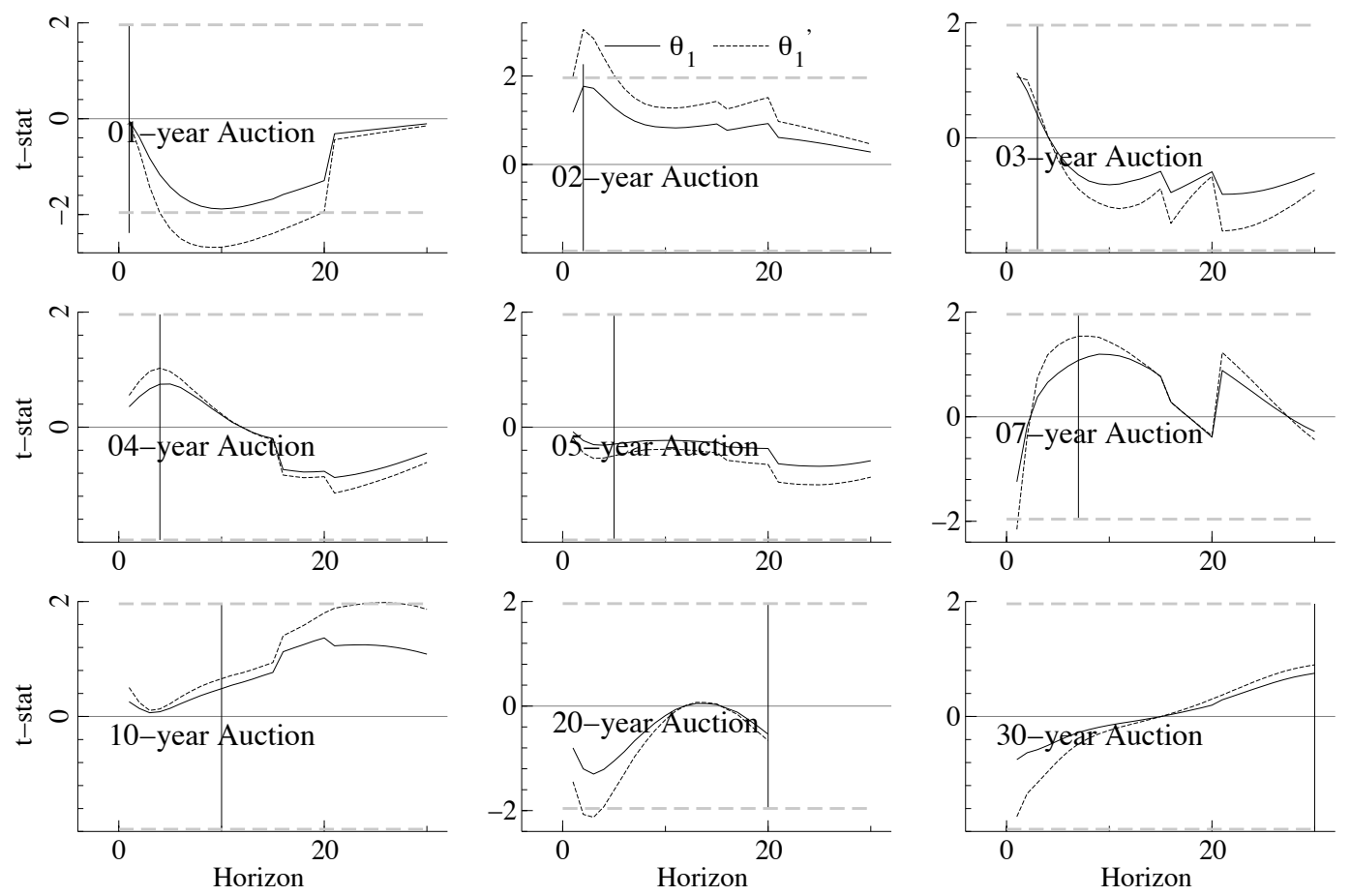
Figure 4.22: Auction Event Studies on Three-day Changes in Inflation Corrected Yields.

The frames below show test statistics against the null hypothesis of no effect of auctions on inflation corrected yields. Each point on the curve represents the t-statistic for the hypothesis that the auction event at the horizon shown in the top corner has no effect on the relative yields shown across the horizontal axis. The solid line shows the test against the hypothesis of no change in either the mean or variance, three days before and the day of the auction,

$$
\theta_{1}=\frac{\frac{1}{k} \sum_{i=1}^{k} \Delta_{3} \mathbf{Y}(\pi)_{i}^{(N)}}{\sqrt{\operatorname{Var}\left({\overline{\Delta_{3} \mathbf{Y}(\pi)}}_{j}^{(N)}\right)}},
$$

where each $\Delta_{i} \mathbf{Y}(\pi)_{k}^{(N)}=\mathbf{Y}(\pi)_{k}^{(N)}-\mathbf{Y}(\pi)_{k-i}^{(N)}$, the change in yield in excess of the expected inflation estimate on the day of the auction event, and each $j$ are dates at least 5 days before or after any auction. The dotted lines in each frame show the test statistic against the null of no change in the mean,

$$
\theta_{1}^{\prime}=\frac{\frac{1}{k} \sum_{i=1}^{k} \Delta_{3} \mathbf{Y}(\pi)_{i}^{(N)}}{\sqrt{\frac{1}{N^{2}} \sum_{h=1}^{N}\left(\Delta_{3} \mathbf{Y}(\pi)_{h}^{(N)}-\frac{1}{l} \sum_{i=1}^{l} \Delta_{3} \mathbf{Y}(\pi)_{l}^{(N)}\right)^{2}}} .
$$

The horizontal axis shows the response horizon, each frame represents auctions in different maturity classes. Auctions within 6 months of a particular maturity horizon are considered within the nearest class. For example, 29 year 6 -month auctions are included within the 30 year category.
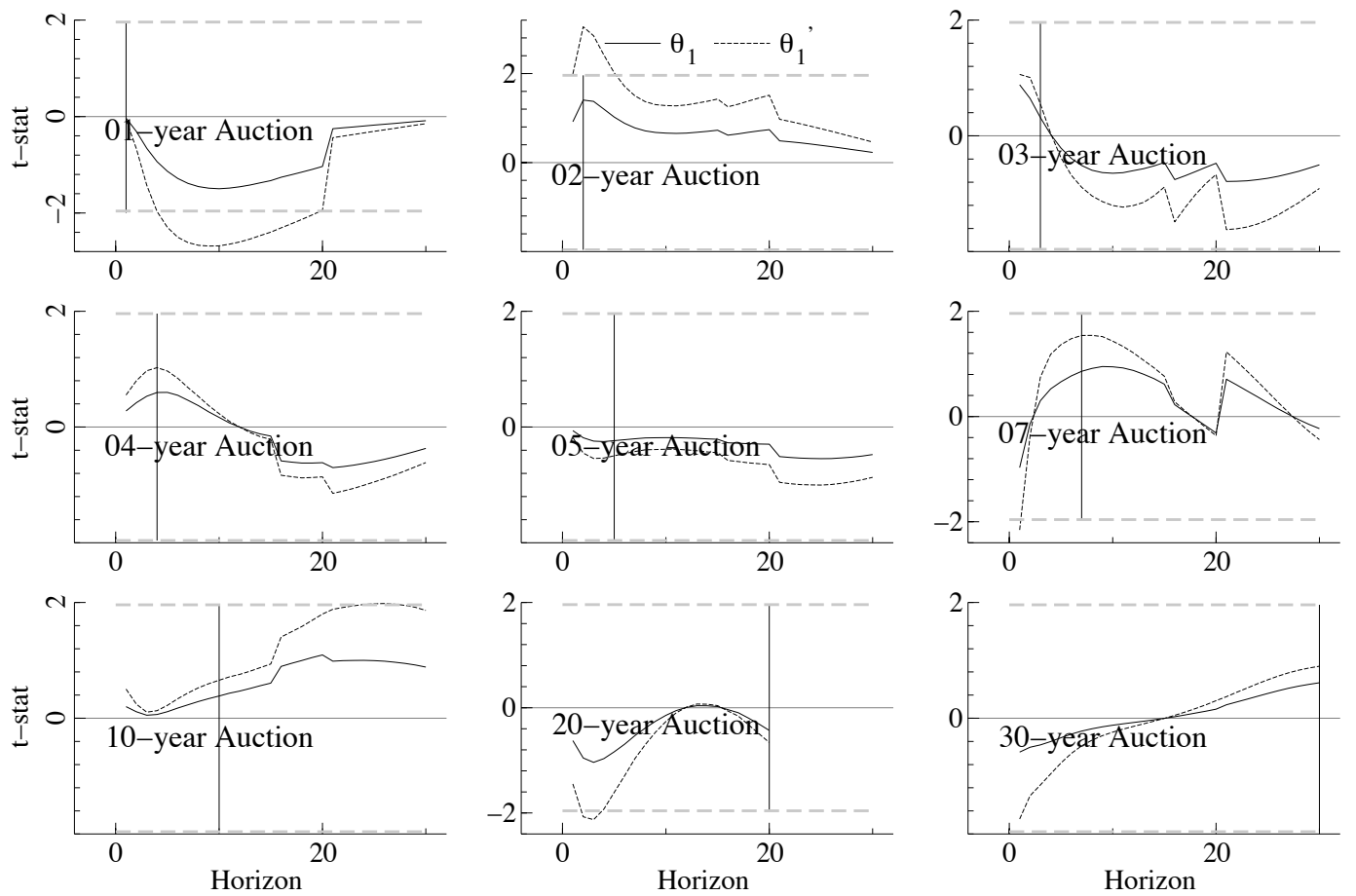
Figure 4.23: Changes in Relative Yields Between Previous and Following Day. Each point on the curve represents the t-statistic for the hypothesis that the auction event at the horizon shown in the top corner has no effect on the inflation corrected yields shown across the horizontal axis. The solid line shows the test against the hypothesis of no change in either the mean or variance, one day before until one day after the auction event.

$$
\theta_{1}=\frac{\frac{1}{k} \sum_{i=1}^{k} L^{-1}\left(\mathbf{Y}(\pi)_{i}^{(N)}\right)-L\left(\mathbf{Y}(\pi)_{i}^{(N)}\right)}{\sqrt{\operatorname{Var}\left(\overline{L^{-1}\left(\mathbf{Y}(\pi)_{i}^{(N)}\right)-L\left(\mathbf{Y}(\pi)_{i}^{(N)}\right)}\right)}}
$$

where $L(\cdot)$ is the lag operator, and each $\mathbf{Y}(\pi)_{k}^{(N)}$ is the $k^{t h}$ auction event. $L^{-1}\left(\mathbf{Y}(\pi)_{i}^{(N)}\right)-$ $L\left(\mathbf{Y}(\pi)_{i}^{(N)}\right)$ equals the change in yield in excess of the expected inflation estimate between the day before of the auction event and the next business day. Each $j$ are dates at least 2 days before or after any auction. The dotted lines in each frame show the test statistic against the null of no change in the mean

$$
\theta_{1}^{\prime}=\frac{\frac{1}{k} \sum_{i=1}^{k} L^{-1}\left(\mathbf{Y}(\pi)_{i}^{(N)}\right)-L\left(\mathbf{Y}(\pi)_{i}^{(N)}\right)}{\sqrt{\frac{1}{N^{2}} \sum_{h=1}^{N}\left(L^{-1}\left(\mathbf{Y}(\pi)_{h}^{(N)}\right)-L\left(\mathbf{Y}(\pi)_{h}^{(N)}\right)-\frac{1}{l} \sum_{i=1}^{l}\left(L^{-1}\left(\mathbf{Y}(\pi)_{i}^{(N)}\right)-L\left(\mathbf{Y}(\pi)_{i}^{(N)}\right)\right)\right)}}
$$

The horizontal axis shows the response horizon, each frame represents auctions in different maturity classes. Auctions within 6 months of a particular maturity horizon are considered within the nearest class. For example, 29 year 6-month auctions are included within the 30 year category.
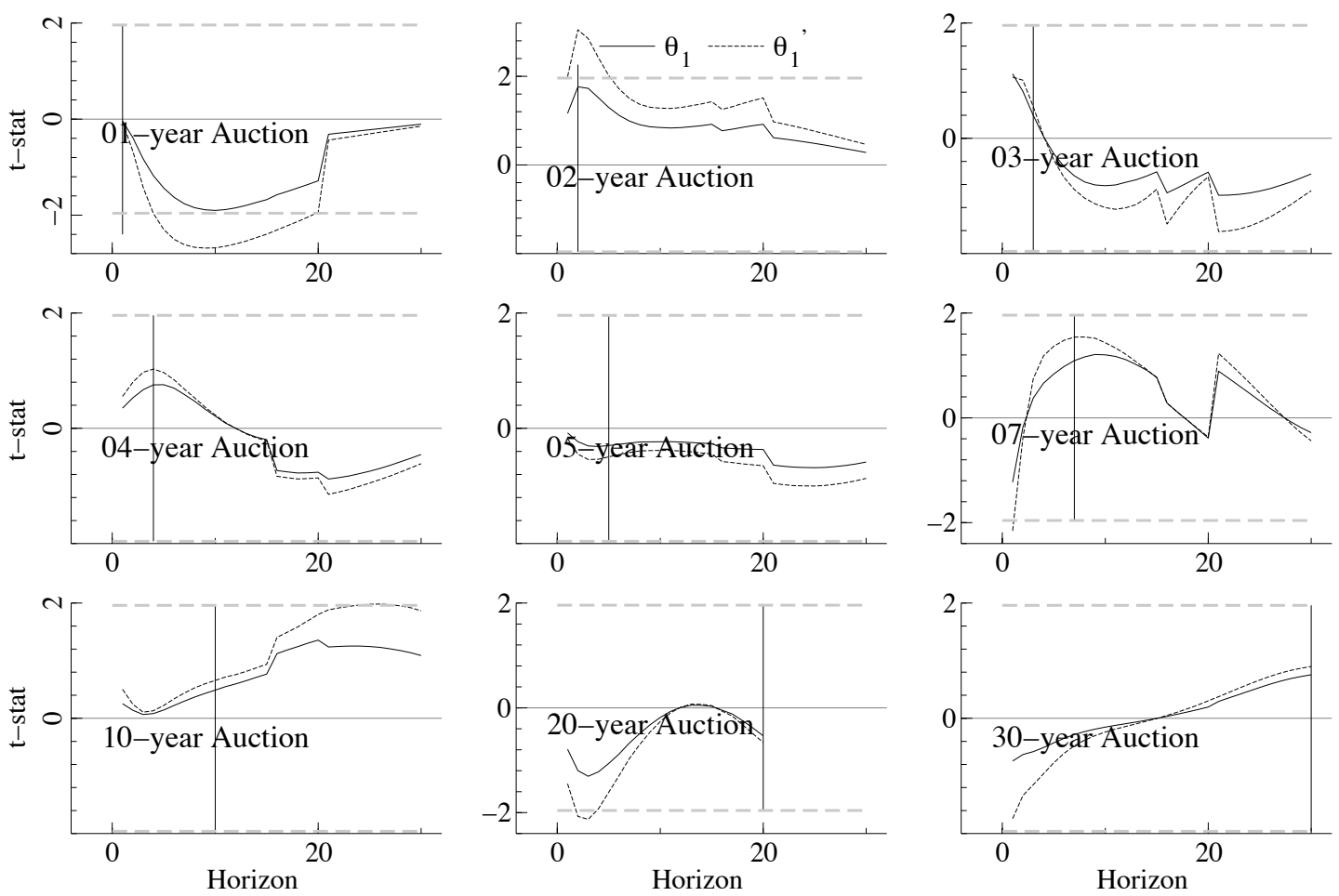
Figure 4.24: Changes in Inflation Corrected Yields Between Previous and TwoBusiness Days Following Auction.

The frames below show test statistics against the null hypothesis of no effect of auctions on inflation corrected yields. The solid line shows the test against the hypothesis of no change in either the mean or variance of the change either mean or variance between one day before and two days after the auction event.

$$
\theta_{1}=\frac{\frac{1}{k} \sum_{i=1}^{k} L^{-2}\left(\mathbf{Y}(\pi)_{i}^{(N)}\right)-L\left(\mathbf{Y}(\pi)_{i}^{(N)}\right)}{\sqrt{\operatorname{Var}\left(\overline{L^{-2}\left(\mathbf{Y}(\pi)_{i}^{(N)}\right)-L\left(\mathbf{Y}(\pi)_{i}^{(N)}\right)}\right)}}
$$

where $L(\cdot)$ is the lag operator, and each $\mathbf{Y}(\pi)_{k}^{(N)}$ is the $k^{t h}$ auction event. $L^{-2}\left(\mathbf{Y}(\pi)_{i}^{(N)}\right)-$ $L\left(\mathbf{Y}(\pi)_{i}^{(N)}\right)$ equals the change in yield in excess of the expected inflation estimate between the day before of the auction event and the next business day. Each $j$ are dates at least 2 days before or after any auction. The dotted lines in each frame show the test statistic against the null of no change in the mean

$$
\theta_{1}^{\prime}=\frac{\frac{1}{k} \sum_{i=1}^{k} L^{-2}\left(\mathbf{Y}(\pi)_{i}^{(N)}\right)-L\left(\mathbf{Y}(\pi)_{i}^{(N)}\right)}{\sqrt{\frac{1}{N^{2}} \sum_{h=1}^{N}\left(L^{-2}\left(\mathbf{Y}(\pi)_{h}^{(N)}\right)-L\left(\mathbf{Y}(\pi)_{h}^{(N)}\right)-\frac{1}{l} \sum_{i=1}^{l}\left(L^{-2}\left(\mathbf{Y}(\pi)_{i}^{(N)}\right)-L\left(\mathbf{Y}(\pi)_{i}^{(N)}\right)\right)\right)}}
$$

The horizontal axis shows the response horizon, each frame represents auctions in different maturity classes. Auctions within 6 months of a particular maturity horizon are considered within the nearest class. For example, 29 year 6-month auctions are included within the 30 year category.
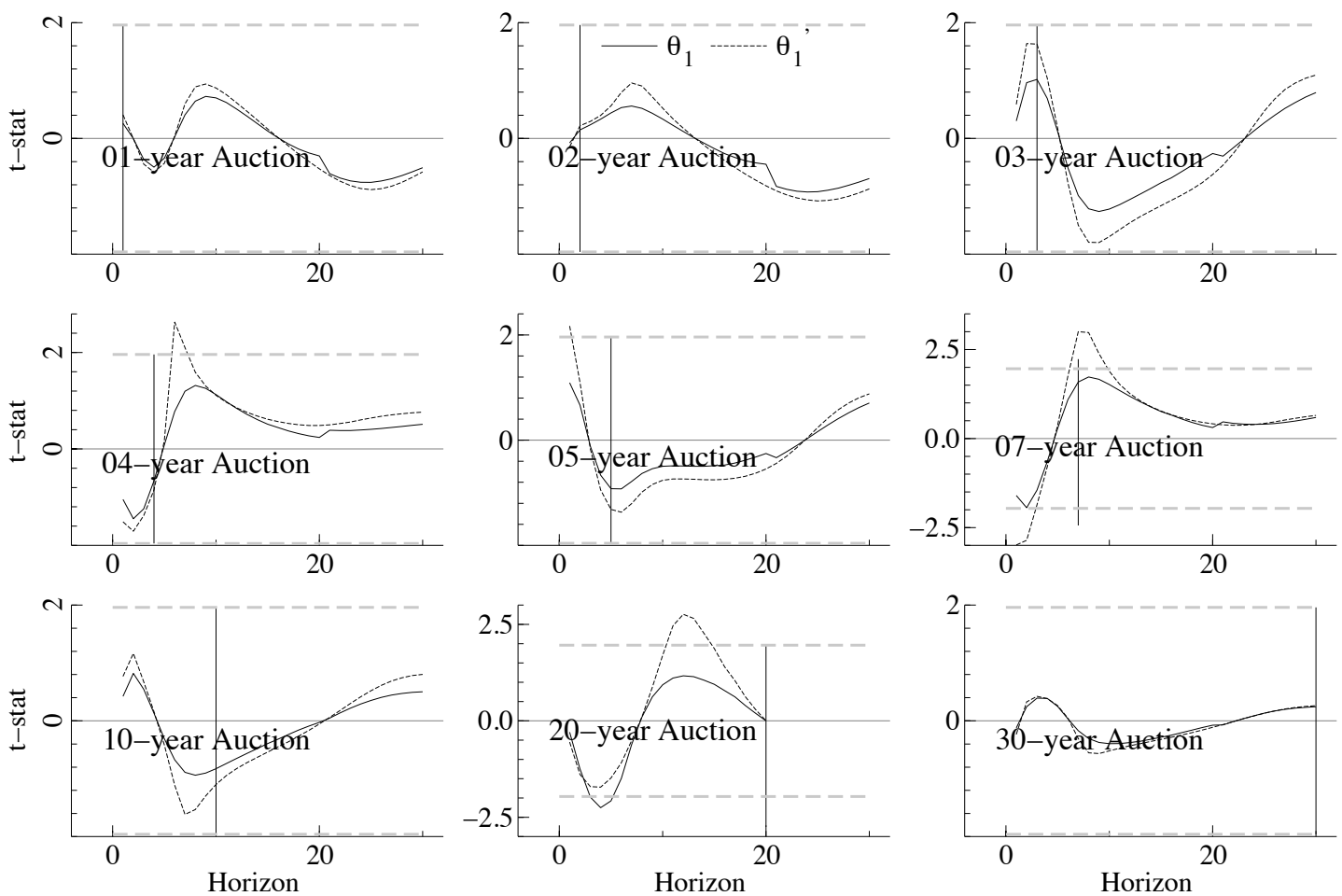
Figure 4.25: Changes in Inflation Corrected Yields Between Two Days Previous and Day Following Auction.

The frames below show test statistics against the null hypothesis of no effect of auctions on relative yields. Each point on the curve represents the t-statistic for the hypothesis that the auction event at the horizon shown in the top corner has no effect on the relative yields shown across the horizontal axis. The solid line shows the test against the hypothesis of no change in either the mean or variance of the change in relative yield between one day before and two days after the auction event.

$$
\theta_{1}=\frac{\frac{1}{k} \sum_{i=1}^{k} L^{-1}\left(\mathbf{Y}(\pi)_{i}^{(N)}\right)-L^{2}\left(\mathbf{Y}(\pi)_{i}^{(N)}\right)}{\sqrt{\operatorname{Var}\left(\overline{L^{-1}\left(\mathbf{Y}(\pi)_{i}^{(N)}\right)-L^{2}\left(\mathbf{Y}(\pi)_{i}^{(N)}\right)}\right)}}
$$

where $L(\cdot)$ is the lag operator, and each $\mathbf{Y}(\pi)_{k}^{(N)}$ is the $k^{t h}$ auction event. $L^{-1}\left(\mathbf{Y}(\pi)_{i}^{(N)}\right)-$ $L^{2}\left(\mathbf{Y}(\pi)_{i}^{(N)}\right)$ equals the change in yield in excess of the expected inflation estimate between two days before and the day after the auction event. Each $j$ are dates at least 2 days before or after any auction. The dotted lines in each frame show the test statistic against the null of no change in the mean

$$
\theta_{1}^{\prime}=\frac{\frac{1}{k} \sum_{i=1}^{k} L^{-1}\left(\mathbf{Y}(\pi)_{i}^{(N)}\right)-L\left(\mathbf{Y}(\pi)_{i}^{(N)}\right)}{\sqrt{\frac{1}{N^{2}} \sum_{h=1}^{N}\left(L^{-1}\left(\mathbf{Y}(\pi)_{h}^{(N)}\right)-L^{2}\left(\mathbf{Y}(\pi)_{h}^{(N)}\right)-\frac{1}{l} \sum_{i=1}^{l}\left(L^{-1}\left(\mathbf{Y}(\pi)_{i}^{(N)}\right)-L^{2}\left(\mathbf{Y}(\pi)_{i}^{(N)}\right)\right)\right)}}
$$

The horizontal axis shows the response horizon, each frame represents auctions in different maturity classes. Auctions within 6 months of a particular maturity horizon are considered within the nearest class. For example, 29 year 6-month auctions are included within the 30 year category.
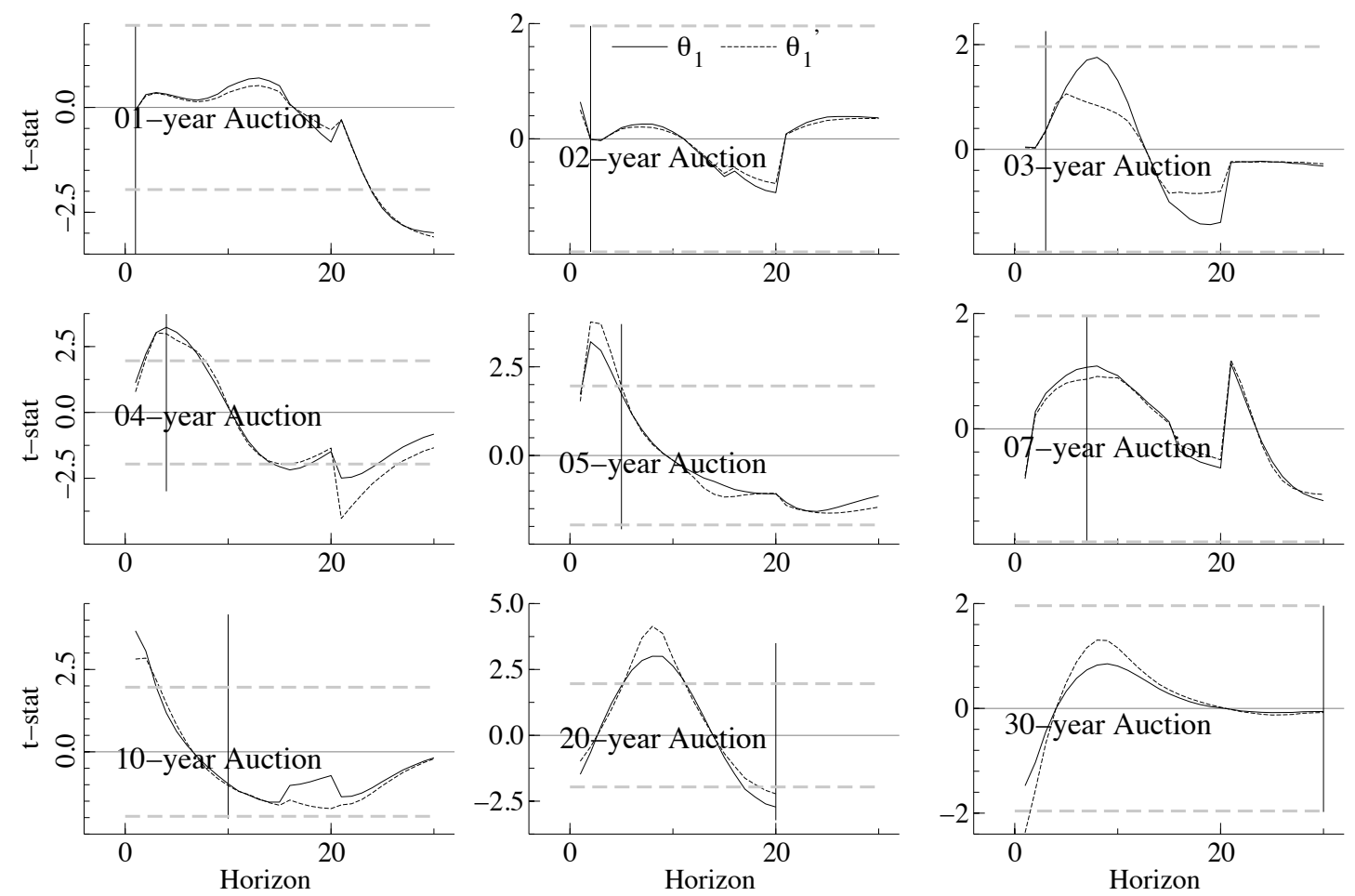


\section{Figure 4.26: Auction Event Timing During On/Off-the-run Sample.}

The figure below shows the timing of Treasury Auctions between April 27, 1989 and Dec. 31, 2007. This period corresponds to the availability of Bloomberg on/off-the-run discount yields.

Each symbol in the top frame represents an auction at the maturity horizon shown in the vertical axis. The bottom frame shows the total quantity accepted in each auction, in billions of dollars. The symbols in the middle frame correspond to symbols used for each maturity horizon shown in the top frame. The bottom frame shows discount yields for the two, five, and 30-year maturities, constructed from a subset of primarily on-the-run bonds.
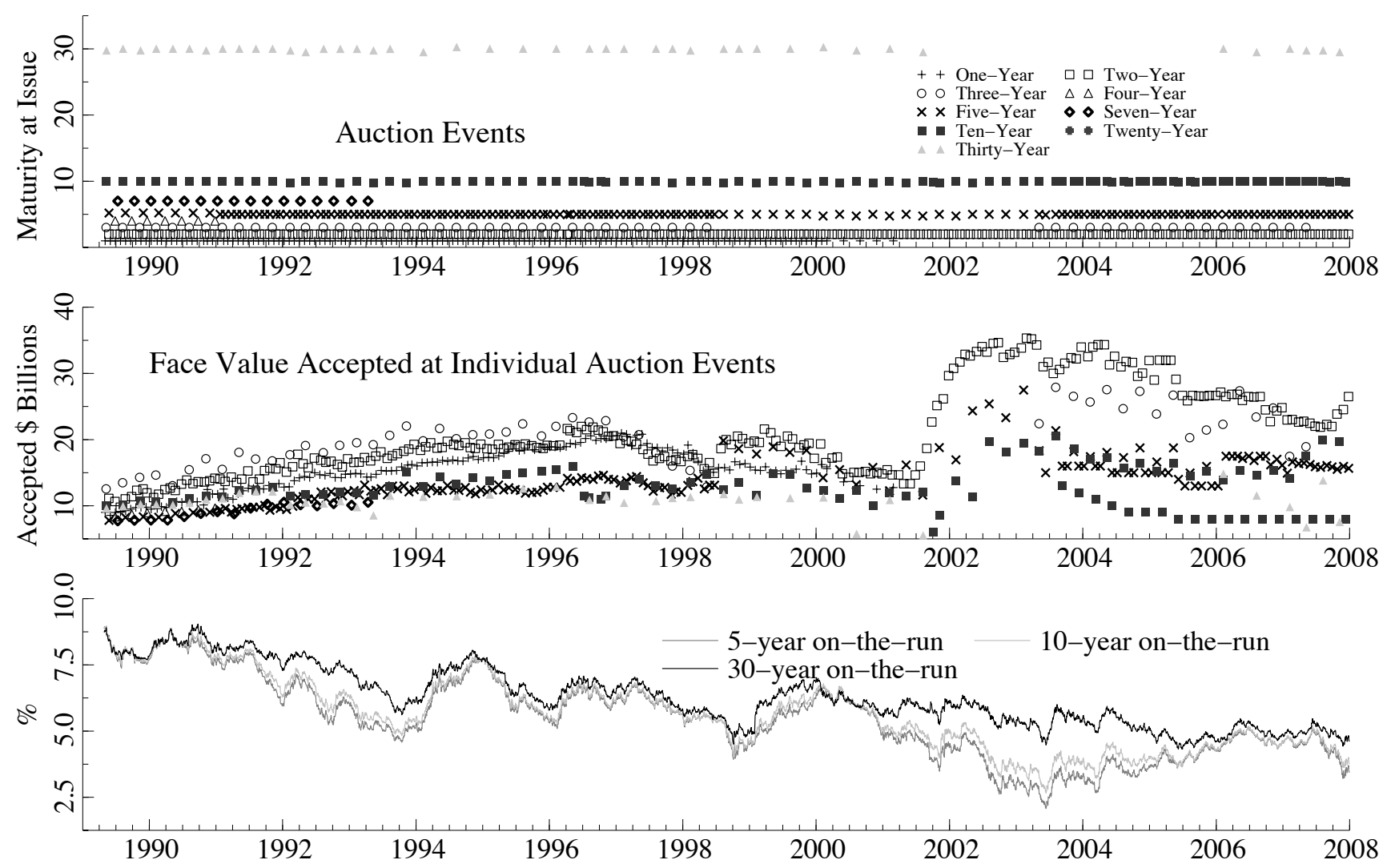


\section{Figure 4.27: Off-the-run Discount Yield Premium}

The figure below shows the difference between yields of Gürkaynak et al. (2007) and the on/offthe-run data series from Bloomberg Professional expressed in basis points. The Bloomberg data, converted to continuously compounded zero-coupon discount rates, are computed using the set of on-the-run treasuries and off-the-run treasuries of matching maturity where on-the-run issues are unavailable.

The jump in the twenty-year series in February of 1999 marks the first day that off-the-run bonds are used to compute a point at the twenty-year horizon. Before that date the twenty-year rate was computed using a linear interpolation between the ten and thirty year bonds.
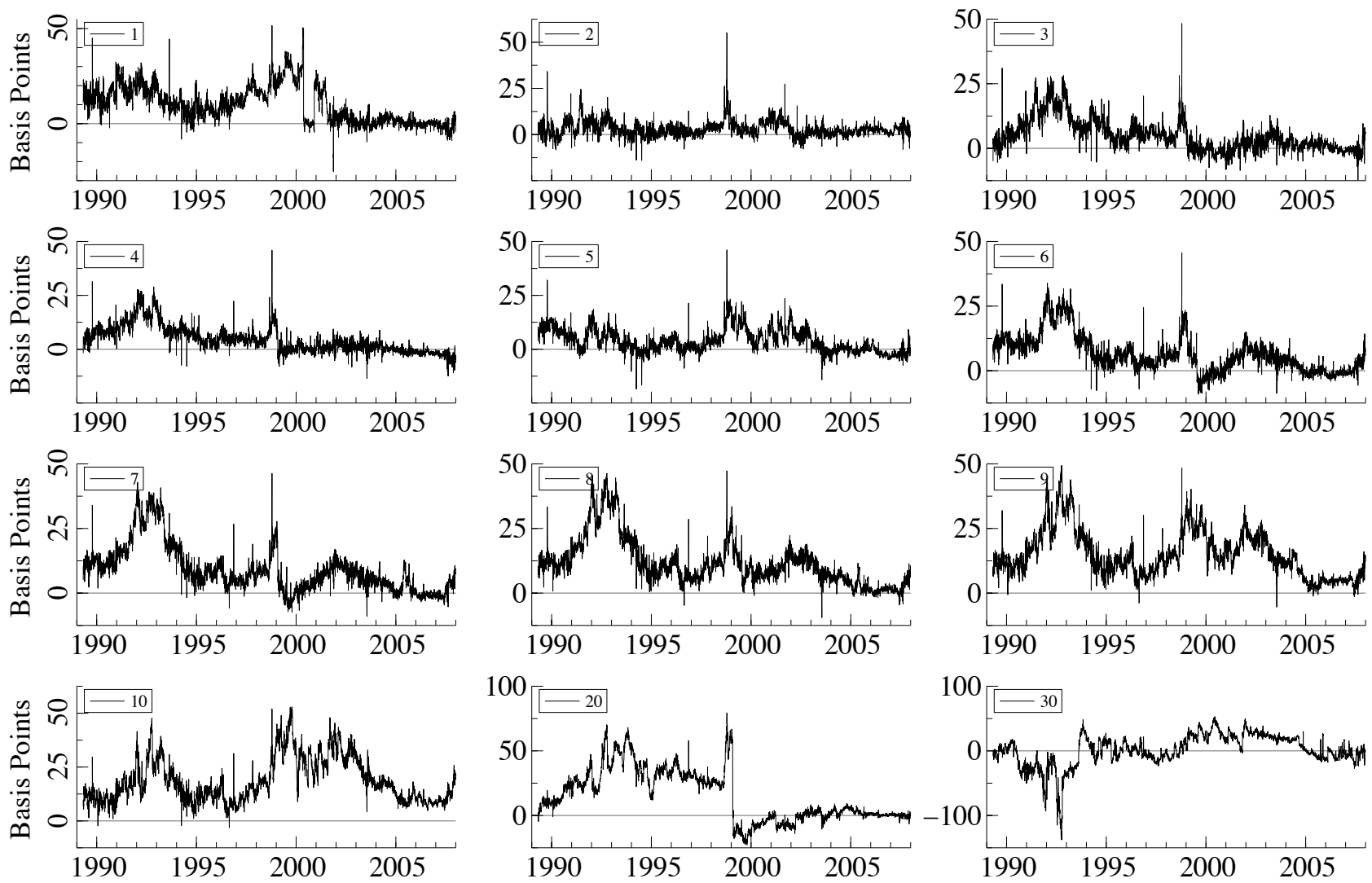


\section{Figure 4.28: Ten-Year Yields from On and Off-the-run Prices}

The figure below shows the ten-year yields of Gürkaynak et al. (2007) and the Bloomberg Professional data on/off-the-run yield series. The Bloomberg data, converted to continuously compounded zero-coupon discount rates, are computed using the set of on-the-run treasuries and off-the-run treasuries of matching maturity where on-the-run issues are unavailable.

The bottom frame show a larger view of the 10-year frame from Figure 4.27. Vertical bars mark ten-year auction events.
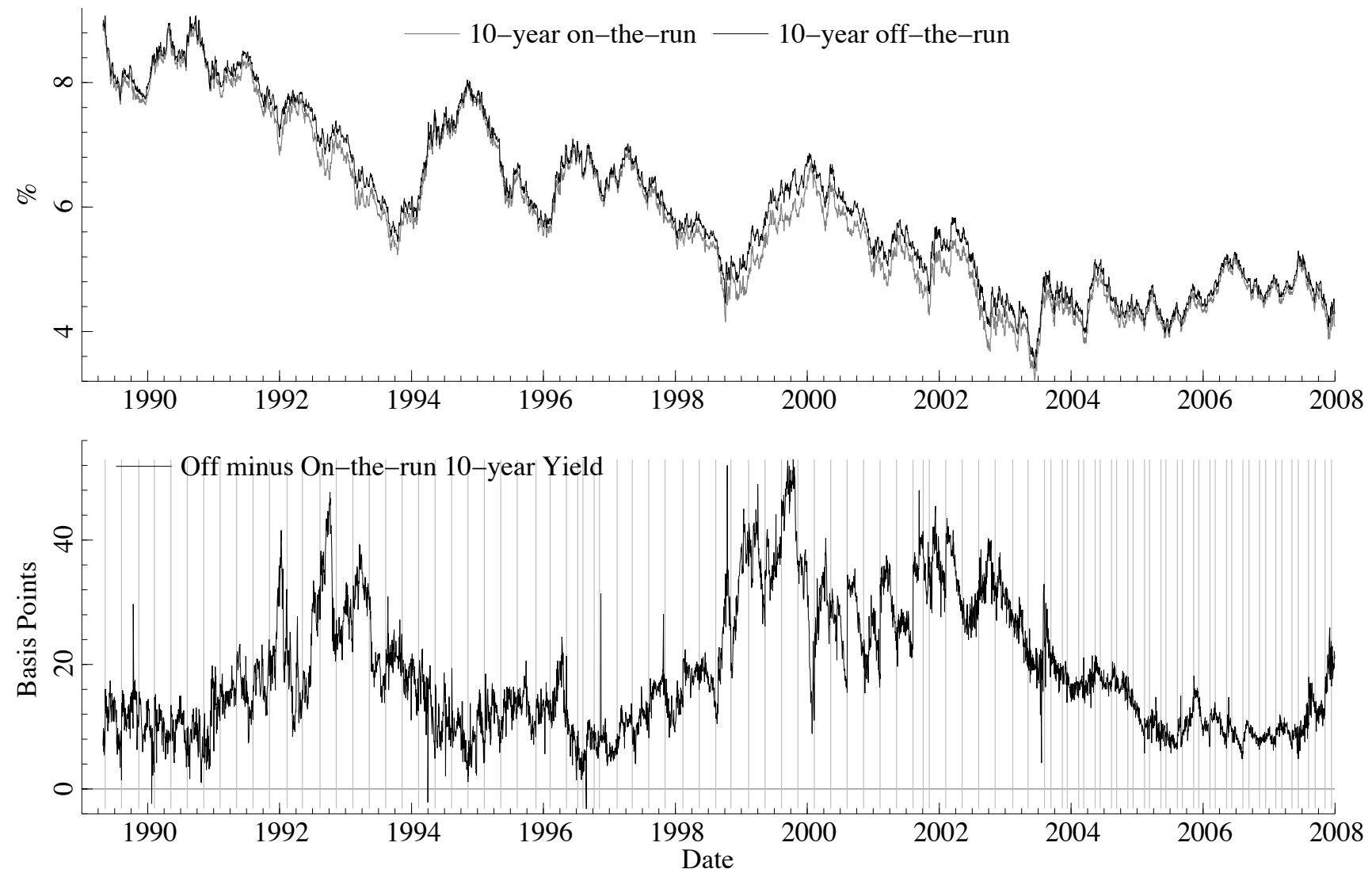


\section{Figure 4.29: Cumulative Changes in Relative on-the-run Yields}

The figure shows the cumulative changes in relative yields from the Bloomberg on/off-the-run discount yield curve over a period beginning 5 business days before until 4 days following an auction, expressed in basis points. Each frame shows the period around the auction event of the maturity horizon shown in the top left corner. Dark solid vertical lines represent auction events, dashed lines announcements and light solid lines issue dates after auctions.

No twenty-year auctions take place during the sample period, and the four and seven-year event frames represent only 7 and 16 auctions respectively.
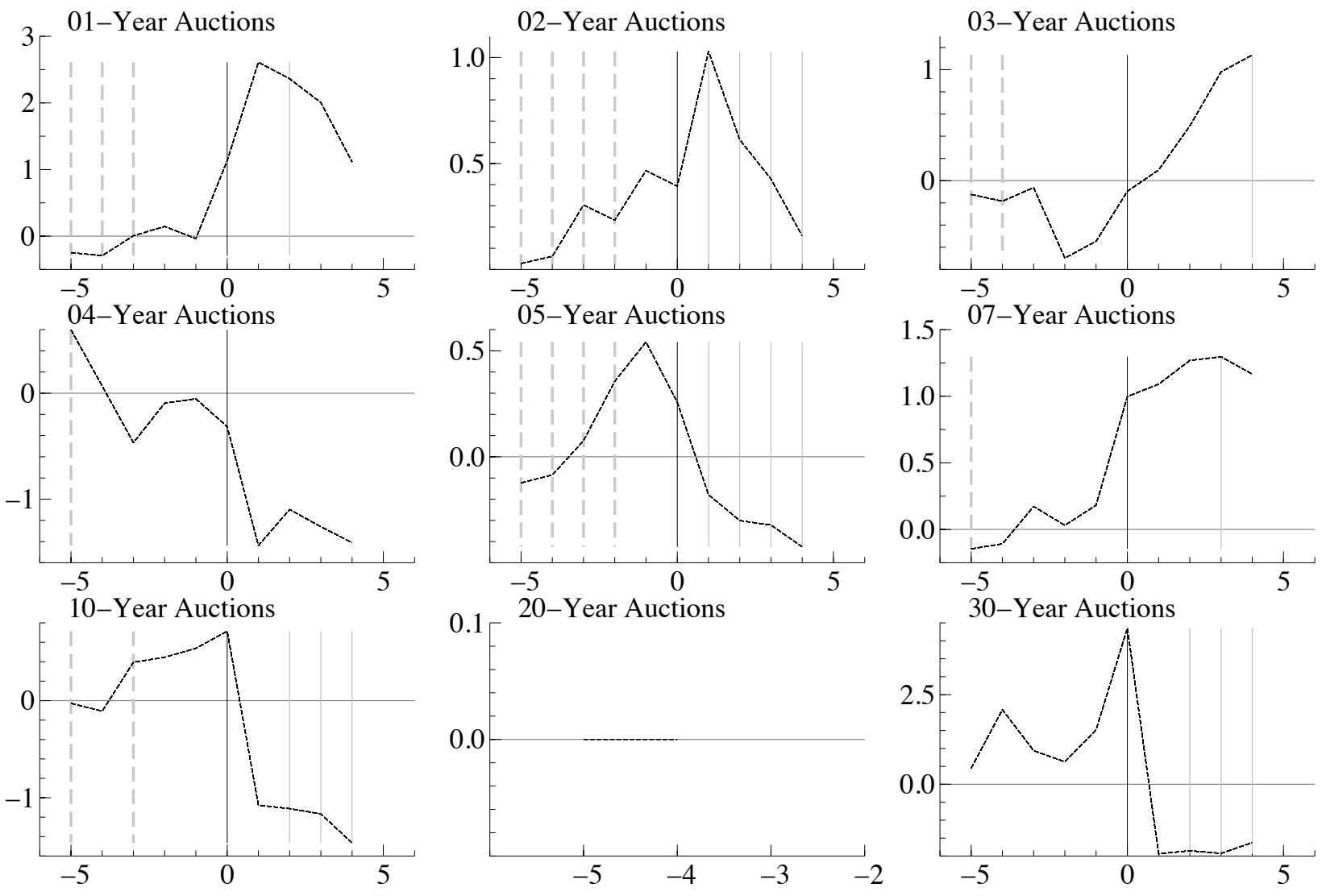


\section{Figure 4.30: Cumulative Changes in On/Off-the-run Relative Yield}

The figure shows the average cumulative changes in on/off-the-run relative yields during the period 50 business days preceding and following an auction, expressed in basis points. Each frame shows the period around the auction event of the maturity horizon shown in the top left corner. Dark solid vertical lines represent auction events, dashed lines announcements and light solid lines issue dates after auctions.

$$
\overline{C A R}^{(N)}(-50, m)=\sum_{\tau=-50}^{m}\left({\overline{\Delta^{o}}}_{\tau}^{(N)}\right), \text { for } m \in\{-50 . .49\}
$$
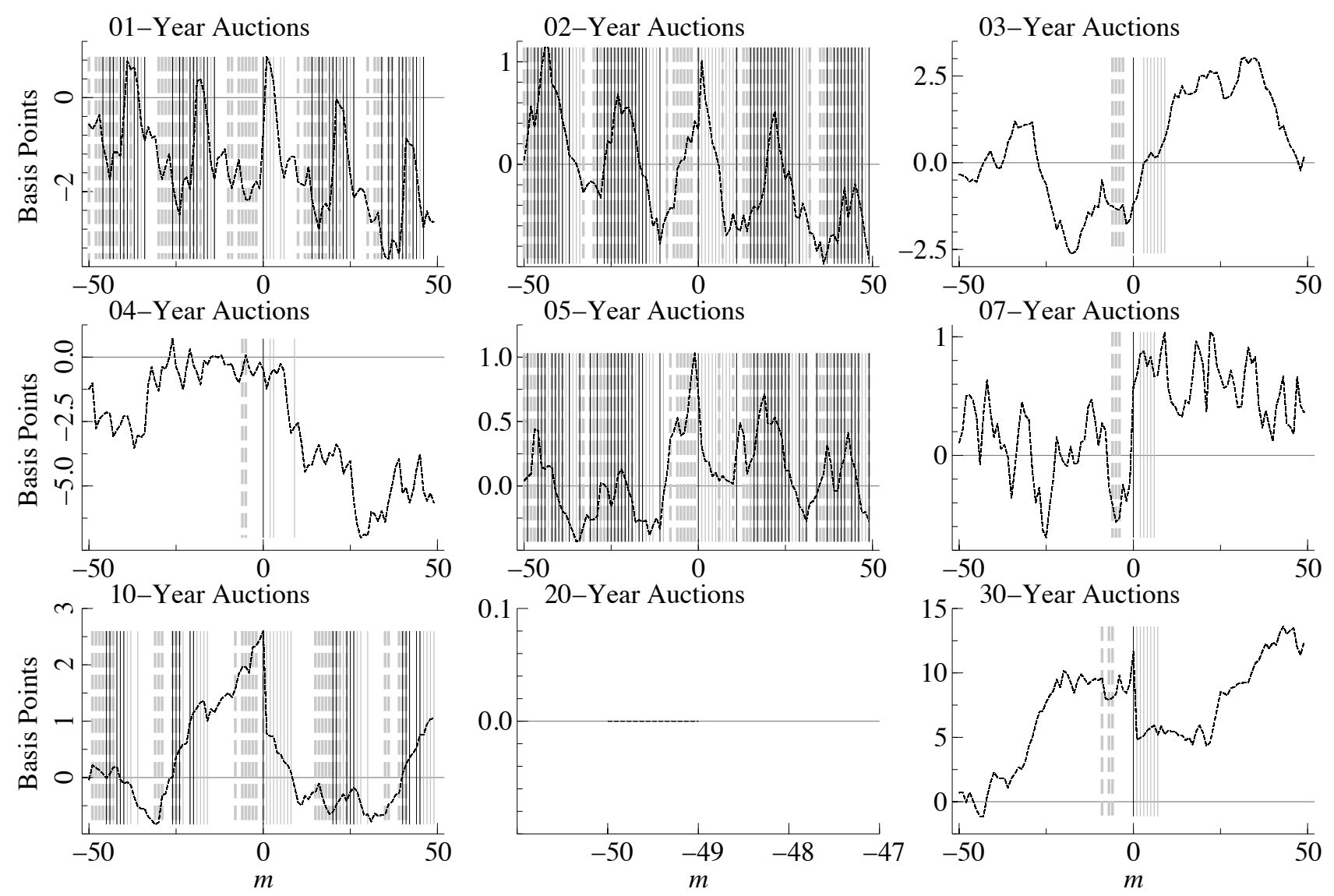
Figure 4.31: Test Statistics for Auction Event Studies On/Off-the-run Relative Yields.

The frames below show test statistics against the null hypothesis of no effect of auctions on relative yields. Each point on the curve represents the t-statistic for the hypothesis that the auction event at the horizon shown in the top corner has no effect on the relative yields shown across the horizontal axis. The solid line shows the test against the hypothesis of no change in either the mean or variance,

$$
\theta_{1}=\frac{\frac{1}{k} \sum_{i=1}^{k} \Delta^{o} \mathbf{Y}_{i}^{(N)}}{\sqrt{\operatorname{Var}\left(\overline{\Delta^{o} \mathbf{Y}_{j}^{(N)}}\right)}}
$$

where each ${ }^{o} \mathbf{Y}_{k}^{(N)}$ is the yield in excess of the average on the day of the auction event, and each $j$ are dates at least 3 days before or after any auction. The dotted lines in each frame show the test statistic against the null of no change in the mean

$$
\theta_{1}^{\prime}=\frac{\frac{1}{k} \sum_{i=1}^{k} \Delta^{o} \mathbf{Y}_{i}^{(N)}}{\sqrt{\frac{1}{N^{2}} \sum_{h=1}^{N}\left(\Delta^{o} \mathbf{Y}_{h}^{(N)}-\frac{1}{l} \sum_{i=1}^{l} \Delta^{o} \mathbf{Y}_{l}^{(N)}\right)^{2}}}
$$

This test does not rely on the subsample of dates not within two days of the auction event to produce an estimate of the variance. The horizontal axis shows the response horizon, each frame represents auctions in different maturity classes. Auctions within 6 months of a particular maturity horizon are considered within the nearest class. For example, 29 year 6 -month auctions are included within the 30 year category.
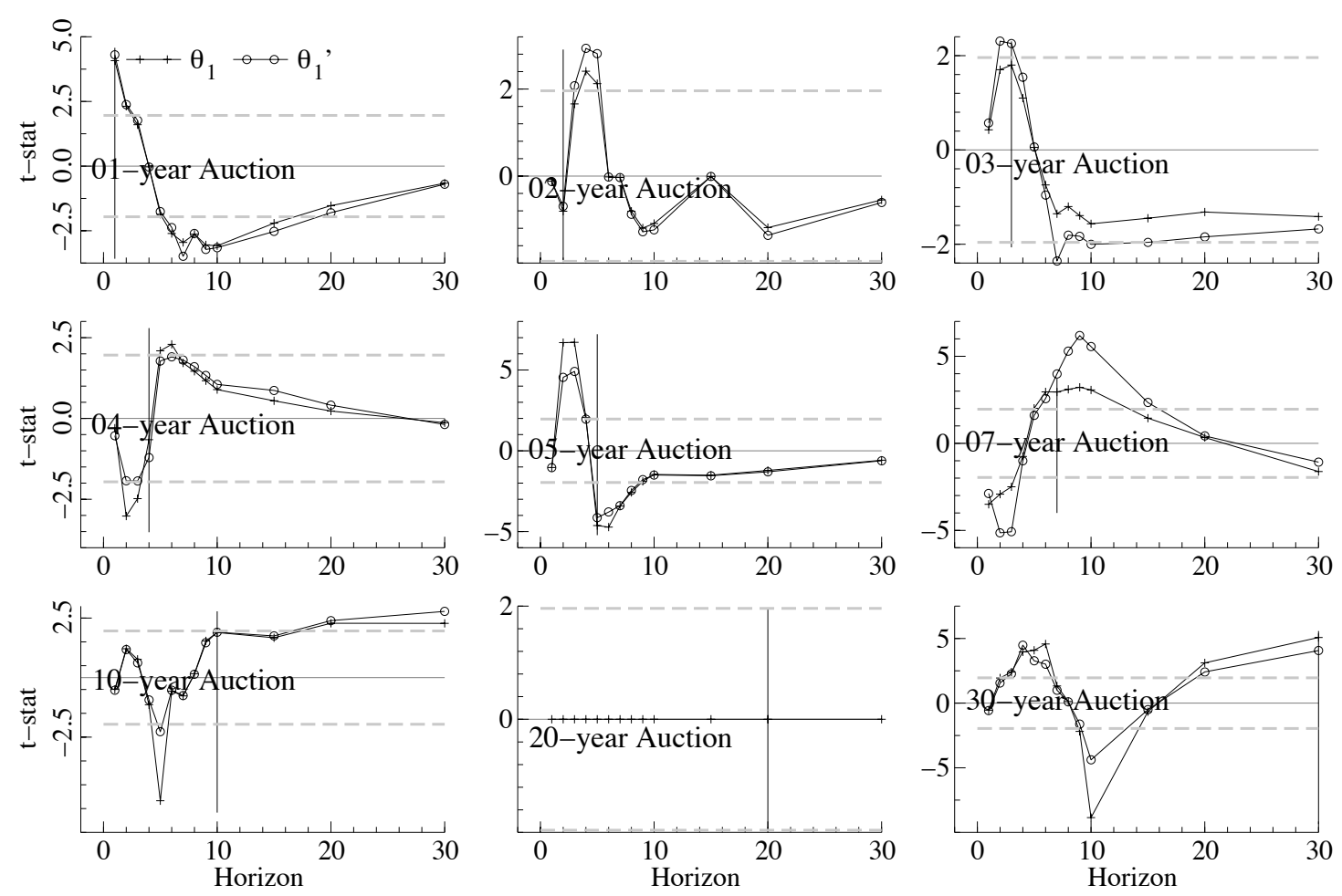
Figure 4.32: Event Studies of Two-day Changes in On/Off-the-run Relative Yields.

The frames below show test statistics against the null hypothesis of no effect of auctions on the two-day change in relative yields from the on-the-run series. Each point on the curve represents the t-statistic for the hypothesis that the auction event at the horizon shown in the top corner has no effect on the relative yields shown across the horizontal axis. The solid line shows the test against the hypothesis of no change in either the mean or variance of the change in relative yield between two days before and the day of the auction.

$$
\theta_{1}=\frac{\frac{1}{k} \sum_{i=1}^{k} \Delta_{2}^{o} \mathbf{Y}_{i}^{(N)}}{\sqrt{\operatorname{Var}\left({\overline{\Delta_{2}{ }^{o} \mathbf{Y}_{j}^{(N)}}}^{(N)}\right.}}
$$

where each $\Delta_{i}{ }^{o} \mathbf{Y}_{k}^{(N)}={ }^{o} \mathbf{Y}_{k}^{(N)}-{ }^{o} \mathbf{Y}_{k-i}^{(N)}$, the change in yield in excess of the average on the day of the auction event, and each $j$ are dates at least 4 days before or after any auction. The dotted lines in each frame show the test statistic against the null of no change in the mean

$$
\theta_{1}^{\prime}=\frac{\frac{1}{k} \sum_{i=1}^{k} \Delta_{2}{ }^{o} \mathbf{Y}_{i}^{(N)}}{\sqrt{\frac{1}{N^{2}} \sum_{h=1}^{N}\left(\Delta_{2}{ }^{o} \mathbf{Y}_{h}^{(N)}-\frac{1}{l} \sum_{i=1}^{l} \Delta_{2}{ }^{o} \mathbf{Y}_{l}^{(N)}\right)^{2}}}
$$

This test does not rely on the subsample of dates not within two days of the auction event to produce an estimate of the variance. The horizontal axis shows the response horizon, each frame represents auctions in different maturity classes. Auctions within 6 months of a particular maturity horizon are considered within the nearest class.
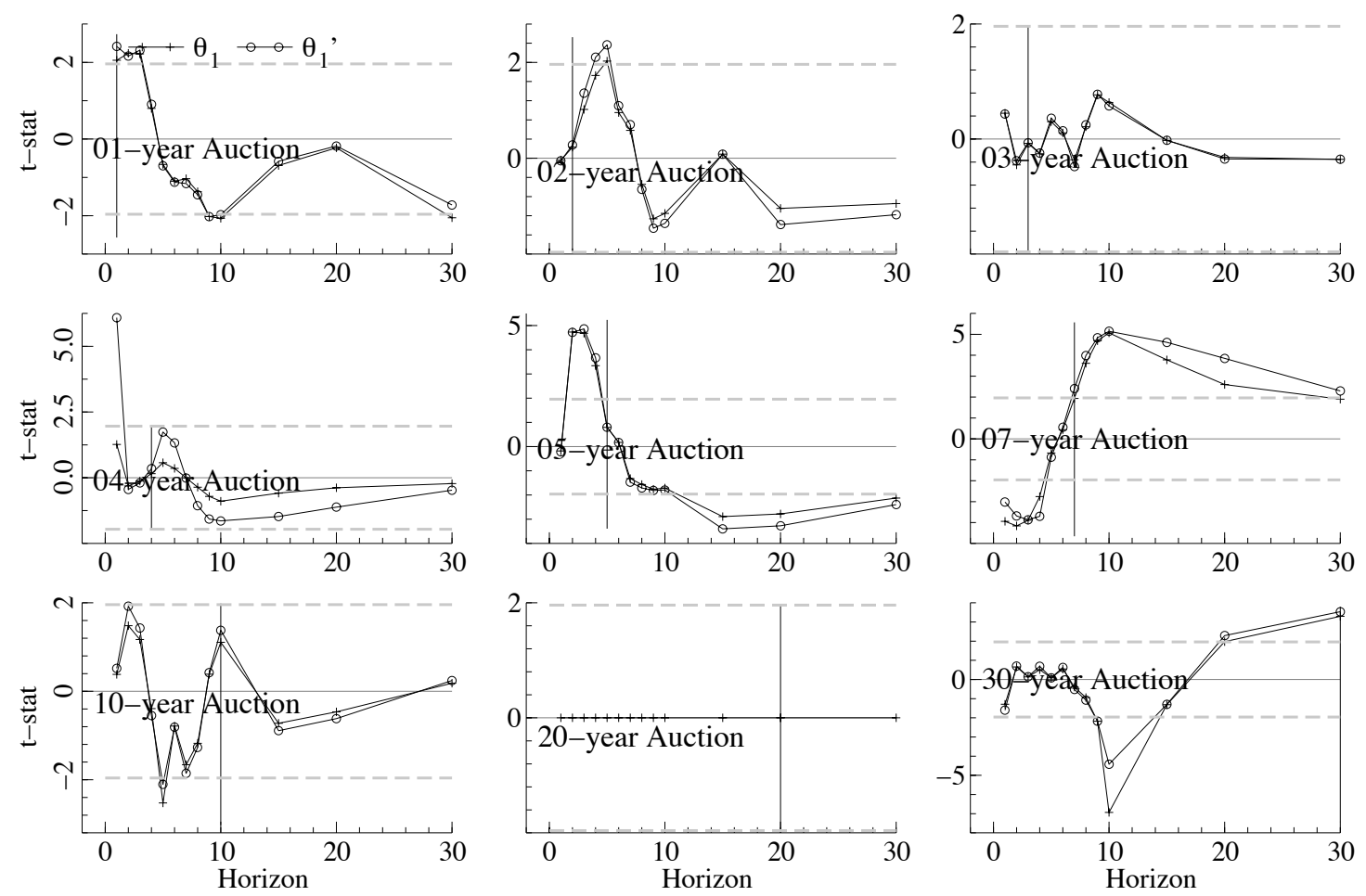
Figure 4.33: Studies of Three-day Changes in On/Off-the-run Relative Yields. The frames below show test statistics against the null hypothesis of no effect of auctions on relative yields from the on-the-run series. Each point on the curve represents the t-statistic for the hypothesis that the auction event at the horizon shown in the top corner has no effect on the relative yields shown across the horizontal axis. The solid line shows the test against the hypothesis of no change in either the mean or variance of the change in relative yield between three days before and the day of the auction.

$$
\theta_{1}=\frac{\frac{1}{k} \sum_{i=1}^{k} \Delta_{3}{ }^{o} \mathbf{Y}_{i}^{(N)}}{\sqrt{\operatorname{Var}\left({\overline{\Delta_{3}}}^{o} \mathbf{Y}_{j}^{(N)}\right)}}
$$

where each $\Delta_{i}{ }^{o} \mathbf{Y}_{k}^{(N)}={ }^{o} \mathbf{Y}_{k}^{(N)}-{ }^{o} \mathbf{Y}_{k-i}^{(N)}$, the change in yield in excess of the average on the day of the auction event, and each $j$ are dates at least 5 days before or after any auction. The dotted lines in each frame show the test statistic against the null of no change in the mean

$$
\theta_{1}^{\prime}=\frac{\frac{1}{k} \sum_{i=1}^{k} \Delta_{3}{ }^{o} \mathbf{Y}_{i}^{(N)}}{\sqrt{\frac{1}{N^{2}} \sum_{h=1}^{N}\left(\Delta_{3}{ }^{o} \mathbf{Y}_{h}^{(N)}-\frac{1}{l} \sum_{i=1}^{l} \Delta_{3}{ }^{o} \mathbf{Y}_{l}^{(N)}\right)^{2}}}
$$

The horizontal axis shows the response horizon, each frame represents auctions in different maturity classes. Auctions within 6 months of a particular maturity horizon are considered within the nearest class. For example, 29 year 6-month auctions are included within the 30 year category.
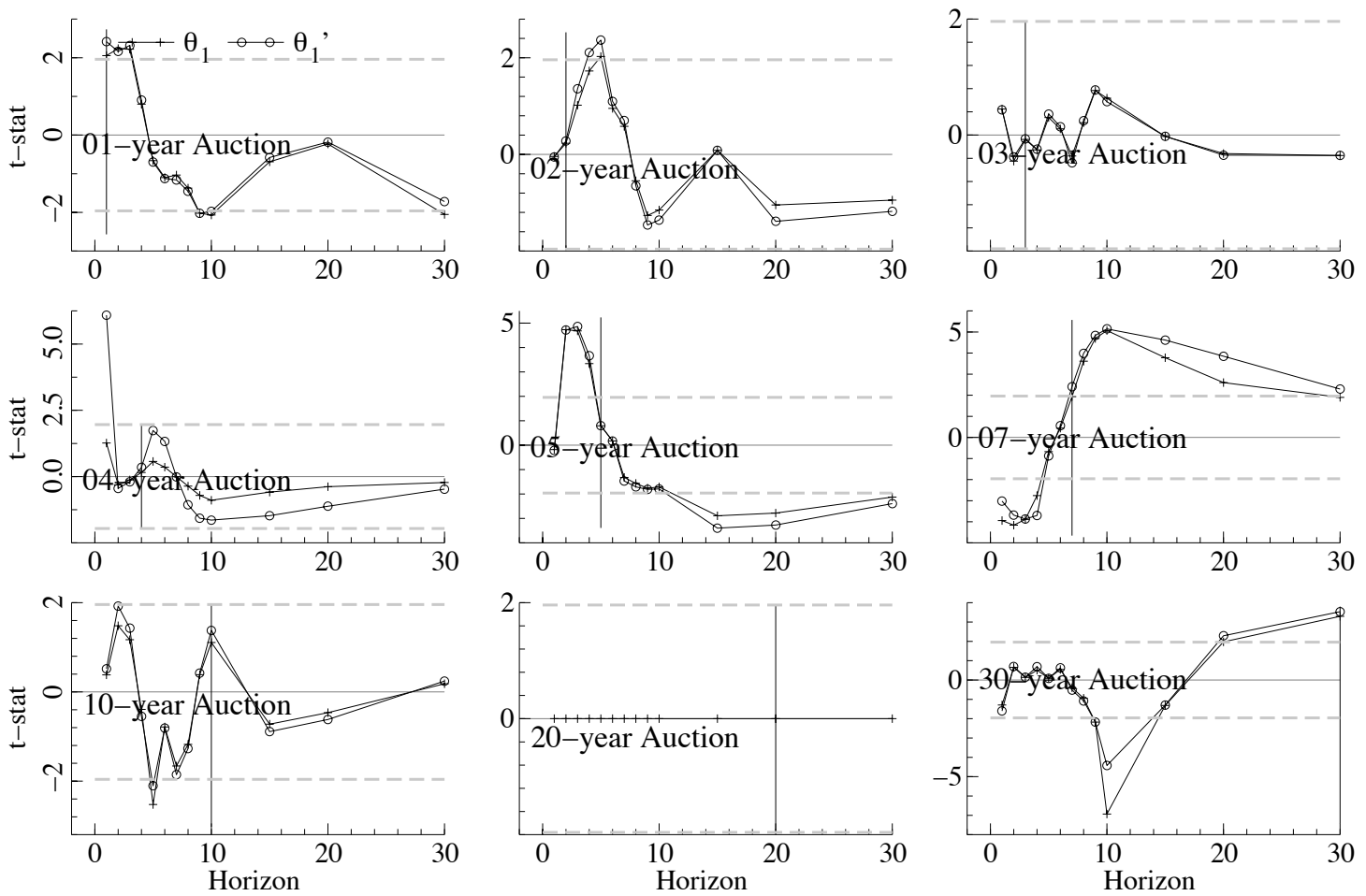
Figure 4.34: Changes in On/Off-the-run Relative Yields Between Previous and Following Day.

The frames below show test statistics against the null hypothesis of no effect of auctions on relative yields. Each point on the curve represents the t-statistic for the hypothesis that the auction event at the horizon shown in the top corner has no effect on the relative yields shown across the horizontal axis. The solid line shows the test against the hypothesis of no change in either the mean or variance of the change in relative yield between one day before until one day after the auction event.

$$
\theta_{1}=\frac{\frac{1}{k} \sum_{i=1}^{k} L^{-1}\left({ }^{o} \mathbf{Y}_{i}^{(N)}\right)-L\left({ }^{o} \mathbf{Y}_{i}^{(N)}\right)}{\sqrt{\operatorname{Var}\left(\overline{L^{-1}\left({ }^{o} \mathbf{Y}_{i}^{(N)}\right)-L\left({ }^{o} \mathbf{Y}_{i}^{(N)}\right)}\right)}}
$$

where $L(\cdot)$ is the lag operator, and each ${ }^{o} \mathbf{Y}_{k}^{(N)}$ is the $k^{t h}$ auction event. $L^{-1}\left({ }^{o} \mathbf{Y}_{i}^{(N)}\right)-L\left({ }^{o} \mathbf{Y}_{i}^{(N)}\right)$ equals the change in yield in excess of the average between the day before of the auction event and the next business day. Each $j$ are dates at least 2 days before or after any auction. The dotted lines in each frame show the test statistic against the null of no change in the mean

$$
\theta_{1}^{\prime}=\frac{\frac{1}{k} \sum_{i=1}^{k} L^{-1}\left({ }^{o} \mathbf{Y}_{i}^{(N)}\right)-L\left({ }^{o} \mathbf{Y}_{i}^{(N)}\right)}{\sqrt{\frac{1}{N^{2}} \sum_{h=1}^{N}\left(L^{-1}\left({ }^{o} \mathbf{Y}_{h}^{(N)}\right)-L\left({ }^{o} \mathbf{Y}_{h}^{(N)}\right)-\frac{1}{l} \sum_{i=1}^{l}\left(L^{-1}\left({ }^{o} \mathbf{Y}_{i}^{(N)}\right)-L\left({ }^{o} \mathbf{Y}_{i}^{(N)}\right)\right)\right)}}
$$

The horizontal axis shows the response horizon, each frame represents auctions in different maturity classes. Auctions within 6 months of a particular maturity horizon are considered within the nearest class. For example, 29 year 6-month auctions are included within the 30 year category.
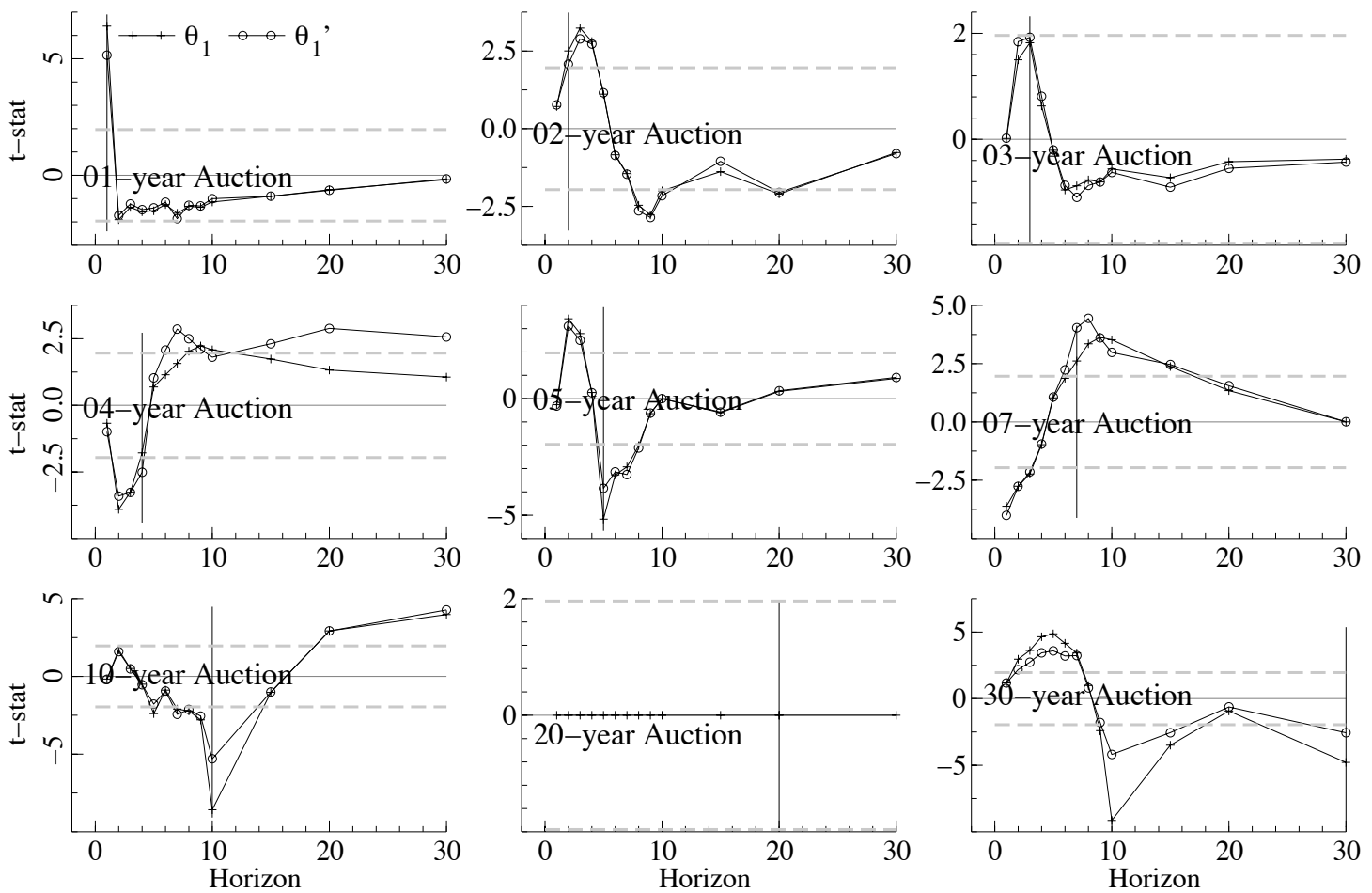
Figure 4.35: Changes in On/Off-the-run Relative Yields Between Previous and Two-Business Days Following Auction.

The frames below show test statistics against the null hypothesis of no effect of auctions on relative yields. Each point on the curve represents the t-statistic for the hypothesis that the auction event at the horizon shown in the top corner has no effect on the relative yields shown across the horizontal axis. The solid line shows the test against the hypothesis of no change in either the mean or variance of the change in relative yields one day before and two days after the auction event.

$$
\theta_{1}=\frac{\frac{1}{k} \sum_{i=1}^{k} L^{-2}\left({ }^{o} \mathbf{Y}_{i}^{(N)}\right)-L\left({ }^{o} \mathbf{Y}_{i}^{(N)}\right)}{\sqrt{\operatorname{Var}\left(\overline{L^{-2}\left({ }^{o} \mathbf{Y}_{i}^{(N)}\right)-L\left({ }^{o} \mathbf{Y}_{i}^{(N)}\right)}\right)}}
$$

where $L(\cdot)$ is the lag operator, and each $\left.{ }^{o} \mathbf{Y}_{k}^{(N)}\right)$ is the $k^{t h}$ auction event. $L^{-2}\left({ }^{o} \mathbf{Y}_{i}^{(N)}\right)-L\left({ }^{o} \mathbf{Y}_{i}^{(N)}\right)$ equals the change in yield in excess of the average between the day before of the auction event and the next business day. Each $j$ are dates at least 2 days before or after any auction. The dotted lines in each frame show the test statistic against the null of no change in the mean

$$
\theta_{1}^{\prime}=\frac{\frac{1}{k} \sum_{i=1}^{k} L^{-2}\left({ }^{o} \mathbf{Y}_{i}^{(N)}\right)-L^{2}\left({ }^{o} \mathbf{Y}_{i}^{(N)}\right)}{\sqrt{\frac{1}{N^{2}} \sum_{h=1}^{N}\left(L^{-2}\left({ }^{o} \mathbf{Y}_{h}^{(N)}\right)-L\left({ }^{o} \mathbf{Y}_{h}^{(N)}\right)-\frac{1}{l} \sum_{i=1}^{l}\left(L^{-2}\left({ }^{o} \mathbf{Y}_{i}^{(N)}\right)-L\left({ }^{o} \mathbf{Y}_{i}^{(N)}\right)\right)\right)}}
$$

The horizontal axis shows the response horizon, each frame represents auctions in different maturity classes. Auctions within 6 months of a particular maturity horizon are considered within the nearest class. For example, 29 year 6-month auctions are included within the 30 year category.
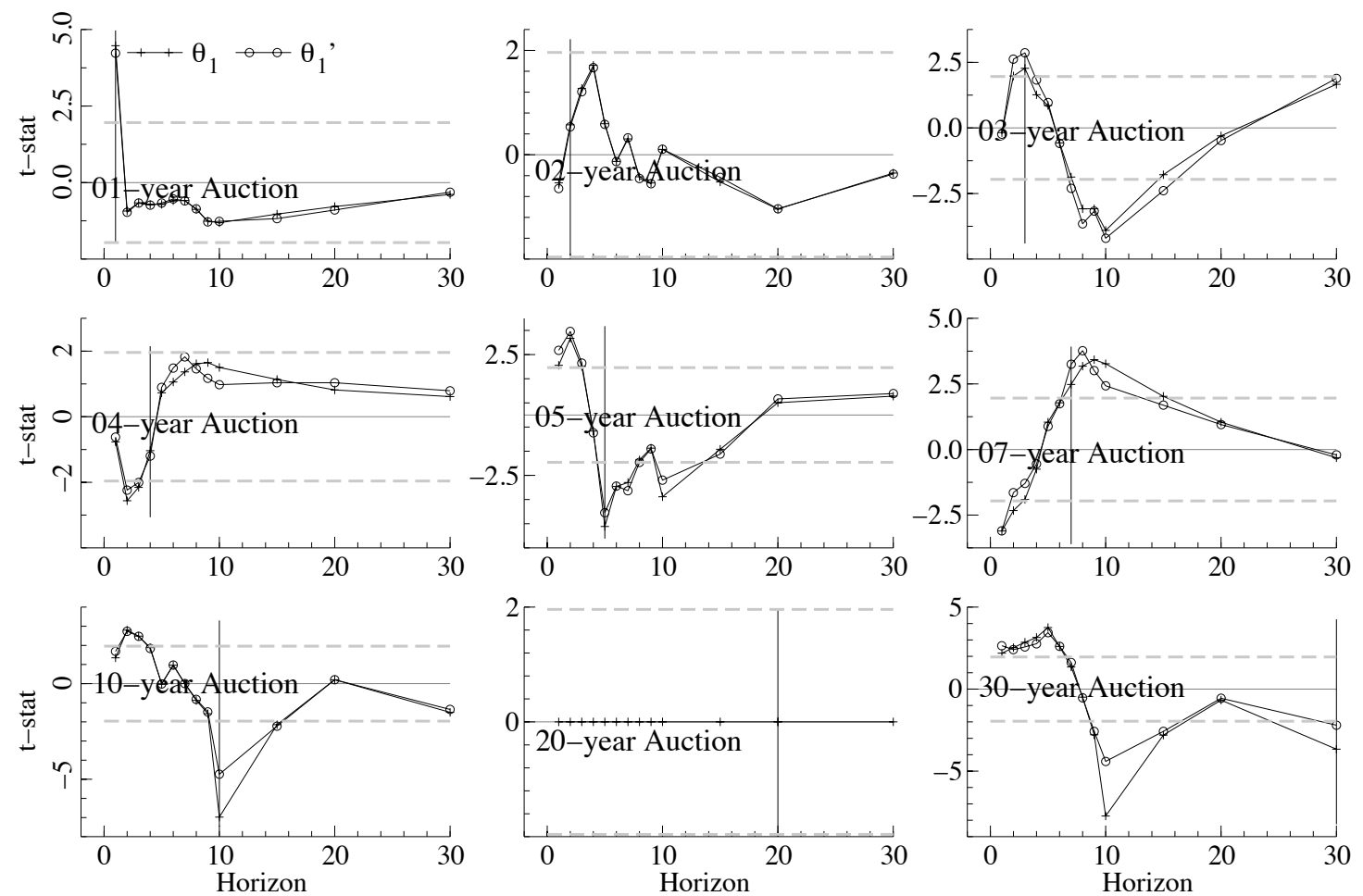
Figure 4.36: Changes in On/Off-the-run Relative Yields Between Previous and Three-Business Days Following Auction.

The frames below show test statistics against the null hypothesis of no effect of auctions on relative yields. Each point on the curve represents the t-statistic for the hypothesis that the auction event at the horizon shown in the top corner has no effect on the relative yields shown across the horizontal axis. The solid line shows the test against the hypothesis of no change in either the mean or variance of the change in relative yield between the previous and three days after the auction event.

$$
\theta_{1}=\frac{\frac{1}{k} \sum_{i=1}^{k} L^{-3}\left({ }^{o} \mathbf{Y}_{i}^{(N)}\right)-L\left({ }^{o} \mathbf{Y}_{i}^{(N)}\right)}{\sqrt{\operatorname{Var}\left(\overline{L^{-3}\left({ }^{o} \mathbf{Y}_{i}^{(N)}\right)-L\left({ }^{o} \mathbf{Y}_{i}^{(N)}\right)}\right)}}
$$

where $L(\cdot)$ is the lag operator, and each $\left.{ }^{o} \mathbf{Y}_{k}^{(N)}\right)$ is the $k^{t h}$ auction event. $L^{-3}\left({ }^{o} \mathbf{Y}_{i}^{(N)}\right)-L\left({ }^{o} \mathbf{Y}_{i}^{(N)}\right)$ equals the change in yield in excess of the average between the day before of the auction event and the next business day. Each $j$ are dates at least 3 days before or after any auction. The dotted lines in each frame show the test statistic against the null of no change in the mean

$$
\theta_{1}^{\prime}=\frac{\frac{1}{k} \sum_{i=1}^{k} L^{-3}\left({ }^{o} \mathbf{Y}_{i}^{(N)}\right)-L\left({ }^{o} \mathbf{Y}_{i}^{(N)}\right)}{\sqrt{\frac{1}{N^{2}} \sum_{h=1}^{N}\left(L^{-3}\left({ }^{o} \mathbf{Y}_{h}^{(N)}\right)-L\left(o \mathbf{Y}_{h}^{(N)}\right)-\frac{1}{l} \sum_{i=1}^{l}\left(L^{-3}\left({ }^{o} \mathbf{Y}_{i}^{(N)}\right)-L\left({ }^{o} \mathbf{Y}_{i}^{(N)}\right)\right)\right.}} .
$$

The horizontal axis shows the response horizon, each frame represents auctions in different maturity classes. Auctions within 6 months of a particular maturity horizon are considered within the nearest class. For example, 29 year 6-month auctions are included within the 30 year category.
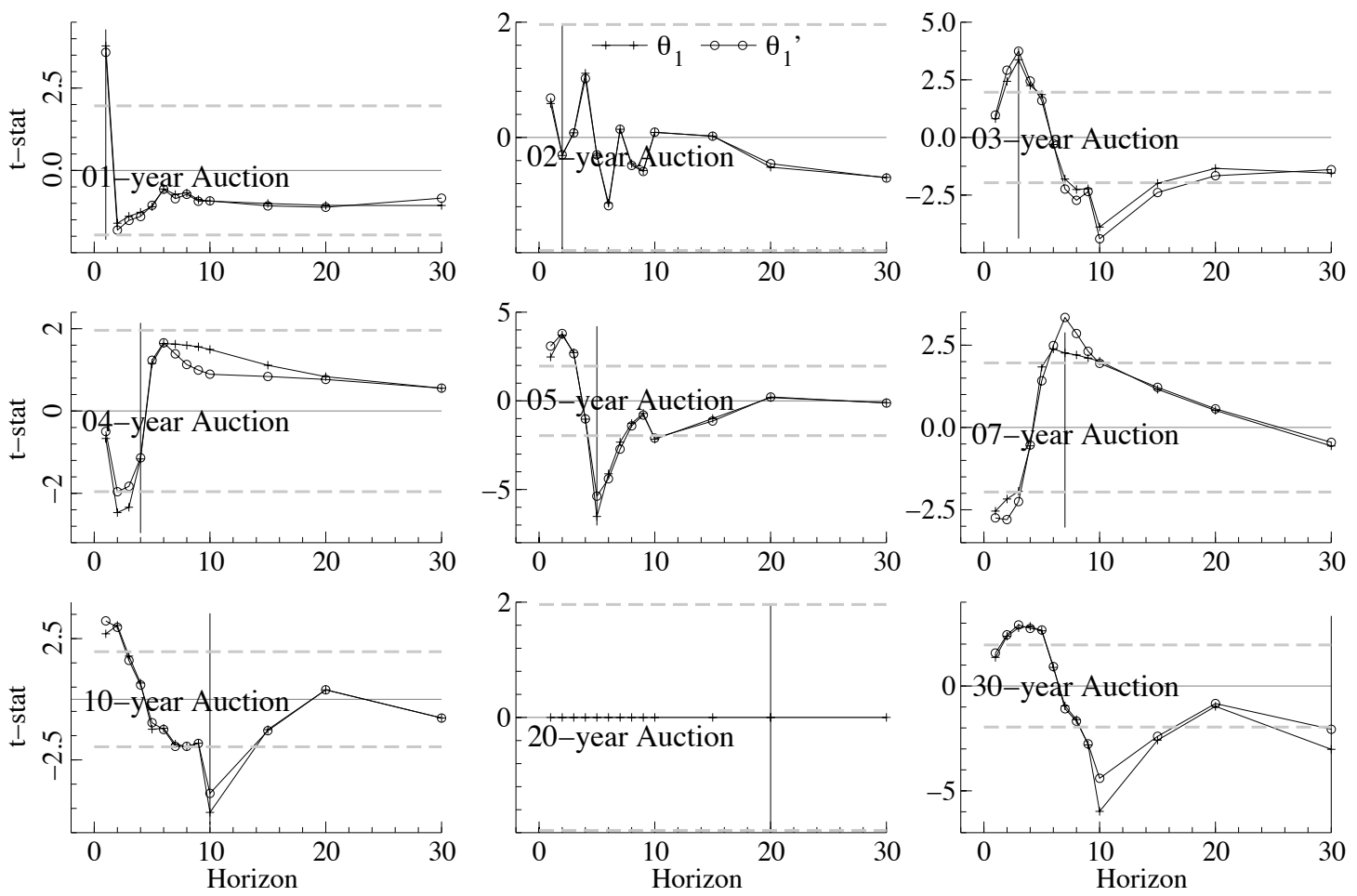
Figure 4.37: Changes in On/Off-the-run Relative Yields Between Previous and Four-Business Days Following Auction.

The frames below show test statistics against the null hypothesis of no effect of auctions on relative yields. Each point on the curve represents the t-statistic for the hypothesis that the auction event at the horizon shown in the top corner has no effect on the relative yields shown across the horizontal axis. The solid line shows the test against the hypothesis of no change in either the mean or variance of the change in relative yield between the previous and four days after the auction event.

$$
\theta_{1}=\frac{\frac{1}{k} \sum_{i=1}^{k} L^{-4}\left({ }^{o} \mathbf{Y}_{i}^{(N)}\right)-L\left({ }^{o} \mathbf{Y}_{i}^{(N)}\right)}{\sqrt{\operatorname{Var}\left(\overline{L^{-4}\left({ }^{o} \mathbf{Y}_{i}^{(N)}\right)-L\left({ }^{o} \mathbf{Y}_{i}^{(N)}\right)}\right)}}
$$

where $L(\cdot)$ is the lag operator, and each $\left.{ }^{o} \mathbf{Y}_{k}^{(N)}\right)$ is the $k^{t h}$ auction event. $L^{-4}\left({ }^{o} \mathbf{Y}_{i}^{(N)}\right)-L\left({ }^{o} \mathbf{Y}_{i}^{(N)}\right)$ equals the change in yield in excess of the average between the day before of the auction event and the next business day. Each $j$ are dates at least 4 days before or after any auction. The dotted lines in each frame show the test statistic against the null of no change in the mean

$$
\theta_{1}^{\prime}=\frac{\frac{1}{k} \sum_{i=1}^{k} L^{-4}\left({ }^{o} \mathbf{Y}_{i}^{(N)}\right)-L\left({ }^{o} \mathbf{Y}_{i}^{(N)}\right)}{\sqrt{\frac{1}{N^{2}} \sum_{h=1}^{N}\left(L^{-4}\left({ }^{o} \mathbf{Y}_{h}^{(N)}\right)-L\left(o \mathbf{Y}_{h}^{(N)}\right)-\frac{1}{l} \sum_{i=1}^{l}\left(L^{-4}\left({ }^{o} \mathbf{Y}_{i}^{(N)}\right)-L\left({ }^{o} \mathbf{Y}_{i}^{(N)}\right)\right)\right.}} .
$$

The horizontal axis shows the response horizon, each frame represents auctions in different maturity classes. Auctions within 6 months of a particular maturity horizon are considered within the nearest class. For example, 29 year 6-month auctions are included within the 30 year category.
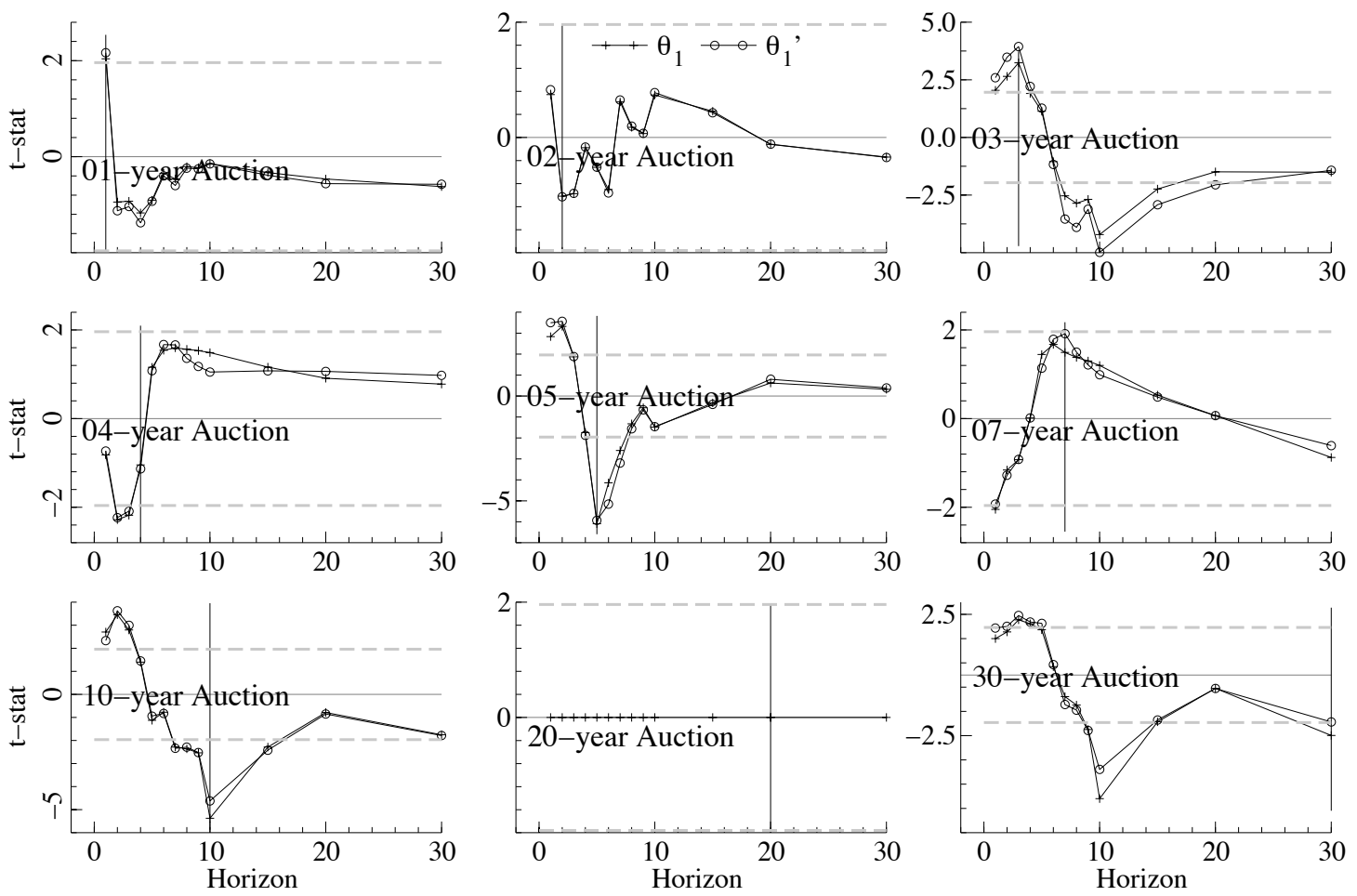


\section{References}

Asquith, P., Mullins, D., 1986. Equity issues and offering dilution. Journal of Financial Economics 15, 61-89.

Babbel, D., Merrill, C., Meyer, M., De Villiers, M., 2004. The effect of transaction size on off-the-run treasury prices. Journal of Financial and Quantitative Analysis, 595-611.

Balduzzi, P., Elton, E., Green, T., 2009. Economic news and bond prices: Evidence from the us treasury market. Journal of Financial and Quantitative Analysis 36 (04), 523-543.

Cagan, P., 1956. The Monetary Dynamics of Hyper-Inflation. Studies in the Quantity theory of Money. University of Chicago Press.

Campbell, J. Y., Lo, a. W., MacKinlay, C. A., 1997. The Econometrics of Financial Markets. Princeton University Press.

Carpenter, S., Demiralp, S., June 2006. The liquidity effect in the federal funds market: Evidence from daily open market operations. Journal of Money, Credit, and Banking 38 (4), 901-920.

Carpenter, S., Demiralp, S., 2008. The liquidity effect in the federal funds market: Evidence at the monthly frequency. Journal of Money, Credit, and Banking 40 (1), 1.

Doornik, J. A., 2007. Object-Oriented Matrix Programming Using Ox, 3rd Edition. Timberlake Consultants Press and Oxford.

Estrella, A., Hardouvelis, G., 1991. The term structure as a predictor of real economic activity. Journal of Finance, 555-576. 
Estrella, A., Mishkin, F., 1998. Predicting us recessions: Financial variables as leading indicators. Review of Economics and Statistics 80 (1), 45-61.

Fama, E., Fisher, L., Jensen, M., Roll, R., 1969. The adjustment of stock prices to new information. International Economic Review, 1-21.

Feinman, J., May 1993. Estimating the open market desk's daily reaction function. Journal of Money, Credit, and Banking 25 (2), 231-247.

Fleming, M., Remolona, E., 1999. Price formation and liquidity in the us treasury market: the response to public information. Journal of Finance, 1901-1915.

Fleming, M. J., 2002. Are larger treasury issues more liquid? evidence from bill reopenings. Journal of Money, Credit and Banking 34 (3), 707-735.

Florio, A., 2006. Asymmetric interest rate smoothing: the fed approach. Economics Letters $93(2), 190-195$.

Garbade, K., 2007. The emergence of 'regular and predictable' as a treasury debt management strategy. Economic Policy Review 13 (1).

Gilchrist, S., July-August 2001. Identifying the liquidity effect at the daily frequency (commentary). Federal Reserve Bank of St. Louis Review 83 (4), 59-82.

Goldreich, D., Hanke, B., Nath, P., 2005. The price of future liquidity: Time-varying liquidity in the us treasury market. Review of Finance 9 (1), 1-32.

Gürkaynak, R., Sack, B., Wright, J., 2007. The u.s. treasury yield curve: 1961 to the present. Journal of Monetary Economics 54 (8), 2291-2304. 
Guthrie, G., Wright, J., 2002. The optimal design of interest rate target changes. SSRN ELibrary.

Guthrie, G., Wright, J., February 2004. The optimal design of interest rate target changes. Journal of Money, Credit, and Banking 36 (1), 115-137.

Hamilton, J. D., 1997. Measuring the liquidity effect. American Economic Review 87 (1), 80-97.

Hamilton, J. D., Jordá, O., February 2002. A model for the federal funds rate target. Journal of Political Economy 110 (5), 1135-67.

Harvey, C. a., 1989. Forecasting, Structural Time Series Models and the Kalman Filter. University of Cambridge.

Hausman, J. A., Lo, a. W., MacKinlay, A. C., June 1992. An ordered probit analysis of transaction stock prices. Journal of Financial Economics 31 (3), 319-379.

Holthausen, R., Leftwich, R., Mayers, D., 1987. The effect of large block transactions on security prices: A cross-sectional analysis. Journal of Financial Economics 19 (2), 237267.

Hughes, M., Smith, S., Winters, D., 2008. The effect of auctions on daily treasury-bill volatility. Quarterly Review of Economics and Finance 48 (1), 48-60.

Kos, D., 2004. Domestic open market operations during 2004. Annual Report Domestic Open Market Operations. 
MacKinlay, A., 1997. Event studies in economics and finance. Journal of Economic Literature, 13-39.

Mankiw, N., 1987. The optimal collection of seigniorage. Journal of Monetary Economics $20(2), 327-41$.

McCallum, B. T., 1981. Price level determinacy with an interest rate policy rule and rational expectations. Journal of Monetary Economics 8 (3), 319 - 329.

Myers, R. H., 1990. Classical and Modern Regression With Applications. Duxbury.

Nerlove, M., 1958. Adaptive expectations and cobweb phenomena. The Quarterly Journal of Economics 72 (2), 227-240.

Rudebusch, G., 2002. Term structure evidence on interest rate smoothing and monetary policy inertia. Journal of Monetary Economics 49 (6), 1161 - 1187.

Sack, B., Wieland, V., 2000. Interest-rate smoothing and optimal monetary policy: A review of recent empirical evidence. Journal of Economics and Business 52 (1-2), 205-228.

Scholes, M., 1972. The market for securities: Substitution versus price pressure and the effects of information on share prices. Journal of Business, 179-211.

Seligman, J., 2006. Does urgency affect price at market? An analysis of us treasury shortterm finance. Journal of Money Credit and Banking 38 (4), 989.

Simon, D., 1991. Segmentation in the treasury bill market: Evidence from cash management bills. Journal of Financial and Quantitative Analysis, 97-108. 
Simon, D., 1994. Further evidence on segmentation in the treasury bill market. Journal of Banking and Finance 18, 139-151.

Taylor, J. B., July-August 2001. Expectations, open market operations, and changes in the federal funds rate. Federal Reserve Bank of St. Louis Review 83 (4), 33-58.

Thornton, D. L., July 2001. Identifying the liquidity effect at the daily frequency. Federal Reserve Bank of St. Louis Review 83 (4), 59-82.

Thornton, D. L., 2004. The fed and short term rates: Is it open market operations, open mouth operations, or interest rate smoothing? Journal of Banking and Finance 28, 475498.

Thornton, D. L., April 2006. The daily liquidity effect. Working Papers 2006-020A, Federal Reserve Bank of St. Louis.

Thornton, D. L., November/December 2007. Open market operations and the federal funds rate. Federal Reserve Bank of St. Louis Review 89 (6), 549-570.

Warga, A., 1992. Bond returns, liquidity, and missing data. Journal of Financial and Quantitative Analysis, 605-617.

Woodford, M., July 1999. Optimal monetary policy inertia. NBER Working Papers 7261, National Bureau of Economic Research, Inc. 


\section{Appendix A}

\section{Appendix: The Kalman Filter}

A state space model consists of a measurement or observation equation

$$
y_{t}=\mathbf{C} x_{t}+\mathbf{H} \alpha_{t}+e_{t}
$$

and transition equation, describing the path of the state variable,

$$
\alpha_{t}=\mathbf{A}+\mathbf{F} \alpha_{t-1}+v_{t}
$$

Where $y_{t}$ is a $n \times 1$ vector observed at time $t$, and $\alpha_{t}$ a $k \times 1$ vector of unobserved state variables. The $n \times k$ matrix $\mathbf{H}$ relates the observed and unobserved components, and the $k \times k$ matrix $\mathbf{F}$ relates the $k$ state variables to their lagged values. The $n \times r$ matrix $\mathbf{C}$ consists of parameters relating $y_{t}$ to the $r \times 1$ vector of exogenous or predetermined variables $x_{t}$. Let $\mathbb{E}(\cdot)$ be the expectations operator based on all information available in the previous period as the observed operand. ${ }^{1}$ Error terms have the properties $\mathbb{E}\left(e_{t}\right)=\mathbb{E}\left(v_{t}\right)=\mathbb{E}\left(e_{t} v_{s}^{\prime}\right)=0$, $\mathbb{E}\left(e_{t} e_{t}^{\prime}\right)=\mathbf{R}$, and $\mathbb{E}\left(v_{t} v_{t}^{\prime}\right)=\mathbf{Q}, \forall t, s$, although the correlation restrictions may be relaxed.

The Kalman filter provides a minimum mean-squared-error estimate of an unobserved state vector $\alpha$ from a two-step algorithm of prediction and updating. For each period $t$, the algorithm produces a prediction of $\alpha_{t+1}$ based on all available up to, and including, $t$. Then,

\footnotetext{
${ }^{1}$ Such as with other notations, given information set $\boldsymbol{\Psi}, E\left(w_{t} \mid \Psi_{t-1}\right)$ or $E_{t \mid t-1}$.
} 
at time $t+1$, after observing the realized value of the observable variable $y_{t+1}$, incorporates the new information included in the prediction error into a forecast for the state vector in period $t+1$.

Given all information available at time $t-1$, let the optimal estimator of $\alpha_{t-1}$ equal $a_{t-1}$ and let $\mathbb{E}\left(a_{t}\right)=\mathbb{E}\left(\alpha_{t}\right)$, the optimal estimate of $\alpha_{t}$ given information up to time $t-1$ be,

$$
\mathbb{E}\left(a_{t}\right)=\mathbb{E}\left(\alpha_{t}\right)=\mathbf{A}+\mathbf{F} a_{t-1} .
$$

Here, it is important to note the distinction between $\alpha_{t}$ and $a_{t}$. The value of $a_{t}$ is based not only on information from periods $\{t-1, t-2, \ldots, 0\}$, but also the observed value of $y_{t-1}$. However, $y_{t-1}$ was not available to forecast $\mathbb{E}\left(a_{t-1}\right)$, just as the information about $y_{t}$ is excluded from the prediction of $\mathbb{E}\left(a_{t}\right)$. The vector $\alpha_{t}$ is unobservable, and, thus, only estimates of its true value can be made.

Let the covariance matrix of the estimation error equal,

$$
\Sigma_{t-1}=\mathbb{E}\left[\left(\alpha_{t-1}-a_{t-1}\right)\left(\alpha_{t-1}-a_{t-1}\right)^{\prime}\right] .
$$

Again, this differs from the expectation of $\boldsymbol{\Sigma}_{t}$, written as

$$
\mathbb{E}\left(\Sigma_{t}\right)=\mathbf{F} \Sigma_{t-1} \mathbf{F}^{\prime}+\mathbf{Q} .
$$

The former is the value of the estimation error covariance, given all information up to, and including, that of the current period. Equations (A-3) and (A-5) are the prediction equations of the Kalman filter.

The updating occurs by finding new values for $a_{t+1}$ and $\boldsymbol{\Sigma}_{t+1}$, given the new information observed at time $t$. These updates are written in terms of the expectations and previous 
realizations of the state and covariance matrix of the estimation errors.

$$
\begin{aligned}
a_{t} & =\mathbb{E}\left(a_{t}\right)+\mathbb{E}\left(\boldsymbol{\Sigma}_{t}\right) \mathbf{H}^{\prime} \mathbf{B}^{-1}\left(y_{t}-\mathbb{E}\left(y_{t}\right)\right) \\
& =\mathbf{A}+\mathbf{F} a_{t-1}+\left(\mathbf{F} \boldsymbol{\Sigma}_{t-1} \mathbf{F}^{\prime}+\mathbf{Q}\right) \mathbf{H}^{\prime} \mathbf{B}^{-1}\left(y_{t}-\mathbb{E}\left(y_{t}\right)\right), \\
\boldsymbol{\Sigma}_{t} & =\mathbb{E}\left(\boldsymbol{\Sigma}_{t}\right)-\mathbb{E}\left(\boldsymbol{\Sigma}_{t}\right) \mathbf{H}^{\prime} \mathbf{B}^{-1} \mathbf{H} \mathbb{E}\left(\boldsymbol{\Sigma}_{t}\right),
\end{aligned}
$$

where $\mathbf{B}=\mathbf{H} \mathbb{E}\left(\boldsymbol{\Sigma}_{t}\right) \mathbf{H}^{\prime}+\mathbf{R}$.

Alternatively, taking

$$
\begin{aligned}
\mathbf{K}_{t} & =\mathbb{E}\left(\boldsymbol{\Sigma}_{t}\right) \mathbf{H}^{\prime} \mathbf{B}^{-1} \\
& =\left(\mathbf{F} \boldsymbol{\Sigma}_{t-1} \mathbf{F}^{\prime}+\mathbf{Q}\right) \mathbf{H}^{\prime} \mathbf{B}^{-1}
\end{aligned}
$$

the updating equations become

$$
\begin{aligned}
a_{t} & =\mathbf{A}+\mathbf{F} a_{t-1}+\mathbf{K}_{t}\left(y_{t}-\mathbb{E}\left(y_{t}\right)\right) \\
\boldsymbol{\Sigma}_{t} & =\mathbb{E}\left(\boldsymbol{\Sigma}_{t}\right)-\mathbf{K}_{t} \mathbf{H} \mathbb{E}\left(\boldsymbol{\Sigma}_{t}\right)
\end{aligned}
$$

The Kalman gain matrix $\mathbf{K}_{t}$ determines the proportion of the present period's error to be included in the next period's estimate of the state vector.

Initiation of the Kalman filter algorithm occurs with appropriately chosen values for $a_{0}$ and $\boldsymbol{\Sigma}_{0}$. From those values, $\mathbb{E}\left(a_{1}\right)$ and $\mathbb{E}\left(\boldsymbol{\Sigma}_{1}\right)$ are calculated, then used along with $y_{1}$ to calculate $\boldsymbol{\Sigma}_{2}$ and $a_{2}$, and so on. For each period $t$, the prediction error equals $\mathbf{v}_{\mathbf{t}}=y_{t}-\mathbb{E}\left(y_{t}\right)$. Numerical methods can be used to minimize the log likelihood over the parameter space $\Psi$,

$$
\log L(\Psi)=-\frac{1}{2} \log 2 \pi-\frac{1}{2} \sum_{t=1}^{T} \log |\mathbf{B}|-\frac{1}{2} \sum_{t=1}^{T} \mathbf{v}_{t}^{\prime} \mathbf{B}^{-1} \mathbf{v}_{t}
$$

Harvey (1989) (pg. 125) provides a complete examination of MLE procedures. 


\section{A.1 Application of the Kalman Filter to the model of $\S 2.3$}

In a univariate case as in the model of $\S 2.3, y$ is a $T \times 1$ vector of observations, $x$ a $T \times k$ non-stochastic matrix and $\mathbf{c}$ a $k \times 1$ vector of parameters relating the exogenous data to the observation series. The measurement equation and transition equations can be written as:

$$
\begin{gathered}
y_{t}=x_{t} \mathbf{c}+\mathbf{H} \alpha_{t} \\
\alpha_{t}=\mathbf{A}+\mathbf{F} \alpha_{t-1}+\mathbf{u}_{\mathbf{t}}
\end{gathered}
$$

with $\mathbf{H}=\left[\begin{array}{ll}1 & 1\end{array}\right], \mathbf{F}=\left[\begin{array}{ll}0 & 0 \\ 0 & 1\end{array}\right], \mathbf{A}=\left[\begin{array}{l}0 \\ \mu\end{array}\right], \mathbf{R}=0$, and $\mathbf{Q}=\operatorname{Var}\left(\mathbf{u}_{t} \mathbf{u}_{t}^{\prime}\right)=\left[\begin{array}{cc}\sigma_{\varepsilon}^{2} & 0 \\ 0 & \sigma_{\xi}^{2}\end{array}\right]$.

This model simplifies to

$$
\begin{aligned}
y_{t} & =x_{t} \mathbf{c}+\left[\begin{array}{ll}
1 & 1
\end{array}\right] \alpha_{t} \\
\alpha_{t} & =\left[\begin{array}{l}
\gamma_{t} \\
\eta_{t}
\end{array}\right]=\left[\begin{array}{l}
0 \\
\mu
\end{array}\right]+\left[\begin{array}{ll}
0 & 0 \\
0 & 1
\end{array}\right]\left[\begin{array}{l}
\gamma_{t-1} \\
\eta_{t-1}
\end{array}\right]+\left[\begin{array}{l}
\varepsilon_{t} \\
\xi_{t}
\end{array}\right]
\end{aligned}
$$

With $\mathbb{E}(\eta)$ and $\mathbb{E}(\gamma)$ the elements of $a$, the optimal predictor of the state variable $\alpha_{t}$, as in equation (A-3), and finding $a_{t-1}$ using (A-6) gives,

$$
\mathbb{E}\left(a_{t}\right)=\mathbb{E}\left(\alpha_{t}\right)=\left[\begin{array}{l}
\mathbb{E}\left(\gamma_{t}\right) \\
\mathbb{E}\left(\eta_{t}\right)
\end{array}\right]=\mathbf{A}+\mathbf{F} a_{t-1}=\left[\begin{array}{l}
0 \\
\mu
\end{array}\right]+\left[\begin{array}{ll}
0 & 0 \\
0 & 1
\end{array}\right]\left(\left[\begin{array}{l}
\mathbb{E}\left(\gamma_{t-1}\right) \\
\mathbb{E}\left(\eta_{t-1}\right)
\end{array}\right]+\mathbf{K}_{t-1} \mathbf{v}_{\mathbf{t}-1}\right)
$$

Since, as shown in Harvey (1989) (pg 119) that

$$
\lim _{t \rightarrow \infty} \mathbf{K}_{t}=\mathbf{K}=\frac{\bar{\Sigma}}{\bar{\Sigma}+\mathbf{R}}
$$


dropping time subscripts, and letting the $i, j^{t h}$ element of $\mathbb{E}(\boldsymbol{\Sigma})=\hat{\sigma}_{i j}$,

$$
\begin{aligned}
\mathbf{K} & =\left(\mathbf{F} \boldsymbol{\Sigma} \mathbf{F}^{\prime}+\mathbf{Q}\right) \mathbf{H}^{\prime} \mathbf{B}^{-1} \\
& =(\mathbb{E}(\boldsymbol{\Sigma})) \mathbf{H}^{\prime}\left(\mathbf{H} \mathbb{E}(\boldsymbol{\Sigma}) \mathbf{H}^{\prime}+\mathbf{R}\right)^{-1} \\
& =\left[\begin{array}{ll}
\hat{\sigma}_{11} & \hat{\sigma}_{12} \\
\hat{\sigma}_{21} & \hat{\sigma}_{22}
\end{array}\right]\left[\begin{array}{l}
1 \\
1
\end{array}\right]\left(\left[\begin{array}{ll}
1 & 1
\end{array}\right]\left[\begin{array}{ll}
\hat{\sigma}_{11} & \hat{\sigma}_{12} \\
\hat{\sigma}_{21} & \hat{\sigma}_{22}
\end{array}\right]\left[\begin{array}{l}
1 \\
1
\end{array}\right]\right)^{-1} \\
& =\left[\begin{array}{c}
\frac{\hat{\sigma}_{11}}{\hat{\sigma}_{11}+\hat{\sigma}_{12}+\hat{\sigma}_{21}+\hat{\sigma}_{22}} \\
\hat{\sigma}_{22}
\end{array}\right]
\end{aligned}
$$

Since covariance terms equal zero,

$$
\mathbf{K}=\left[\begin{array}{c}
\frac{\hat{\sigma}_{11}}{\hat{\sigma}_{11}+\hat{\sigma}_{22}} \\
\frac{\hat{\sigma}_{22}}{\hat{\sigma}_{11}+\hat{\sigma}_{22}}
\end{array}\right]
$$

Rewriting (B-5) gives,

$$
\mathbb{E}\left(\alpha_{t}\right)=\left[\begin{array}{l}
\mathbb{E}\left(\gamma_{t}\right) \\
\mathbb{E}\left(\eta_{t}\right)
\end{array}\right]=\left[\begin{array}{l}
0 \\
\mu
\end{array}\right]+\left[\begin{array}{ll}
0 & 0 \\
0 & 1
\end{array}\right]\left(\left[\begin{array}{l}
\mathbb{E}\left(\gamma_{t-1}\right) \\
\mathbb{E}\left(\eta_{t-1}\right)
\end{array}\right]+\left[\begin{array}{c}
\frac{\hat{\sigma}_{11}}{\hat{\sigma}_{11}+\hat{\sigma}_{22}} \\
\frac{\hat{\sigma}_{22}}{\hat{\sigma}_{11}+\hat{\sigma}_{22}}
\end{array}\right] \mathbf{v}_{\mathbf{t}-\mathbf{1}}\right)
$$

Harvey (1989) (pg. 111) shows that the prediction error

$$
\mathbf{v}_{t}=y_{t}-E_{t-1} y_{t}=\mathbf{H}\left(\alpha_{t}-a_{t}\right)+e_{t}, \quad \forall t=\{1 . . T\}
$$

In this framework, $e_{t}=0 \forall t$, since that component exists in the state vector as $\varepsilon$. Whether the state $\alpha$ is defined as the scalar sum of $\eta_{t}+e_{t}$, or as the vector $\left[\begin{array}{c}\gamma_{t} \\ \eta_{t}\end{array}\right]$, with $\gamma_{k}=e_{k}$, entering into the measurement equation as $\mathbf{H} \alpha_{t}$ is irrelevant. The vector representation provided here provides a clearer intuition as to how the prediction error is partitioned, and how the partition would be incorporated under a different specification of $\mathbf{F}$. Using (B-12), (B-11) can be written as:

$\mathbb{E}\left(a_{t}\right)=\mathbb{E}\left(\alpha_{t}\right)=\left[\begin{array}{l}\mathbb{E}\left(\gamma_{t}\right) \\ \mathbb{E}\left(\eta_{t}\right)\end{array}\right]=\left[\begin{array}{l}0 \\ \mu\end{array}\right]+\left[\begin{array}{ll}0 & 0 \\ 0 & 1\end{array}\right]\left(\left[\begin{array}{l}\mathbb{E}\left(\gamma_{t-1}\right) \\ \mathbb{E}\left(\eta_{t-1}\right)\end{array}\right]+\left[\begin{array}{c}\frac{\hat{\sigma}_{11}}{\hat{\sigma}_{11}+\hat{\sigma}_{22}} \\ \frac{\hat{\sigma}_{22}}{\hat{\sigma}_{11}+\hat{\sigma}_{22}}\end{array}\right]\left[\begin{array}{ll}1 & 1\end{array}\right]\left[\begin{array}{c}\gamma_{t-1}-\mathbb{E}\left(\gamma_{t-1}\right) \\ \eta_{t-1}-\mathbb{E}\left(\eta_{t-1}\right)\end{array}\right]\right)$ 
and, with $\mathbf{H} \alpha_{t}=\delta_{t}$,

$$
\begin{aligned}
\mathbf{H E}(\alpha)=\mathbb{E}\left(\delta_{t}\right) & =\mu+\frac{\hat{\sigma}_{22}}{\hat{\sigma}_{11}+\hat{\sigma}_{22}}\left(\eta_{t}+\gamma_{t}-\mathbb{E}\left(\eta_{t}\right)-\mathbb{E}\left(\gamma_{t}\right)\right) \\
& =\mu+\frac{\hat{\sigma}_{22}}{\hat{\sigma}_{11}+\hat{\sigma}_{22}}\left(\delta_{t}-\mathbb{E}\left(\delta_{t}\right)\right) .
\end{aligned}
$$

John H. 